\title{
Evaluation of the impact of the voucher program for improving maternal health behavior and status in Bangladesh
}

Md. Noorunnabi Talukder

Population Council

Ubaidur Rob

Population Council

Syed Abu Jafar Md. Musa

Ashish Bajracharya

Population Council

Kaji Tamanna Keya

Population Council

See next page for additional authors

Follow this and additional works at: https://knowledgecommons.popcouncil.org/departments_sbsr-rh

Part of the Demography, Population, and Ecology Commons, Family, Life Course, and Society Commons, Gender and Sexuality Commons, International Public Health Commons, and the Women's Health Commons How does access to this work benefit you? Let us know!

\section{Recommended Citation}

Talukder, Md. Noorunnabi, Ubaidur Rob, Syed Abu Jafar Md. Musa, Ashish Bajracharya, Kaji Tamanna Keya, Forhana Rahman Noor, Eshita Jahan, Md. Irfan Hossain, Jyotirmoy Saha, and Benjamin Bellows. 2014. "Evaluation of the impact of the voucher program for improving maternal health behavior and status in Bangladesh," Final report. Dhaka: Population Council. 


\section{Authors}

Md. Noorunnabi Talukder, Ubaidur Rob, Syed Abu Jafar Md. Musa, Ashish Bajracharya, Kaji Tamanna

Keya, Forhana Rahman Noor, Eshita Jahan, Md. Irfan Hossain, Jyotirmoy Saha, and Benjamin Bellows 


\section{EVALUATION OF THE IMPACT OF THE VOUCHER PROGRAM FOR IMPROVING MATERNAL HEALTH BEHAVIOR AND STATUS IN BANGLADESH}

Md. Noorunnabi Talukder Ubaidur Rob Syed Abu Jafar Md. Musa

Ashish Bajracharya Kaji Tamanna Keya Forhana Rahman Noor

Eshita Jahan Md. Irfan Hossain Jyotirmoy Saha Ben Bellows 


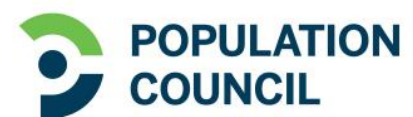 \\ Ideas. Evidence. Impact.}

The Population Council confronts critical health and development issues-from stopping the spread of HIV to improving reproductive health and ensuring that young people lead full and productive lives. Through biomedical, social science, and public health research in 50 countries, we work with our partners to deliver solutions that lead to more effective policies, programs, and technologies that improve lives around the world. Established in 1952 and headquartered in New York, the Council is a nongovernmental, nonprofit organization governed by an international board of trustees.

Population Council

House 15B, Road 13

Gulshan, Dhaka

Bangladesh 1212

Tel: +88028821227

Fax: +88028823127

Email: info.bangladesh@popcouncil.org

popcouncil.org

Suggested citation: Talukder, M.N., U. Rob, S.A.J.M. Musa, A. Bajracharya, K.T. Keya, F.R. Noor, E. Jahan, M.I. Hossain, J. Saha, B. Bellows. 2014. Evaluation of the Impact of the Voucher Program for Improving Maternal Health Behavior and Status in Bangladesh. Dhaka: Population Council. 


\section{Table of Contents}

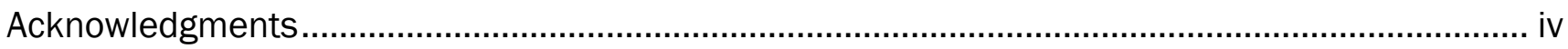

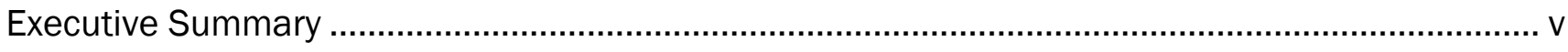

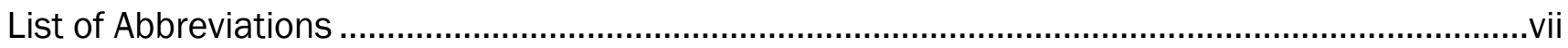

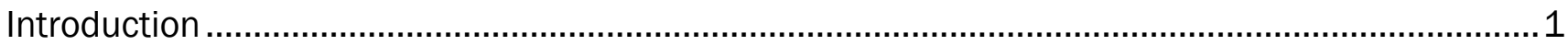

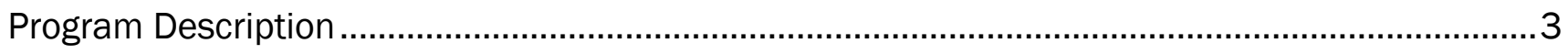

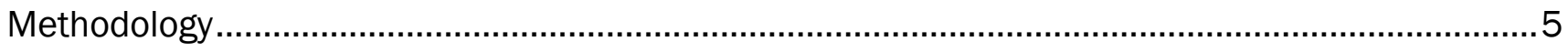

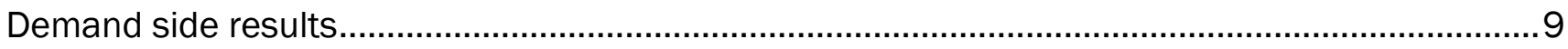

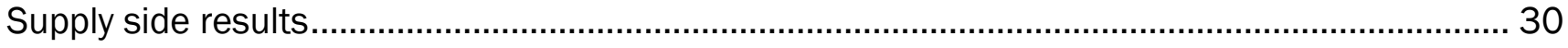

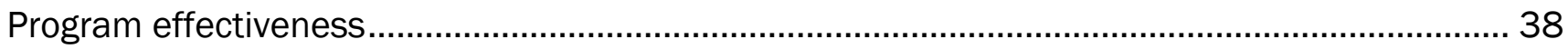

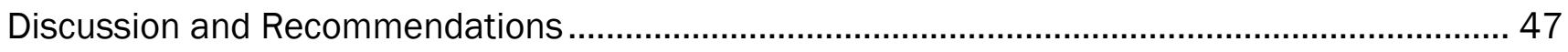

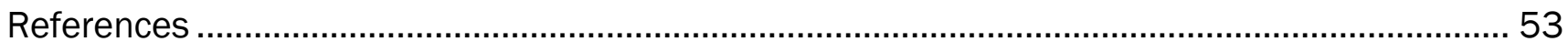

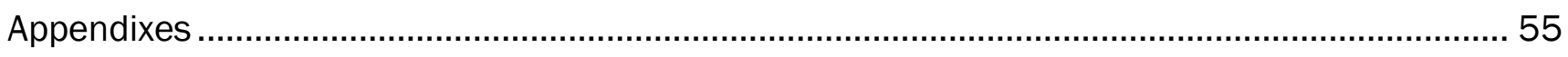




\section{Acknowledgments}

The Population Council would foremost like to express its sincere gratitude to the Bill and Melinda Gates Foundation for their financial contribution.

Special thanks are due to district and upazila government officials-Civil Surgeons, Deputy Directors of Family Planning, Upazila Health and Family Planning Officers, Upazila Family Planning Officers, and Medical Officers for Maternal and Child Health-and service providers and other office support staff in the study areas for their cooperation with this survey. We are grateful to the field workers who provided a list of mothers and helped the research team locate selected households. We are also thankful to the women who participated in the survey. In addition, we would like to convey our sincere gratitude to the study team involved in the data collection process.

We are thankful to M.M. Neazuddin, Secretary, Ministry of Health and Family Welfare; Dr. Syed Abu Jafar Md. Musa, Director PHC and Line Director, MNCAH of the Directorate General of Health Services (DGHS) of the Ministry of Health and Family Welfare; Dr. Mohammed Sharif, Diirector (MCH-Services) and Line Director (MC$\mathrm{RH}$ ), Directorate General of Family Planning; Dr. A.B.M. Jahangir Alam, former Director, Primary Health Care and Line Director, Essential Service Delivery, Directorate General of Health Services; Dr. Jafar Ahmad Hakim, former Director (MCH-Services) and Line Director (MC-RH), Directorate General of Family Planning; Dr. Pabitra Kumar Kundu, Assistant Director \& DPM, DSF, Directorate General of Health Services; Dr. Azizul Alim, Deputy Program Manager, EOC, Reproductive Health, Directorate General of Health Services; and Mr. Abdus Salam Khan, former National Coordinator, Demand-Side Financing, WHO, Bangladesh for their guidance and cooperation at every step of the study.

Finally, we are grateful to Population Council colleagues for technical, administrative, and logistical support. 


\section{Executive Summary}

\section{CONTEXT}

Vouchers, a demand-side financing (DSF) instrument for health care services, were introduced in Bangladesh in 2006. The DSF program grants vouchers to pregnant women to receive free antenatal, delivery, and postpartum care services as well as free medicine, and financial assistance is provided for transportation. Deliveries with skilled service providers are financially incentivized and providers are reimbursed for their services from a special fund. After piloting the DSF scheme initially in 21 sub-districts (upazilas), the government expanded it to another 12 upazilas in 2007 (the second phase), and in its third phase in 2010 the program was expanded to another 11 upazilas. To measure DSF's effect on improved access, quality, and

reduced inequity for reproductive health $(\mathrm{RH})$ services, during the third phase of the program Population Council conducted a comprehensive evaluation with both baseline and endline surveys in 11 DSF upazilas and compared their outcomes with those from upazilas served by similar facilities not included in the DSF program.

\section{METHODOLOGY}

A quasi-experimental design assessed the program's impact within communities in the 11 DSF upazilas, with data collected from women who delivered within the year preceding the survey. A total of 6,634 women from 22 study upazilas were interviewed in the pre- and post-intervention population based surveys. Assessments at health facilities involved five types of data collection: client exit interviews, observations of client and provider interactions, interviews with providers, facility assessments, and in-depth interviews (IDIs) with program managers. This evaluation study employed Difference-in-Difference (DID) analysis, comparing outcomes in voucher and non-voucher areas, and cross-sectional comparison of service utilization in public and private facilities, to assess the voucher program's performance. To further understand vouchers' impact on outcomes, two sets of analyses were performed. First, all intervention upazilas were compared with control upazilas (Panel 1). Secondly, five high performing upazilas where the voucher program was implemented effectively were compared with the control upazilas (Panel 2).

\section{EVIDENCE}

Utilization of skilled care. This study shows that the voucher program had statistically significant impacts on use of antenatal care (ANC), delivery care, and postnatal care (PNC) services, particularly in the five high performing upazilas:

- Attendance for four or more ANC visits increased by 21.8 percentage points in high performing voucher upazilas, compared to 14.6 in control upazilas (a difference in difference of 7.2 percentage points).

- Increase in the facility based deliveries in high performing voucher was greater than the increase in control upazilas, with the difference in difference estimate of 7.2 percentages points.

- Use of PNC services were increased remarkably by 50.9 percentages points in high performing voucher upazilas, whereas 37.1 percentage points in control upazilas (DiD estimates of 13.8).

Uptake of these services at public facilities and from trained service providers was significantly higher in the higher performing upazilas, particularly for PNC services for which some upazilas were 20 to 22 percentage points higher than control upazilas. These results did not hold when all 11 intervention upazilas were considered (including those where the voucher program was not fully implemented).

Equity in maternal health service access. An asset-based wealth index was calculated for each household, and equity between the richest and poorest groups was analyzed for uptake of ANC, PNC, and delivery services using equity ratios. Overall, uptake for these services increased in voucher and control upazilas in each quintile, with progressively larger increases for selected services by wealth status in voucher upazilas, indicating that a reduction in inequities was more substantial in voucher upazilas than in control upazilas. 
Strong improvements in equity were seen for PNC services, whereas use of normal delivery services declined with higher wealth status, substituted by higher use of cesarean delivery services.

Out-of-pocket expenditures. Although use of a voucher does not ensure a completely free service, results show that it does reduce out-of-pocket costs, particularly compared to cost changes observed in control upazilas. Less money was spent at public facilities for cesarean deliveries in voucher upazilas, with public facility fees about one third of those at private facilities (Taka 4,688 versus Taka 14,675). For normal delivery services, voucher clients spent an average of Taka 1,167, compared to Taka 1,828 by non-voucher clients, while voucher clients spent one third as much for cesarean deliveries as non-voucher clients.

Provider competency. Providers were found deficient in their knowledge of basic maternal health service components. The mean score of doctors' knowledge was 67 percent, while mid-level providers scored 58 percent in all voucher areas. Scores for both doctors' and mid-level providers' counseling skills for birth planning, discharge after delivery, postpartum care, newborn care and feeding, and managing obstetric complications were also low, ranging from 43 percent to 58 percent. Skills assessments for obstetric complication management reveals disappointing performances from mid-level providers, who could not achieve an average minimum competency score $(50 \%)$ in any of the five obstetric complication areas.

Quality of services. Although the voucher program's main objective is improving service access and utilization, service quality was an important component, and changes in quality at Upazila Health Complexes (UHCs) were evaluated between 2010 and 2012 using a weighted composite score. Results show that composite quality scores were generally low, although increases in quality for both voucher and control upazilas were observed between the baseline and endline surveys. Larger improvements were observed for PNC service quality, where quality score increased 22 units in the high performing voucher upazilas, whereas improvements in ANC service quality were more modest. No clear pattern of service quality increases could be attributable to the voucher program, although the change in quality score for PNC services in higher performing voucher areas was six points higher than the change in the control areas.

\section{PROGRAM IMPROVEMENT}

Complaints of delayed payments and reimbursement for certain services, like transportation, were widespread among voucher users. On average, it was reported that it took four months for UHCs to process payments to voucher users. Providers emphasized the need for improvements in financial management, as well as the incentives offered. Increased financial assistance for clients was also emphasized.

\section{KEY PROGRAM RECOMMENDATIONS}

\section{Facility}

Facility readiness. Although the vouchers are a demand side intervention, supply side investment is still necessary for ensuring provider availability and provision of quality support services such as ultrasonography and safe blood transmission. Increasing mid-level providers at different levels for normal delivery services is also critical to increase the rate of institutional delivery. Improvement in service quality is also required for delivery services.

Provider capacity. Service providers need skills training as part of the program and professional monitoring from a higher level should be in place.

\section{Policy}

- Financial assistance needs to be increased in the context of present market value. Additional resources should be allocated to subsidize the cost women incur to purchase medicine and undergo laboratory services.

- An increase in incentive amounts for providers commensurate with their additional workloads should be examined. A carefully designed incentive for providers can be considered as an alternative.

- DSF is the only safety net project implemented by the government to ensure poor, rural pregnant mothers' safe deliveries. The program should be scaled up gradually in other upazilas to bring equity in accessibility to safe delivery service for rich and poor. 


\section{List of Abbreviations}

\begin{tabular}{|c|c|}
\hline ANC & Antenatal Care \\
\hline APH & Antepartum Hemorrhage \\
\hline BDHS & Bangladesh Demographic and Health Survey \\
\hline $\mathrm{BEmOC}$ & Basic Emergency Obstetric Care \\
\hline BMGF & Bill and Melinda Gates Foundation \\
\hline $\mathrm{CC}$ & Community Clinic \\
\hline CEmOC & Comprehensive Emergency Obstetric Care \\
\hline $\mathrm{CPI}$ & Client and Provider Interaction \\
\hline CQS & Composite Quality Score \\
\hline CSBA & Community Skilled Birth Attendant \\
\hline DID & Difference-in-Difference \\
\hline DGFP & Directorate General of Family Planning \\
\hline DGHS & Directorate General of Health Services \\
\hline DPM & Deputy Program Manager \\
\hline DSF & Demand-Side Financing \\
\hline EDD & Expected Delivery Date \\
\hline EPI & Expanded Program on Immunization \\
\hline EmOC & Emergency Obstetric Care \\
\hline FP & Family Planning \\
\hline FWA & Family Welfare Assistant \\
\hline FWV & Family Welfare Visitor \\
\hline GoB & Government of Bangladesh \\
\hline GTZ & German Technical Corporation \\
\hline HA & Health Assistant \\
\hline HEU & Health Economics Unit \\
\hline HFWC & Health and Family Welfare Center \\
\hline HNPSP & Health, Nutrition and Population Sector Program \\
\hline $\mathrm{IMCl}$ & Integrated Management of Childhood IIInesses \\
\hline MA & Medical Assistant \\
\hline $\mathrm{MCH}$ & Maternal and Child Health \\
\hline MCWC & Maternal and Child Welfare Center \\
\hline MDG & Millennium Development Goal \\
\hline MIS & Management Information System \\
\hline MO & Medical Officer \\
\hline MNCAH & Maternal, Neonatal, Child and Adolescent Health \\
\hline
\end{tabular}




$\begin{array}{ll}\text { MNCH } & \text { Maternal, Neonatal and Child Health } \\ \text { MO-MCH } & \text { Medical Officer, Maternal and Child Health } \\ \text { MoHFW } & \text { Ministry of Health and Family Welfare } \\ \text { MTP } & \text { Medically Trained Provider } \\ \text { NGO } & \text { Non-Governmental Organization } \\ \text { OBA } & \text { Output-Based Aid } \\ \text { OOP } & \text { Out-of-pocket } \\ \text { P4P } & \text { Pay-for-Performance } \\ \text { PNC } & \text { Postnatal Care } \\ \text { PPH } & \text { Postpartum Hemorrhage } \\ \text { PPS } & \text { Probability Proportional to Size } \\ \text { RH } & \text { Reproductive Health } \\ \text { RMO } & \text { Residential Medical Officer } \\ \text { SACMO } & \text { Sub-Assistant Community Medical Officer } \\ \text { SBA } & \text { Skilled Birth Attendant } \\ \text { SPSS } & \text { Statistical Package for Social Sciences } \\ \text { TBA } & \text { Traditional Birth Attendant } \\ \text { TT } & \text { Tetanus Toxoid } \\ \text { UHFPO } & \text { Upazila Health and Family Planning Officer } \\ \text { UFPO } & \text { Upazila Family Planning Officer } \\ \text { UHC } & \text { Upazila Health Complex } \\ \text { UNICEF } & \text { United Nations Children's Fund } \\ \text { WHO } & \text { World Health Organization } \\ & \end{array}$




\section{Introduction}

Vouchers, a demand side financing instrument, were introduced in the health sector of a number of low income countries to increase access and use of key health services. Subsidizing users with resources enables their purchase of required services and choice of provider from a number of alternatives (Bellows et al. 2013, Bellows, Bellows, and Warren 2011). Vouchers are intended to increase demand for services and are used to reduce direct costs of health care for households at risk of not seeking care in the absence of the subsidy (Borghi et al. 2006). This voucher-based system, or "demand side" financing, is a substitute for the traditional "supply side" approach to financing service delivery and includes a range of interventions that channel government or donor subsidies to service users rather than service providers. Demand side programs vary from small pilot programs to larger national programs (Bellows et al. 2013). Some government-run demand side programs in several Asian, African, and Latin American countries have aimed to expedite progress in achieving the Millennium Development Goal (MDG) of reducing maternal mortality. DSF schemes are alternatively termed as voucher and accreditation programs.

In the Bangladesh voucher-based system, service recipients, particularly those living below the poverty line, are given an incentive by the government to use designated, skilled health care providers. Initial findings from the few assessments of maternal and reproductive health $(\mathrm{RH})$ voucher and accreditation programs suggest, if implemented well, they have great potential for achieving policy objectives such as increased access and use, reduced inequities, and enhanced program efficiency and service quality (Bellows, Bellows, and Warren 2011). Currently there is a paucity of evidence, however, describing how various voucher and accreditation programs function in different settings, for various RH services. There is also limited understanding of their effects on quality of care and service utilization, especially among the poor and underserved. Most importantly, there is no evidence to date on their impact on maternal health and $\mathrm{RH}$ behaviors and statuses for individuals as well as populations, especially for health status indicators relevant to MDGs. There is a big gap in the scientific literature on the performance and impact of voucher and accreditation programs for maternal health.

The Bill and Melinda Gates Foundation funded Population Council's five year study addressing the lack of evidence of RH voucher performance, in five developing countries: Kenya, Uganda, Tanzania, Bangladesh, and Cambodia. In Bangladesh the Council conducted an external, quasi-experimental evaluation at health facilities and provided evidence of population effects of the public sector voucher program on both maternal care quality and its utilization by low income women. This report summarizes the key findings from Bangladesh.

Despite Bangladesh's impressive performance in reducing its maternal mortality ratio from 650 per 100,000 live births in 1989-to 194 in 2010, a key challenge remains: increasing use of maternal health services from qualified providers. In rural areas, maternal health services are available in upazila facilities, but they are not fully utilized, and now Upazila Health Complexes (UHCs) are being strengthened to provide emergency obstetric care $(\mathrm{EmOC})$. Despite government efforts, the existing health care system has yet to significantly increase institutional deliveries and EMOC quality. Seventy-seven percent of deliveries continue at home, assisted by traditional birth attendants (TBAs) with limited knowledge and skills (NIPORT, Mitra and Associates, and ICF International 2013). Home deliveries by untrained persons are a stark reminder of the underutilization of existing maternal, neonatal and child health services $(\mathrm{MNCH})$ and disparities in health statuses, as these home births, with their higher risks of maternal mortality, are concentrated among the poor.

Supply side subsidies' effects tend to be limited and only marginally advantageous for the poor. Poor families face resource constraints and other disincentives to using health facilities. Concerns about costs hinder professional maternity care and EmOC service provision, and contribute to maternal death (Koenig et al. 2007; Rob, Talukder, and Ghafur 2006). In rural areas, pregnant women travel 10 kilometers on average to reach UHCs for deliveries, and the expense can be a barrier to care seeking. High transportation costs and other outof-pocket costs limit access to health care for those who need it most (Glassman, Todd, and Gaarder 2007, Khan 2005). Several studies have found that women in Bangladesh need to mobilize significant financial resources and social capital to fund out-of-pocket expenses for maternity care from hospitals that are officially 
free (Khan 2005, Pitchforth et al. 2006). Historically, all of these factors contribute to the underutilization of existing health system in rural areas.

In 2006, the government recognized the need to prioritize maternal health among the poorest and introduced demand-side financing initiatives for maternal health to reduce financial barriers for rural women. The intended outcome of the program is to promote institutional delivery and improve access to Upazila Health Complexes, reducing maternal mortality. 


\section{Program Description}

As part of its Health Nutrition and Population Sector Program (HNPSP), the Directorate General of Health Services (DGHS) for Bangladesh's Ministry of Health and Family Welfare (MoHFW) is implementing a pilot maternal health voucher scheme, a demand-side financing (DSF) program, in 46 upazilas. In addition to increasing use of qualified birth attendants, particularly by poor women, this pilot program intends to mitigate the financial costs of delivery and reduce maternal and neonatal morbidity and mortality.

Bangladesh's DSF program was initially launched in July 2004, but for various reasons, was not implemented until August 2006, and was only initiated in two upazilas. In mid-2007, DSF activities were initiated in 19 additional upazilas. The first phase thus comprised 21 upazilas, with nine upazilas using a universal targeting mechanism to reach all pregnant women and 12 upazilas using a means test to limit voucher benefits to identified poor pregnant women. A second phase in late 2007 expanded the program to another 12 upazilas (Koehlmoos et al. 2008). In 2010 a third phase included 11 new upazilas. Both the second and third phases provide financial assistance through vouchers to poor pregnant women only. By 2014 the program was operational in 46 upazilas (one DSF upazila was divided into three administrative upazilas) in 31 districts.

DSF intends to transfer purchasing power to the poor, to allow them to choose services directly from accredited providers, while providers are reimbursed for their services from a special fund (Standing, Peters, and Varghese 2003). The program distributes vouchers to pregnant women entitling them to: free antenatal care (ANC), delivery, emergency referral and postnatal care (PNC) services; free medicine for complications and delivery; and cash stipends for transportation. Transportation costs, disbursed in the form of unconditional cash grants, includes Taka 500 (US\$7) (for 3 ANC visits, delivery, and 1 PNC service) to UHCs, and additional Taka 500 (US\$7) for referral (if needed) to a designated health facility or hospital. In addition, cash and in-kind incentives are provided to pregnant women if they deliver with a designated qualified service provider. Incentives include Taka 2,000 (US\$29) and a gift box if a woman delivers either in a facility or at home assisted by a skilled birth attendant (SBA).

Unlike many other voucher programs, the Bangladesh DSF program established a voucher management agency within MoHFW; most voucher programs contract a third party to manage the program (Bellows et al. 2013). This MoHFW unit is known as the DSF Committee, and its constituent units vary in size and function at different health system levels. At the central policy level, the national DSF Committee provides strategic and policy oversight. District Designation bodies manage selection and accreditation of participating upaliza facilities as well as a number of service providers, assessing their capacities for providing services at a specified standard of quality of care. Upazila DSF committees function as the program's financial and managerial core, distributing vouchers to eligible beneficiaries, paying incentives to women who qualify, and reimbursing providers after service delivery. Beneath upazila DSF committees, local DSF committees assist in identifying eligible voucher recipients, distributing vouchers, and publicizing the program in their communities. When a client needs services, she redeems her voucher for a specified service with an accredited provider. The service provider is then reimbursed for the cost of providing the service upon submission of the voucher and supporting evidence to the upazila DSF committee.

The DSF scheme also allocates funds to facilities, which are then proportionately divided among staff and a facility maintenance fund. Cash incentives are offered to eligible service providers. Generally, 50 percent of the program's funds are deposited in the "seed fund" where associated costs are incurred. Thus, the DSF for maternal health care in Bangladesh is a combination of supply side incentives for providers and demand side cash transfer for clients.

The World Health Organization (WHO) provides technical assistance to the DSF program that includes administrative and monitoring support through one coordinator posted in each DSF upazila. These coordinators play a key local role by helping UHC management run the DSF program. These WHO coordinators are overseen by a National DSF Coordinator, based in the national DSF unit in Dhaka. 
A comprehensive evaluation of the DSF program in 2009 focused on 21 DSF upazilas with two years' implementation, with 21 control upazilas selected for comparison. Initially, MoHFW's Health Economics Unit (HEU), with support from German Technical Cooperation (GTZ), undertook a rapid assessment of the pilot project to review the voucher scheme's implementation and progress (Koehlmoos et al. 2008). Then Abt Associates conducted an economic evaluation supported by GTZ (Hatt et al. 2010, Nguyen et al. 2012). The evaluation relied on matched control retrospective comparisons using a pre-post analysis of the DSF program's impact on maternal health service use.

Population Council's evaluation employed a quasi-experimental design with both baseline and endline surveys. The baseline survey preceded the government's implementation of the DSF program's third phase. Population Council's evaluated 11 newly accredited DSF districts (upazilas) and compares their outcomes with outcomes in similar upazilas without a DSF program. This evaluation also measured changes in the quality of care in facilities, which was not studied before. 


\section{Methodology}

\section{OBJECTIVES}

The objectives of the evaluation are:

- To assess the effect of the DSF program on improving access to, quality of, and reducing inequities in the use of reproductive health $(\mathrm{RH})$ services.

- To evaluate the DSF program's impact on improving RH behaviors and outcomes at the population level.

\section{STUDY DESIGN}

A quasi-experimental control group design utilized both baseline and endline surveys, with an interval of 27 months between the two surveys.

\section{LOCATION}

The Government of Bangladesh started piloting the DSF scheme initially in 21 upazilas and expanded it to 33 upazilas in 2007. In 2010, the government expanded the activities to 11 new upazilas. These 11 new upazilas, each with one UHC facility, were selected to serve as the experimental group for this study, and the same number of matched control upazilas and facilities were selected.

This evaluation includes 22 UHCs and their catchment populations. Eleven UHCs implementing the DSF program in its third phase comprise the intervention facilities, and 11 UHCs not participating in the DSF program were selected from the same or nearby districts to serve as control facilities. Matching DSF facilities with non-DSF facilities considered several characteristics for each facility, such as availability of emergency obstetric care $(\mathrm{EmOC})$ services, number of available service providers and support staff, number of beds, presence of an anesthesiologist and gynecologist pair, and literacy rate as proxy for the upaliza's socioeconomic status. Among the 22 UHCs selected, 14 facilities provide comprehensive emergency obstetric care (CEmOC) and eight facilities provide basic emergency obstetric care (BEmOC) services (Table A, Appendix).

\section{STUDY POPULATION}

Surveys with eligible women measured the impact of the program at the population level. Respondents for the survey comprised poor women 18 to 45 years old who received essential maternity care including ANC, delivery, and PNC for themselves (as well as their newborns) prior to discharge following delivery as well as postpartum care at six weeks.

Nationally, 14.6 percent of deliveries occurred at a health facility, of any level, in the five years preceding the most recent DHS, and that figure was used for sample size calculations. To detect a 12 percent increase in the proportion of facility-based births, 1,650 experimental subjects and 1,650 control subjects were required to reject the null hypothesis that the proportion of facility-based births for experimental and control subjects is equal with probability (power) of 0.8 (Rob, Rahman, and Bellows 2011).

Survey respondents were drawn from facility catchment areas in the experimental and control sites. From each of the 22 sites, 150 respondents were selected in multi-stage sampling. To begin, three out of nine unions from each upazila were selected through probability proportional to size (PPS) for the required number of samples, with 50 respondents per union. The next stage involved selection of three villages from each union through PPS. Finally, from each village, the required number of respondents was selected at random from lists of pregnant mothers prepared by field workers. 


\section{PROGRAM EVALUATION}

\section{In facilities}

Health facility assessments included four types of data collection, namely client exit interviews, observations of client and provider interactions, provider interviews, and facility infrastructure assessments. Broadly, quality of care, provider competence, and facility readiness were studied.

- Quality of care: The quality of care administered in study facilities was measured through direct observation of ANC and PNC services to determine whether key service provision procedures were followed, along with exit interviews with delivery clients that focused on their experiences and perceptions of their quality of care.

Client and provider interactions (CPIs) were observed among 50 clients from each UHC when clients received ANC services or PNC from the maternity unit. PNC clients included women who received predischarge PNC after delivery and women who received PNC from a facility within six weeks of delivery. Baseline and endline assessments involved 2,181 observations of CPIs, which include both process (how clients are treated and whether they actively participate) and content (what clients are told, technical competence, accuracy of information, provision of essential information) of consultations. To achieve the target number of observations, the research team spent about 12 days at each facility, which also familiarized the research team and resulted in more typical behavior of the providers.

To obtain clients' opinions of their quality of service and satisfaction, exit interviews with 2,230 clients were conducted at all $22 \mathrm{UHCs}$, in the baseline and endline surveys. Exit interviews were conducted if clients received delivery care, ANC, and PNC at delivery or within six weeks postpartum from the facility. Data were collected over 12 days at each facility.

The key limitation of this quality assessment is, in cases where women were referred to higher facilities, referral indications, transportation details, and pregnancy and health outcomes were not studied.

- Provider competence: Baseline and endline surveys among service providers assessed their maternal health knowledge and capacities, as well as their DSF program experiences and opinions. Interviews also helped researchers understand DSF's organization and related activities, and ascertain providers' perceptions of both barriers and operational challenges that may influence voucher clients' acceptance of services, as well as providers' attitudes about the reimbursement process. A total of 295 providers were interviewed in the pre-survey, and 209 providers were interviewed in the post-survey. Survey participants included managers and direct providers including consultants, doctors, and nurses for maternal health services at the upazila level and providers at the union level. Approximately 14 service providers (10 from UHCs and 4 from Health and Family Welfare Centers) were interviewed during the baseline survey, from every study site. At endline, Health and Family Welfare Center (HFWC $)^{1}$ service providers were not interviewed, as HFWCs are not included in the DSF program.

- Facility assessment: The 22 UHCs offering obstetric care were classified as basic or comprehensive (BEmOC or $\mathrm{CEMOC}$ ) facilities, and information on the characteristics of these facilities for accessibility, bed strength, human resources, training, referral communications and processes, availability of equipment, drugs and supplies, and infection control procedures was collected both at baseline and endline.

\section{In communities}

The population-based survey of eligible women was the main form of community assessment. Participants were randomly selected from a list of women who delivered in the year prior prepared by government health and family planning (FP) field workers. Baseline and endline surveys measured changes, for project outcomes,

${ }^{1}$ HFWC, an outpatient center located at the union level (lowest administrative unit covering 30,000 to 40,000 rural population), provides maternal health checkups, family planning services, essential heath care, and limited curative care 
and compared voucher respondents and eligible non-beneficiaries from control areas according to: access and use of services, attitudes, experiences and reasons for use or non-use of vouchers, behaviors and attitudes of voucher holders versus non-voucher holders, delivery outcome, and costs of care. In particular, preferences for accredited services and reasons for use or non-use of these services were explored. A total of 6,634 women from 22 study upazilas were interviewed in the baseline and endline surveys (Table B, Appendix).

\section{Policy}

- Program trends: To describe trends in program uptake and study an upazila level time series of program uptake data from 2010 to 2012, service statistics and management information system (MIS) data were collected from all 22 UHCs. Trend analysis of maternal health service statistics for study facilities measured changes over time. This trend analysis reveals the extent to which changes in the proportion of institutional deliveries influenced maternal and neonatal outcomes for that period of time.

- Stakeholders' analysis: Key program managers were consulted, and relevant documents were reviewed to study the program's implementation as well as experiences with its utilization.

\section{Analysis and interpretation}

To evaluate the DSF scheme's impact, a quasi-experimental design examined various aspects of maternal health care, including trends in program uptake, institutional delivery rates, maternal and neonatal outcomes, quality of care, experiences of both service providers and users, and program cost. The study collected primary data through qualitative and quantitative methods twice, with a 27 month interim, from 11 intervention and 11 comparison upazilas.

The same instruments were used for the baseline and endline surveys. The program evaluation occurred primarily at two levels, with specific objectives for each: at obstetric facilities in upazilas, and among recently delivered mothers in communities. National and policy evaluation of the program included secondary data from governments and in-depth interviews with program managers.

\section{Difference-in-Difference analysis of key maternal health outcomes}

Difference-in-Difference (DID) analysis assessed difference in changes in maternal health outcomes between 2010 and 2012 in voucher areas-minus the difference in changes in outcome in the control areas. Difference, "d," is a more accurate estimate of the voucher program's impact if there is good reason to assume covariate balance and baseline trends were parallel prior to the intervention. The equation of " $d$ " is:

$$
\hat{d}=\left(\bar{Y}^{2012} \text { Voucher }-\bar{Y}^{2010} \text { Voucher }\right)-\left(\bar{Y}^{2012} \text { Control }-\bar{Y}^{2010}{ }_{\text {Control }}\right)
$$

\section{Comparing voucher and non-voucher clients}

To estimate the impact of the voucher program more specifically, some key analysis was conducted between voucher clients and non-voucher clients in the endline survey. The voucher versus non-voucher analysis was observed for some key outcomes, such as respondents' knowledge in 2012 of maternal healthcare services, utilization of maternal health care services, and out-of-pocket expenses.

\section{Comparing public and private facilities}

The voucher program is implemented in designated public health facilities and voucher recipients are reimbursed if they receive services from those designated centers. To observe the voucher program's impact on government health centers, public facilities and private health centers were compared according to utilization of their maternal health services and their cost.

\section{Voucher upazila performance}

Not all 11 voucher upazilas evaluated performed equally in voucher distribution, service utilization with vouchers, and facility-based delivery. Five upazilas performed well while the other six did not perform 
satisfactorily. To understand $\mathrm{RH}$ vouchers' actual effects, the intervention areas were categorized into two panels: Panel 1, representing all voucher upazilas, and Panel 2 comprising five high performing voucher upazilas. Two types of data were used to categorize a DSF upazila as high performing: 1) Secondary DSF data on upalizas' percentage of deliveries utilizing vouchers, and 2) the percentage of women interviewed in the endline survey from a particular upazila who had delivered their last child utilizing a voucher book.

If a high percentage of clients in an upaliza delivered using a voucher and fairly good number of voucher women were interviewed in the endline survey, that upazila was included in working list of high performing voucher upazilas. After a two stage screening process, Tungipara, Gangachara, Fakirhat, Haluaghat, and Shyamnagar upazilas were selected as high performing voucher areas.

\section{Two sets of Difference-in-Difference analysis}

Panel 1 describes differences between 11 original voucher upazilas versus 11 control upazilas. These 11 control upazilas were originally matched before the baseline survey using set criteria including available service providers, logistics and equipment, medicines, support staff, wards and beds, presence of anesthetist and gynecologist, and comprehensive EmOC services or basic obstetric care services.

Panel 2 describes differences between five high performing upazilas and the 11 control upazilas to assess vouchers' actual impact. The five high performing upazilas are embedded in the 11 voucher upazilas in Panel 1. To introduce no additional subjective bias and preserve the integrity of the initial match, the same 11 control upazilas of Panel 1 were maintained in the Panel 2 analysis.

Both panels broadly compare intervention and control upazilas, before and after the survey results. 


\section{Demand side results}

This evaluation is designed to generate evidence on the DSF program's performance and impact that will be relevant to policymakers and program managers in Bangladesh and other countries who currently work with such programs or are considering initiating comparable programs in similar or different circumstances.

\section{CLIENT CHANGES}

\section{Women's awareness of maternal health services}

Women were asked several questions to determine their awareness of pregnancy, delivery, and postpartum care. Pregnant women should visit a health facility or service provider for ANC check ups at least four times during pregnancy according to WHO recommendations, yet clients remain confused about the number and timing of ANC visits. At present, approximately one in every six women in the full sample and one in every five women in high performing voucher areas could state the correct number of medical check ups during pregnancy, while nearly half thought they should have only three check ups (Table 1).

TABLE 1 Knowledge of women about selected maternal health service components over time (percent)

\begin{tabular}{|c|c|c|c|c|c|c|c|c|c|c|}
\hline \multirow{3}{*}{ Knowledge Indicator } & \multicolumn{5}{|c|}{ Panel 1, All voucher areas } & \multicolumn{5}{|c|}{ Panel 2, High performing voucher areas } \\
\hline & \multicolumn{2}{|c|}{ Intervention } & \multicolumn{2}{|c|}{ Control } & \multirow[t]{2}{*}{ DID } & \multicolumn{2}{|c|}{ Intervention } & \multicolumn{2}{|c|}{ Control } & \multirow[t]{2}{*}{ DID } \\
\hline & 2010 & 2012 & 2010 & 2012 & & 2010 & 2012 & 2010 & 2012 & \\
\hline \multicolumn{11}{|l|}{ ANC visits required } \\
\hline 3 visits & 29.3 & 43.4 & 32.3 & 43.1 & 3.3 & 28.1 & 45.6 & 32.3 & 43.1 & $6.7 *$ \\
\hline 4 visits & 11.8 & 17.4 & 11.5 & 15.1 & 2.0 & 13.6 & 19.9 & 11.5 & 15.1 & 2.7 \\
\hline \multicolumn{11}{|l|}{ Danger signs of pregnancy* } \\
\hline $\begin{array}{l}\text { Severe headache and } \\
\text { blurry vision }\end{array}$ & 2.6 & 3.8 & 1.7 & 6.2 & $-3.3 * *$ & 2.7 & 5.8 & 1.7 & 6.2 & -1.4 \\
\hline Eclampsia/convulsion & 18.4 & 21.9 & 17.4 & 22.4 & -1.7 & 19.5 & 32.6 & 17.4 & 22.4 & $8.1 * * *$ \\
\hline Obstructed/prolonged labor & 64.5 & 60.7 & 61.5 & 59.7 & -2.1 & 71.7 & 49.4 & 61.5 & 59.7 & $-20.6 * * *$ \\
\hline Excessive vaginal bleeding & 25.3 & 27.0 & 22.2 & 25.9 & -2.0 & 24.3 & 35.7 & 22.2 & 25.9 & $7.7 * *$ \\
\hline High fever & 2.1 & 2.6 & 2.5 & 3.2 & -0.2 & 1.7 & 2.6 & 2.5 & 3.2 & 0.2 \\
\hline \multicolumn{11}{|l|}{ Birth preparedness* } \\
\hline $\begin{array}{l}\text { Arrangement of blood } \\
\text { donor }\end{array}$ & 4.1 & 3.0 & 3.5 & 3.2 & -0.8 & 3.5 & 5.1 & 3.5 & 3.2 & 1.9 \\
\hline Arrangement of money & 43.5 & 54.0 & 43.8 & 52.6 & 1.7 & 49.5 & 64.0 & 43.8 & 52.6 & 5.7 \\
\hline Arrangement of transport & 14.0 & 27.3 & 14.2 & 23.0 & $4.5^{*}$ & 18.5 & 31.7 & 14.2 & 23.0 & 4.4 \\
\hline $\begin{array}{l}\text { Contact with provider, } \\
\text { SBA selection }\end{array}$ & 32.1 & 48.4 & 34.1 & 55.1 & -4.7 * & 34.4 & 56.0 & 34.1 & 55.1 & 0.6 \\
\hline $\begin{array}{l}\text { Selecting someone to } \\
\text { accompany to facility }\end{array}$ & 6.5 & 11.6 & 7.6 & 13.9 & -1.2 & 9.5 & 17.2 & 7.6 & 13.9 & 1.4 \\
\hline Selection place of delivery & 8.5 & 15.3 & 5.6 & 12.4 & 0.0 & 14.4 & 20.7 & 5.6 & 12.4 & -0.5 \\
\hline $\begin{array}{l}\text { Safe delivery kits for home } \\
\text { delivery }\end{array}$ & 66.7 & 66.2 & 67.3 & 70.9 & -4.1 & 71.9 & 62.0 & 67.3 & 70.9 & $-13.5 * * *$ \\
\hline $\begin{array}{l}\text { Exclusive breastfeeding } \\
\text { for } 6 \text { months }\end{array}$ & 77.9 & 87.8 & 77.8 & 86.9 & 0.8 & 81.9 & 93.4 & 77.8 & 86.9 & 2.4 \\
\hline $\begin{array}{l}\text { Vitamin A uptake } \\
\text { within } 42 \text { days }\end{array}$ & 27.5 & 32.7 & 28.7 & 32.6 & 1.3 & 32.9 & 33.8 & 28.7 & 32.6 & -3.0 \\
\hline $\mathrm{N}$ & 1650 & 1662 & 1650 & 1672 & & 750 & 745 & 1650 & 1672 & \\
\hline
\end{tabular}

omparison shows that familiarity with the long established practice of three ANC check ups was enhanced over time in both Panel 1 and Panel 2 (DID 3.3 percentage points versus 6.7 percentage points) but became statistically significant in Panel 2. The proportion of women aware of the correct ANC schedule (4 visits) increased over time, however, in both Panels with a DID 2.0 and 2.7 percentage points, respectively. One 
point should be noted, however: voucher beneficiaries are entitled to a transportation allowance and three free ANC check ups.

Utilization of skilled obstetric care relies on improved knowledge of danger signs of pregnancy along with birth preparedness practices. In Panel 1, findings indicate the proportion of women who knew the danger signs of pregnancy increased slightly (except for obstructed labor) over time, with small variation across sites. Obstructed or prolonged labor (intervention $61 \%$ versus control $60 \%$ ) is the most frequently mentioned pregnancy risk, followed by excessive vaginal bleeding (intervention $27 \%$ versus control $26 \%$ ) and eclampsia (intervention 22\% versus control 22\%) in Panel 1. A small proportion of women regarded severe headache or blurry vision and high fever as danger signs of pregnancy, but not exceeding six percent (both panels). Against the only statistically significant severe headache knowledge, in Panel 1, DID improved notably and significantly in Panel 2 for eclampsia knowledge (Panel 1, -1.7 percentage points versus 8.1 percentage points in Panel 2), and for excessive vaginal bleeding (Panel 1, -2.0 percentage points versus 7.7 percentage points in Panel 2).

Birth preparedness and complication readiness is the process of planning for a normal birth and anticipating actions needed in case of emergency. Birth preparedness is a key component for safe delivery, which helps ensure women reach professional delivery care when labor begins. Ensuring timely use of skilled maternal care requires several practices, from selecting a skilled provider, to arranging transportation, to identifying blood donors in case of an emergency. Comparison reveals, in both Panel 1 and Panel 2, women had limited knowledge of birth preparedness plans, except for keeping safe delivery kits for home delivery, arranging money, and selecting a SBA.

In Panel 1, the proportion of women with knowledge of birth preparedness practices increased, except for arranging for a blood donor in case of emergency. Small differences exist across intervention and control sites (Panel 1). High performing areas demonstrated a higher magnitude of birth preparedness knowledge than all voucher areas, and analysis shows statistically significant DIDs in Panel 1 for transportation arrangement (DID, 4.5 percentage points) and contacting or selecting SBAs (DID, -4.7 percentage points).

In Panel 1 only half of women in the intervention sites perceived need for identifying a SBA, half mentioned money arrangements, and only 15 percent mentioned selecting an appropriate facility for delivery. This lack of interest or awareness is a great impediment to increasing institutional deliveries. A maximum of five percent of women (both areas) had an idea of arranging blood donors, heightening their risk of death as women giving birth may need blood transfusions in the event of hemorrhage or cesarean section. Knowledge about the necessity of arranging transportation for childbirth and obstetric emergency is mentioned by one fourth of women, with a statistically significant DID 4.5 percentage points in full sample analysis, while one third of women in high performing areas, with DID 4.4 percentage points, mentioned it, partly due to the preference for giving birth at home with safe delivery kits (DID, -4.1 percentage points in Panel 1 and DID, 13.5 percentage points in Panel 2).

Knowledge on exclusive breastfeeding was nearly universal among women in the second survey for all sites. Showing a small increase, uptake of vitamin A within 42 days is known to only one third of women in full and high performing sample analysis.

Both voucher and non-voucher clients' knowledge of selected maternal health services are inconsistent (Table 2, page 11). For a deeper understanding of obstetric care awareness, voucher and non-voucher clients were compared in all voucher areas and high performing areas. In Panel 1, the recommended number of ANC check ups (4 visits) was known by 13 percent of voucher clients compared to 18 percent of non-voucher clients. By contrast, the popularly known number (3 visits) of ANC check ups is more common, with 57 percent of voucher clients mentioning three ANC check ups and 40 percent of non-voucher clients. In Panel 2, ANC check up awareness-for both three and four visits-had similar magnitude and direction. 
TABLE 2 Voucher and non-voucher clients' knowledge of selected maternal health service components, 2012 (percent)

\begin{tabular}{|c|c|c|c|c|}
\hline \multirow[b]{2}{*}{ Knowledge indicator } & \multicolumn{2}{|c|}{ Panel 1, All voucher areas } & \multicolumn{2}{|c|}{ Panel 2, High performing areas } \\
\hline & Voucher client & $\begin{array}{l}\text { Non- voucher } \\
\text { client }\end{array}$ & $\begin{array}{l}\text { Voucher } \\
\text { client }\end{array}$ & $\begin{array}{l}\text { Non-voucher } \\
\text { client }\end{array}$ \\
\hline \multicolumn{5}{|l|}{ ANC visits required } \\
\hline 3 visits & 56.8 & 40.1 & 59.8 & 38.2 \\
\hline 4 visits & 13.4 & 18.4 & 13.7 & 23.1 \\
\hline \multicolumn{5}{|l|}{ Danger signs of pregnancy* } \\
\hline Severe headache and blurry vision & 4.8 & 3.5 & 5.4 & 6.0 \\
\hline Eclampsia/convulsion & 32.8 & 19.0 & 38.3 & 29.7 \\
\hline Obstructed/prolonged labor & 49.8 & 63.4 & 47.7 & 50.3 \\
\hline Excessive vaginal bleeding & 33.1 & 25.5 & 36.7 & 35.2 \\
\hline High fever & 2.4 & 2.7 & 2.7 & 2.5 \\
\hline \multicolumn{5}{|l|}{ Birth preparedness* } \\
\hline Arranging blood donor & 5.2 & 2.5 & 6.6 & 4.3 \\
\hline Arrangement of money & 67.8 & 50.6 & 70.7 & 60.5 \\
\hline Arrangement of transport & 38.3 & 24.5 & 39.1 & 27.8 \\
\hline $\begin{array}{l}\text { Contact with provider/selecting skilled birth } \\
\text { attendant }\end{array}$ & 57.1 & 46.3 & 64.5 & 51.5 \\
\hline Selection of someone to accompany to facility & 23.1 & 8.7 & 25.8 & 12.7 \\
\hline Selection of place of delivery & 25.5 & 12.8 & 28.9 & 16.4 \\
\hline Safe delivery kits for home delivery & 57.4 & 68.4 & 51.2 & 67.7 \\
\hline Exclusive breastfeeding for 6 months & 94.2 & 86.2 & 94.1 & 93.0 \\
\hline Vitamin A uptake within 42 days & 31.9 & 32.9 & 28.1 & 36.8 \\
\hline $\mathbf{N}$ & 329 & 1333 & 256 & 489 \\
\hline
\end{tabular}

Note: *Multiple responses

Overall, voucher clients' awareness of danger signs of pregnancy was higher than non-voucher clients in both panels. Obstructed or prolonged labor is better known to women (voucher areas, 50\% versus non-voucher areas, 63\%) in Panel 1 compared to Panel 2 (voucher areas, 48\% versus non-voucher areas, 50\%). In Panel 1 , a smaller proportion of the voucher clients were aware of eclampsia (voucher client $33 \%$ versus nonvoucher client 19\%) and excessive vaginal bleeding (33\% versus 26\%) compared to the high performing area's eclampsia knowledge (voucher clients 38\% versus non-voucher clients $30 \%$ ) and excessive vaginal bleeding knowledge (voucher clients $37 \%$ versus non-voucher clients $35 \%$ ).

Table 2 clearly shows that the proportion of voucher clients having knowledge on birth preparedness practices is greater than that of non-voucher clients and the findings are similar but comparatively greater in magnitude in high performing areas. More than half of the voucher clients were aware of selecting a skilled provider, and one fourth mentioned selecting an appropriate facility for delivery, indicating a strong preference for the traditional practice of home delivery (all voucher areas). Compared with non-voucher clients, a relatively higher proportion of voucher clients mentioned the need to arrange transportation to a health facility for the birth and obstetric emergency, suggesting some effect of the transportation incentive distributed to the voucher clients. A small proportion of the women (less than 7\%) perceived the importance of arranging blood donor in case of emergency. "Safe delivery kits for home delivery" is the preparation better known to non-voucher clients than voucher clients (68\% in non-voucher clients and $57 \%$ in voucher clients) in Panel 1. Awareness of birth preparedness among women is grossly inadequate, which might influence the level of utilization of facility-based obstetric care.

Voucher clients do not differ much from non-voucher clients regarding knowledge on exclusive breastfeeding and timing of taking vitamin A which is true for Panel 1 as well as Panel 2. Knowledge about the exclusive breastfeeding is found to be nearly universal among women (more than $90 \%$ of women reported knowing it correctly). The proportion of clients with correct knowledge about taking vitamin A within 42 days after birth is remarkably low. 


\section{Maternal health services}

\section{Antenatal care}

Comparison of the utilization of ANC presented in Table 3 suggests an 11 percentage points increase over the two years in Panel 1 and Panel 2, with DID of 1.9 percentage points and 1.7 percentage points, respectively. For ANC visits, utilization differs remarkably between sites over time in both panels. Women with four or more ANC visits increased in Panel 1, and differences between intervention and control sites were negligible (DID 0.7 percentage points). Unlike Panel 1, the magnitude of change for DID of four or more ANC visits ( 7.2 percentage points) was significantly higher in Panel 2.

TABLE 3 Changes in uptake of antenatal care services (percent)

\begin{tabular}{|c|c|c|c|c|c|c|c|c|c|c|}
\hline \multirow{3}{*}{ Characteristics } & \multicolumn{5}{|c|}{ Panel 1, All voucher areas } & \multicolumn{5}{|c|}{ Panel 2, High performing voucher areas } \\
\hline & \multicolumn{2}{|c|}{ Intervention } & \multicolumn{2}{|c|}{ Control } & \multirow[t]{2}{*}{ DID } & \multicolumn{2}{|c|}{ Intervention } & \multicolumn{2}{|c|}{ Control } & \multirow[t]{2}{*}{ DID } \\
\hline & 2010 & 2012 & 2010 & 2012 & & 2010 & 2012 & 2010 & 2012 & \\
\hline Received ANC & 71.2 & 82.4 & 72.5 & 81.8 & 1.9 & 84.7 & 95.7 & 72.5 & 81.8 & 1.7 \\
\hline $\begin{array}{l}\mathrm{N} \\
\text { Number of visits }\end{array}$ & 1650 & 1662 & 1650 & 1672 & & 750 & 745 & 1650 & 1672 & \\
\hline 1 & 24.5 & 15.9 & 26.1 & 18.4 & -0.9 & 15.6 & 6.5 & 26.1 & 18.4 & -1.4 \\
\hline 2 & 18.1 & 14.5 & 22.1 & 18.0 & 0.5 & 14.1 & 9.1 & 22.1 & 18.0 & -0.9 \\
\hline 3 & 21.8 & 18.7 & 20.1 & 17.3 & -0.3 & 25.7 & 18.0 & 20.1 & 17.3 & -4.9 \\
\hline $4+$ & 35.6 & 50.9 & 31.7 & 46.3 & 0.7 & 44.6 & 66.4 & 31.7 & 46.3 & $7.2^{*}$ \\
\hline $\begin{array}{l}\mathrm{N} \\
\text { ANC provider }\end{array}$ & 1174 & 1369 & 1197 & 1367 & & 635 & 713 & 1197 & 1367 & \\
\hline Doctor & 38.6 & 36.7 & 41.3 & 38.6 & 0.8 & 24.1 & 25.4 & 41.3 & 38.6 & 4.0 \\
\hline Nurse/FWV & 23.1 & 17.1 & 21.3 & 15.3 & 0.0 & 26.6 & 17.4 & 21.3 & 15.3 & -3.2 \\
\hline MA/SACMO & 0.8 & 0.3 & 0.3 & 1.3 & $-1.5 * * *$ & 0.5 & 0.3 & 0.3 & 1.3 & $-1.2 *$ \\
\hline CSBA & 0.0 & 6.4 & 0.8 & 3.5 & $3.7 * * *$ & 0.0 & 4.6 & 0.8 & 3.5 & $1.9 *$ \\
\hline $\mathrm{FWA} / \mathrm{HA}$ & 1.2 & 2.0 & 2.4 & 1.0 & $2.2 * *$ & 0.8 & 0.4 & 2.4 & 1.0 & 1.0 \\
\hline $\begin{array}{l}\text { NGO provider, } \\
\text { volunteer }\end{array}$ & 29.7 & 32.7 & 27.7 & 32.3 & -1.7 & 46.1 & 49.8 & 27.7 & 32.3 & -1.0 \\
\hline $\begin{array}{l}\text { Unqualified } \\
\text { providers }\end{array}$ & 6.6 & 4.8 & 6.2 & 8.0 & $-3.5 * *$ & 1.9 & 2.1 & 6.2 & 8.0 & -1.6 \\
\hline $\mathrm{N}$ & 1174 & 1369 & 1197 & 1367 & & 635 & 713 & 1197 & 1367 & \\
\hline $\begin{array}{l}\text { ANC by MTP } \\
N \\
\text { Place of ANC }\end{array}$ & $\begin{array}{l}62.5 \\
1174\end{array}$ & $\begin{array}{l}60.5 \\
1369\end{array}$ & $\begin{array}{l}63.7 \\
1197\end{array}$ & $\begin{array}{l}58.6 \\
1367\end{array}$ & 3.0 & $\begin{array}{l}51.2 \\
635\end{array}$ & $\begin{array}{l}47.7 \\
713\end{array}$ & $\begin{array}{l}63.7 \\
1197\end{array}$ & $\begin{array}{l}58.6 \\
1367\end{array}$ & 1.5 \\
\hline Public & 24.2 & 27.0 & 29.2 & 23.8 & $8.2 * * *$ & 26.8 & 32.3 & 29.2 & 23.8 & $10.9 * * *$ \\
\hline Private & 40.5 & 31.0 & 35.3 & 36.1 & $-10.2 * * *$ & 23.2 & 12.2 & 35.3 & 36.1 & $-11.8 * * *$ \\
\hline NGO & 7.0 & 4.9 & 5.4 & 3.2 & 0.1 & 7.6 & 4.0 & 5.4 & 3.2 & -1.4 \\
\hline Home & 28.3 & 37.1 & 30.1 & 36.9 & 2.0 & 42.4 & 51.5 & 30.1 & 36.9 & 2.3 \\
\hline $\mathrm{N}$ & 1174 & 1369 & 1197 & 1367 & & 635 & 713 & 1197 & 1367 & \\
\hline
\end{tabular}

Note: Inference: $* * * p<0.001 ; * * p<0.01 ; * p<0.05$

The majority of women received antenatal check-ups from medically trained providers which include medical doctors, Family Welfare Visitors (FWVs), nurses, Medical Assistants (MAs), Sub-Assistant Community Medical Officers (SACMOs), and Community Skilled Birth Attendants (CSBAs). The proportion of women who received a check up from medically trained providers slightly decreased over time with a three percentage points DID in Panel 1 and 1.5 percentage points in Panel 2.

Changes in the proportion of women receiving ANC services from MA/SACMO, CSBA, and FWA/HA, were higher and statistically significant in Panel 1 compared to Panel 2. On the other hand, receiving ANC services from unqualified providers slightly decreased in the intervention full sample and the DID was statistically significant.

The difference between intervention and control area in the utilization of a public facility for ANC in Panel 1 was 8.2 percentage points, and the change in Panel 2 was 10.9 percentage points; both results are statistically significant. 


\section{Delivery}

Information on the utilization of delivery presented in Table 4 indicates an increase in the proportion of facility deliveries. Results in Panel 2 are similar to Panel 1 in the direction of the association, but the magnitude of difference is markedly larger. Additionally, results are insignificant in the full sample analysis while it is statistically significant in the selected sample. In Panel 1 , facility delivery became 31 percent in 2012 compared to 19 percent in 2010 in the intervention areas, with control sites experiencing almost the same increase. In Panel 2, facility delivery increased significantly, from 23 percent in 2010 to 41 percent in 2012, with the control sites experiencing a smaller increase.

TABLE 4 Changes in uptake of delivery services (percent)

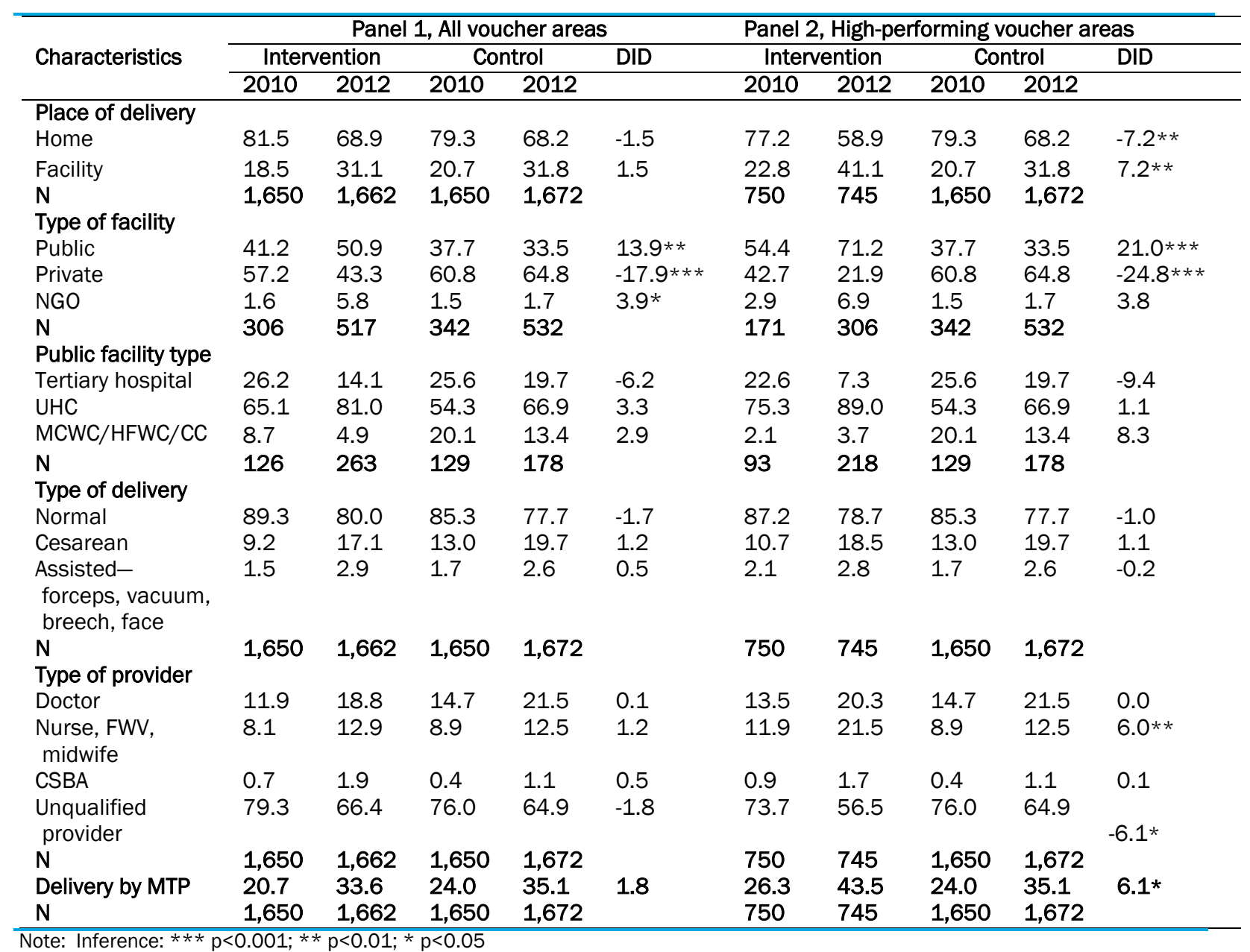

Use of public facilities for delivery increased in intervention sites while control sites experienced a slight decrease. In Panel 1 of the intervention areas, private sector facilities contributed to the majority of institutional deliveries in 2010 (57\%), while the 2012 survey witnessed a larger public sector contribution (51\%). In Panel 2, the public sector contribution was more than three times higher than the private sector ( $71 \%$ versus $22 \%$ ), while the private sector continued to be the largest contributor to institutional delivery $(61 \%$ to $65 \%)$ in control areas. The endline survey reveals, in intervention areas, that upazila hospitals are the most commonly used public sector facility for delivery services (81\% Panel 1 and 89\% Panel 2), followed by tertiary hospitals and other health centers (MCWCs, HFWCs, CCs).

A corollary effect of increased utilization of facility delivery services is increased cesarean and assisted deliveries. The number of normal deliveries decreased by roughly 10 percent in both intervention and control sites, evinced in both Panels 1 and 2. Currently, one third of births in Panel 1 and 44 percent in Panel 2 
intervention sites are attended by medically trained providers (doctors, nurses, FWVs, midwives, CSBAs). DID for deliveries by medically trained providers is 6.1 percentage points in high performing voucher areas compared to 1.8 percentage points in all voucher areas; much of this change in Panel 2 results from a proportional increase in deliveries by nurses, FWVs, and midwives.

Implementing programs in upazila hospitals alone cannot raise delivery rates in rural facilities. For optimum rural health structure utilization, program managers need to pay attention to MCWCs that provide CEmOC.

Table 5 illustrates the pattern in the use of facilities for delivery services, where public sector facilities performed more normal deliveries than cesarean deliveries. A stark contrast was observed for private sector facilities that conducted more cesarean section deliveries than normal deliveries. Roughly three-fifths of the deliveries conducted at the public facilities were normal, while four-fifths of the deliveries at private facilities were by cesarean section (Panel 1 and Panel 2). There has been an increase in the performance of cesarean section deliveries over time across facilities. The share of normal deliveries decreased at private facilities while there was an increase at public facilities after voucher initiation. The financial burden of women delivering at public facilities is assumed to be small due to its larger share of normal delivery.

TABLE 5 Changes in uptake of public and private facility delivery services over time in DSF upazilas (percent)

\begin{tabular}{|c|c|c|c|c|c|c|c|c|}
\hline \multirow{3}{*}{ Characteristics } & \multicolumn{4}{|c|}{ Panel 1, All voucher areas } & \multicolumn{4}{|c|}{ Panel 2, High performing voucher areas } \\
\hline & \multicolumn{2}{|c|}{ Public } & \multicolumn{2}{|c|}{ Private } & \multicolumn{2}{|c|}{ Public } & \multicolumn{2}{|c|}{ Private } \\
\hline & 2010 & 2012 & 2010 & 2012 & 2010 & 2012 & 2010 & 2012 \\
\hline Facility-based delivery & 7.6 & 15.8 & 10.6 & 14.1 & 12.4 & 29.3 & 9.7 & 10.2 \\
\hline $\mathrm{N}$ & 1650 & 1662 & 1650 & 1662 & 750 & 745 & 750 & 745 \\
\hline \multicolumn{9}{|l|}{ Type of delivery } \\
\hline Normal & 63.5 & 57.4 & 28.0 & 11.6 & 59.1 & 60.6 & 26.0 & 11.9 \\
\hline Cesarean & 29.4 & 34.2 & 64.0 & 80.8 & 31.2 & 34.4 & 65.8 & 83.6 \\
\hline Assisted & 7.1 & 8.4 & 8.0 & 7.6 & 9.7 & 5.0 & 8.2 & 4.5 \\
\hline $\mathrm{N}$ & 126 & 263 & 175 & 224 & 93 & 218 & 73 & 67 \\
\hline \multicolumn{9}{|l|}{$\begin{array}{l}\text { Type of service } \\
\text { provider }\end{array}$} \\
\hline Doctor & 42.9 & 39.5 & 78.3 & 85.7 & 45.2 & 38.5 & 72.6 & 88.1 \\
\hline Nurse, FWV, Midwife & 56.3 & 58.9 & 21.7 & 13.8 & 54.8 & 60.1 & 27.4 & 10.4 \\
\hline CSBA & 0.8 & 0.4 & 0.0 & 0.0 & 0.0 & 0.5 & 0.0 & 0.0 \\
\hline Untrained provider & 0.0 & 1.2 & 0.0 & 0.4 & 0.0 & 0.9 & 0.0 & 1.5 \\
\hline $\mathrm{N}$ & 126 & 263 & 175 & 224 & 93 & 218 & 73 & 67 \\
\hline \multicolumn{9}{|l|}{ Facility type } \\
\hline Tertiary hospital & 26.2 & 14.1 & - & - & 22.6 & 7.3 & - & - \\
\hline UHC & 65.1 & 81.0 & - & - & 75.3 & 89.0 & - & - \\
\hline HFWC & 5.6 & 1.9 & - & - & 1.1 & 1.4 & - & - \\
\hline $\mathrm{CC}$ & 0.0 & 0.3 & - & - & 0.0 & 0.5 & - & - \\
\hline MCWC & 2.4 & 2.7 & - & - & 1.1 & 1.8 & - & - \\
\hline $\mathrm{N}$ & 126 & 263 & & & 93 & 218 & & \\
\hline
\end{tabular}

At public facilities, nurses conducted most deliveries, synchronizing the large share of normal deliveries reported there. Among public facilities, UHCs are primarily utilized for deliveries (81\% in Panel 1 and $89 \%$ in Panel 2) and such achievement by UHCs may be an impact of DSF scheme. At private facilities, since most deliveries conducted were by cesarean, providers were mostly doctors (Table 5).

The DSF program's effects on delivery services were analyzed using data from the endline survey. Findings presented in Table 6 (page 15) show more than half of Panel 1 voucher clients using facility delivery services compared to one-fourth of non-voucher clients, while in higher performing areas 64 percent of voucher clients had a facility delivery compared to only 29 percent of non-voucher clients. UHCs were mostly utilized for delivery services by voucher clients. In both Panels, almost all voucher clients went to a UHC, with less than one percent of women utilizing delivery care from a MCWC, while two-thirds of non-voucher clients used a UHC and approximately one-third or less went to a tertiary hospital, followed by a small percentage utilizing MCWC for delivery. Although MCWCs are meant to provide CEmOC services in rural areas, and are eligible for vouchers, MCWCs are significantly underutilized (by less than $1 \%$ voucher clients). Pregnant women without 
vouchers hardly utilized delivery services from community health centers, such UHFWCs and community clinics. Half of voucher clients used a public facility, while six percent or less went to a private facility, and 814 percent of non-voucher clients went to public facility compared to 15 percent or less attending a private facility.

TABLE 6 Changes in uptake of facility-based delivery services, by voucher and non-voucher clients (percent)

\begin{tabular}{|c|c|c|c|c|}
\hline \multirow[t]{2}{*}{ Type of service } & \multicolumn{2}{|c|}{ Panel 1, All voucher areas } & \multicolumn{2}{|c|}{ Panel 2, High performing voucher areas } \\
\hline & Voucher Clients & Non-voucher Clients & Voucher clients & Non-voucher clients \\
\hline Facility-based delivery & 56.2 & 24.9 & 63.7 & 29.2 \\
\hline $\begin{array}{l}\mathrm{N} \\
\text { Place of deliver }\end{array}$ & 329 & 1333 & 256 & 489 \\
\hline Public & 48.3 & 7.8 & 57.8 & 14.3 \\
\hline Private & 6.4 & 15.2 & 3.9 & 11.7 \\
\hline NGO & 1.5 & 1.9 & 2.0 & 3.2 \\
\hline Home & 43.8 & 75.1 & 36.3 & 70.8 \\
\hline $\mathrm{N}$ & 329 & 1333 & 256 & 489 \\
\hline \multicolumn{5}{|l|}{ Type of public facility } \\
\hline Tertiary hospital & 3.8 & 29.8 & 1.4 & 20.0 \\
\hline $\mathrm{UHC}$ & 93.1 & 62.5 & 95.9 & 74.3 \\
\hline MCWC & 0.6 & 5.8 & 0.0 & 5.7 \\
\hline $\mathrm{HFWC} / \mathrm{CC}$ & 2.5 & 1.9 & 2.7 & 0.0 \\
\hline $\mathrm{N}$ & 159 & 104 & 148 & 70 \\
\hline \multicolumn{5}{|l|}{ Type of delivery } \\
\hline Normal & 53.5 & 28.3 & 56.5 & 42.0 \\
\hline Cesarean & 42.2 & 61.1 & 40.4 & 49.0 \\
\hline Assisted & 4.3 & 10.6 & 3.1 & 9.0 \\
\hline $\mathrm{N}$ & 185 & 332 & 163 & 143 \\
\hline \multicolumn{5}{|l|}{ Type of provider } \\
\hline Doctor & 45.9 & 67.5 & 43.6 & 54.5 \\
\hline Nurse/FWV/midwife & 51.8 & 31.6 & 54.0 & 44.1 \\
\hline CSBA & 0.5 & 0.0 & 0.6 & 0.0 \\
\hline Untrained provider & 1.8 & 0.9 & 1.8 & 1.4 \\
\hline $\mathrm{N}$ & 185 & 332 & 163 & 143 \\
\hline
\end{tabular}

oucher and non-voucher clients differ by type of facility delivery. More than half of clients (54\%) in Panel 1 delivered normally, while most non-voucher clients had cesareans (61\%). In Panel 2, the facility-based normal delivery rate was 57 percent among voucher clients and 42 percent among non-voucher clients. Voucher clients mostly used mid-level providers for delivery, followed by doctors, while non-voucher clients mostly used doctors. Increasing the use of mid-level providers for deliveries is critical for increasing institutional delivery rates considering the shortage of doctors in rural areas.

\section{Postnatal care}

Postnatal care utilization (Table 7), which increased dramatically, from 20 percent to 54 percent, is characterized by similar changes across sites in full sample analysis. The change is greater in Panel 2 , with a statistically significant DID of 13.8 percentage points. Motivating women to seek skilled care during the postnatal period still remains a significant challenge for program managers.

The endline survey reveals, of women who received PNC, almost 90 percent received care within two days of birth (both panels), which is much higher than the 2010 average. The improvement in the utilization of PNC within two days after birth is encouraging; indicating the optimum utilization of skilled delivery care to perform postnatal check-ups immediately after birth.

The intervention demonstrates a better situation in the use of public facilities for PNC services than the control. The change in the proportion of women receiving PNC at a public facility in higher performing voucher areas was 21.5 percentage points, while the change was 12.1 percentage points in full sample analysis; both DIDs are highly statistically significant. A large increase in the use of public facilities for 
postnatal check-ups can be attributed to program effect. This increased proportion who sought care from the public sector is lower than the proportion who sought care at home. In contrast, women in the control group were more inclined to receive PNC at home and in private sector facilities.

TABLE 7 Changes in uptake of postnatal care services, by site (percent)

\begin{tabular}{|c|c|c|c|c|c|c|c|c|c|c|}
\hline \multirow{3}{*}{ Characteristics } & \multicolumn{5}{|c|}{ Panel 1, All voucher areas } & \multicolumn{5}{|c|}{ Panel 2, High performing voucher areas } \\
\hline & \multicolumn{2}{|c|}{ Intervention } & \multicolumn{2}{|c|}{ Control } & \multirow[t]{2}{*}{ DID } & \multicolumn{2}{|c|}{ Intervention } & \multicolumn{2}{|c|}{ Control } & \multirow[t]{2}{*}{ DID } \\
\hline & 2010 & 2012 & 2010 & 2012 & & 2010 & 2012 & 2010 & 2012 & \\
\hline Received PNC & 19.5 & 53.7 & 18.7 & 55.8 & -2.9 & 20.8 & 71.7 & 18.7 & 55.8 & $13.8 * * *$ \\
\hline $\begin{array}{l}\mathrm{N} \\
\text { Received within }\end{array}$ & 1650 & 1662 & 1650 & 1672 & & 750 & 745 & 1650 & 1672 & \\
\hline 48 hours & 23.7 & 88.7 & 24.9 & 88.0 & 1.9 & 25.6 & 90.3 & 24.9 & 88.0 & 1.6 \\
\hline 3-7 days & 29.3 & 7.8 & 25.9 & 6.6 & -2.2 & 29.5 & 7.5 & 25.9 & 6.6 & -2.7 \\
\hline 8-42 days & 47.0 & 3.5 & 49.2 & 5.4 & 0.3 & 44.9 & 2.2 & 49.2 & 5.4 & 1.1 \\
\hline $\begin{array}{l}\mathrm{N} \\
\text { Place of PNC }\end{array}$ & 321 & 892 & 309 & 933 & & 156 & 534 & 309 & 933 & \\
\hline Public & 12.8 & 29.6 & 14.6 & 19.3 & $12.1 * * *$ & 15.4 & 41.6 & 14.6 & 19.3 & $21.5 * * *$ \\
\hline Private & 33.3 & 26.7 & 44.0 & 38.2 & -0.8 & 16.0 & 12.7 & 44.0 & 38.2 & 2.6 \\
\hline NGO & 1.2 & 3.8 & 0.3 & 1.0 & 1.9 & 1.9 & 3.7 & 0.3 & 1.0 & 1.1 \\
\hline Home & 52.6 & 39.9 & 41.1 & 41.6 & $-13.2 * *$ & 66.7 & 41.9 & 41.1 & 41.6 & $-25.2 * * *$ \\
\hline $\begin{array}{l}\mathrm{N} \\
\text { PNC provider }\end{array}$ & 321 & 892 & 309 & 933 & & 156 & 534 & 309 & 933 & \\
\hline Doctor & 31.8 & 33.6 & 33.7 & 32.7 & 2.8 & 23.7 & 27.0 & 33.7 & 32.7 & 4.3 \\
\hline Nurse/FWV & 6.5 & 26.9 & 16.5 & 27.1 & $9.8 * *$ & 7.7 & 32.0 & 16.5 & 27.1 & $13.7 * *$ \\
\hline MA/SACMO & 1.9 & 0.1 & 0.6 & 0.1 & $-1.3 *$ & 0.0 & 0.2 & 0.6 & 0.1 & 0.7 \\
\hline CSBA & 0.0 & 3.4 & 0.0 & 1.2 & 2.2 & 0.0 & 2.1 & 0.0 & 1.2 & 0.9 \\
\hline TTBA/FWA/HA & 0.3 & 3.7 & 2.3 & 7.3 & -1.6 & 0.6 & 4.3 & 2.3 & 7.3 & -1.3 \\
\hline NGO worker & 20.2 & 15.8 & 11.7 & 13.3 & -6.0 & 41.0 & 25.7 & 11.7 & 13.3 & $-16.9 * * *$ \\
\hline Unqualified & 39.3 & 16.5 & 35.2 & 18.3 & -5.9 & 27.0 & 8.7 & 35.2 & 18.3 & -1.4 \\
\hline $\mathbf{N}$ & 321 & 892 & 309 & 933 & & 156 & 534 & 309 & 933 & \\
\hline PNC by MTP & 40.2 & 64.0 & 50.8 & 61.1 & $13.5 * *$ & 31.4 & 61.3 & 50.8 & 61.1 & $19.6 * * *$ \\
\hline $\mathrm{N}$ & 321 & 892 & 309 & 933 & & 156 & 534 & 309 & 933 & \\
\hline
\end{tabular}

As with ANC, mostly doctors, nurses, and FWVs were consulted for PNC. When postnatal services are sought from community providers, CSBAs, TTBAs, FWAs, and HAs provided services to less than 10 percent of women after their last pregnancy. Use of NGO workers for PNC declined moderately over time across sites. It is encouraging to note that more than 60 percent of women received PNC from medically trained providers in 2012 with a statistically significant DID in both panels.

\section{Delivery complications management}

A twofold increase was reported for women in both Panels who experienced complications during childbirth. The endline survey reveals that, in intervention areas, half of pregnant women reported complications during childbirth compared to about 57 percent in control areas (Table 8).

A remarkable difference in the rate of delivery complications by type of delivery has been observed across both sites as the proportion of women experiencing complications for normal delivery decreased over time, showing statistically significant negative DID in both panels (DID -15.4 percentage points in all voucher areas and DID -14 percentage points in high-performing voucher areas, Table 8; Table D, Appendix ). Generally, a rise in the number of complications increases the likelihood of larger number of cesarean deliveries, since complications developing during labor generally result in cesarean deliveries (full sample DID 10.9 percentage points and high performing area DID 10.7 percentage points).

In Table 8 (page 17), absence of labor pain was the most reported complication (intervention 35\% and control $36 \%$ ), followed by prolonged labor (intervention $25 \%$ and control 23\%). A small share of the complications was identified as excessive bleeding, obstructed labor and retained placenta each. The magnitude and direction of delivery complications of all voucher areas is similar to high performing voucher area analysis (Table D, Appendix details high performing voucher areas). 
TABLE 8 Changes in delivery complications in all voucher areas (percent)

\begin{tabular}{|c|c|c|c|c|c|}
\hline \multirow{2}{*}{ Characteristics } & \multicolumn{2}{|c|}{ Intervention } & \multicolumn{2}{|c|}{ Control } & \multirow[t]{2}{*}{ DID } \\
\hline & 2010 & 2012 & 2010 & 2012 & \\
\hline Complication & 23.5 & 47.9 & 23.6 & 57.2 & $-9.2 * * *$ \\
\hline $\mathrm{N}$ & 1650 & 1662 & 1650 & 1672 & \\
\hline \multicolumn{6}{|l|}{ Place of delivery } \\
\hline Home & 73.9 & 50.4 & 62.7 & 53.8 & $-14.6 * * *$ \\
\hline Facility & 26.1 & 49.6 & 37.3 & 46.2 & $14.6 * * *$ \\
\hline $\mathrm{N}$ & 387 & 796 & 389 & 956 & \\
\hline \multicolumn{6}{|l|}{ Type of delivery } \\
\hline Normal & 84.8 & 63.2 & 72.0 & 65.8 & $-15.4 * * *$ \\
\hline Cesarean & 13.2 & 30.9 & 23.1 & 29.9 & $10.9 * *$ \\
\hline Assisted & 2.0 & 5.9 & 4.9 & 4.3 & $4.5^{*}$ \\
\hline $\begin{array}{l}\mathrm{N} \\
\text { Complication type* }\end{array}$ & 387 & 796 & 389 & 956 & \\
\hline Absence of labor pain & 0.0 & 35.3 & 0.0 & 36.0 & -0.7 \\
\hline Prolonged labor & 57.1 & 24.7 & 56.0 & 22.9 & 0.7 \\
\hline Excessive bleeding & 25.8 & 3.4 & 24.4 & 4.8 & -2.8 \\
\hline Eclampsia & 8.3 & 1.6 & 4.9 & 2.0 & -3.8 \\
\hline Obstructed labor & 4.1 & 2.6 & 6.9 & 1.8 & 3.6 \\
\hline Retained placenta & 11.4 & 4.8 & 11.6 & 5.9 & -0.9 \\
\hline Less fetal movement & 17.1 & 5.2 & 15.7 & 3.3 & 0.5 \\
\hline Others & 3.4 & 15.6 & 2.8 & 17.4 & 2.4 \\
\hline $\mathrm{N}$ & 387 & 796 & 389 & 956 & \\
\hline
\end{tabular}

More than 90 percent of women who suffered delivery complications received assistance, without any difference in management between intervention and control sites (Table 9, and Table D, Appendix for high performing voucher areas). In the full sample, 58 percent from the intervention and 54 percent from the control were treated by medically trained providers; the rates are statistically significant. Still, unqualified service providers attend 42 percent of complicated cases in all voucher areas and 46 percent in control areas, for which lack of qualified doctors in rural areas may be responsible.

TABLE 9 Changes in uptake of delivery complication services in all voucher areas (percent)

\begin{tabular}{|c|c|c|c|c|c|}
\hline \multirow{2}{*}{ Characteristics } & \multicolumn{2}{|c|}{ Intervention } & \multicolumn{2}{|c|}{ Control } & \multirow[t]{2}{*}{ DID } \\
\hline & 2010 & 2012 & 2010 & 2012 & \\
\hline Received services & 80.1 & 93.0 & 86.1 & 95.0 & 3.9 \\
\hline $\begin{array}{l}\mathrm{N} \\
\text { Place of services* }\end{array}$ & 387 & 796 & 389 & 956 & \\
\hline Home & 69.0 & 45.5 & 60.6 & 52.0 & $-14.9 * * *$ \\
\hline Public & 14.8 & 25.5 & 17.9 & 15.4 & $13.2 * * *$ \\
\hline Private & 20.0 & 26.7 & 31.6 & 31.9 & 6.4 \\
\hline NGO & 0.3 & 2.30 & 0.6 & 0.7 & 1.9 \\
\hline $\begin{array}{l}\mathrm{N} \\
\text { Service provider* }\end{array}$ & 310 & 740 & 335 & 909 & \\
\hline Doctor & 29.4 & 40.4 & 37.0 & 35.3 & $12.7 * *$ \\
\hline Nurse/FWV/midwife & 12.9 & 16.2 & 20.6 & 17.5 & 6.4 \\
\hline CSBA & 0.0 & 1.8 & 0.6 & 0.8 & 1.6 \\
\hline Unqualified providers & 61.9 & 41.6 & 50.7 & 46.4 & $-16.0 * * *$ \\
\hline $\begin{array}{l}\mathrm{N} \\
\text { Services by MTP } \\
\mathrm{N} \\
\text { Facility referred }\end{array}$ & $\begin{array}{l}310 \\
38.1 \\
310\end{array}$ & $\begin{array}{l}740 \\
58.4 \\
740\end{array}$ & $\begin{array}{l}335 \\
49.3 \\
335\end{array}$ & $\begin{array}{l}909 \\
53.6 \\
909\end{array}$ & $16.0 * * *$ \\
\hline $\mathrm{DH} / \mathrm{MC}$ & 33.3 & 24.3 & 12.1 & 17.0 & -13.9 \\
\hline UHC & 33.3 & 15.2 & 15.2 & 25.5 & -28.4 \\
\hline MCWC & 0.0 & 0.0 & 6.0 & 0.0 & 6.0 \\
\hline NGO clinic & 0.0 & 12.0 & 0.0 & 0.0 & 12.0 \\
\hline Private clinic & 33.3 & 48.5 & 66.7 & 57.5 & 24.40 \\
\hline $\mathrm{N}$ & 12 & 33 & 33 & 47 & \\
\hline
\end{tabular}


e referred to another hospital for managing delivery complications, in all voucher areas about half of cases are referred to private clinics, 24 percent are referred to tertiary hospital, and 15 percent are referred to UHCs. In the control areas, most women with complications are sent to private clinics (58\%), followed by UHCs $(26 \%)$ and tertiary hospitals $(17 \%)$.

\section{Equity in maternal health services access}

Equity in access to maternal health services can be understood from an interaction between economic status and the utilization of services. As a measure of economic status, a wealth index was calculated for all 6,634 households in the survey. A wealth index has several advantages. It represents a more permanent status than does either income or consumption. In the form that it is used, a wealth index is more easily measured (with only a single respondent needed in most cases) and requires far fewer questions than either consumption expenditures or income (Rutstein and Johnson 2004).

The wealth index, which is used as a background characteristic in tables and figures of the report, has been tested in a number of countries in relation to inequalities in household income, use of health services, and health outcomes (Rutstein and Johnson 2004). It is an indicator of the level of wealth that is consistent with expenditure and income measures (Rutstein 1999).

The wealth index standardized with the national distribution of the Bangladesh Demographic and Health Survey (BDHS) 2011 was constructed using household asset data and principal components analysis (SPSS module). Asset information was collected in the household questionnaire, which covers information on household ownership of a number of consumer items ranging from a mobile phone and radio to a bicycle or boat, as well as dwelling characteristics like building materials and land ownership. Each asset was assigned a weight (factor score) generated through principal component analysis, and the resulting asset scores were standardized in relation to a standard normal distribution with a mean of zero and standard deviation of one (Gwatkin et al. 2000). Each household was then assigned a score for each asset, and the scores were summed for each household. Individuals were ranked according to the total score of the household in which they resided. The sample was then divided into quintiles ( 5 groups) from one (lowest) to five (highest). Households in the lowest quintile represent the poorest financial situation, whereas households in the highest quintile are regarded as richest. The ratio of lowest to highest quintile was used in estimating the changes in equity. An equity ratio equal to one (1.0) means no differences between the poorest and richest wealth groups' service intake. Any ratio over one (1.0) indicates a greater likelihood of maternal health service utilization of poorest wealth group over the richest wealth group while ratio less than one (1.0) suggests the richest wealth group overpowering the poorest wealth group.

\section{Maternal health check ups}

Remarkable variations by wealth group were observed for ANC (see Table F and Table G, Appendix). The fact that ANC improved in every group means that people's economic condition has a telling effect on their ANC utilization rates, and vouchers could not remove ANC utilization inequity. BDHS 2011 suggested that 48 percent from lowest quintile and 93 percent from highest quintile received at least one ANC service. On the other hand, the endline survey suggests that 69 percent of women from the lowest quintile and 93 percent from the highest quintile received at least one ANC visit: Vouchers have improved ANC utilization of those in the poorest quintile. The most common reason for ANC is simply to have routine check ups. The tendency to seek ANC for specific problems did not show any measurable variation among quintiles in 2012, but seeking ANC care for a problem waned over time in high performing areas analysis.

Seeking ANC varies remarkably from the lowest to the highest wealth group when women are distributed by number of ANC check ups, indicating the impact of wealth on the number of check ups. There was major variation in the distribution of women among wealth groups for four or more ANC visits in the baseline survey (2010). This pattern changed positively in all voucher areas as use of services increased with wealth in 2012; although the change is mostly visible in lower wealth groups, vouchers increase the likelihood of four or more ANC check ups regardless of wealth. 
A variation in seeking ANC from medically qualified providers from the bottom to the top wealth group was observed in 2010 and in 2012. Nationally, 30 percent of women from the lowest wealth quintile received ANC by medically trained providers compared to 87 percent of their richest counterparts. Endline data of all voucher areas demonstrate a similar trend, by which 45 percent of women in the lowest quintile received ANC from medically trained providers compared to 80 percent of women from highest quintile (Table F).

Subsidies for government facilities are appropriately used by the poor as the proportion of women seeking ANC from government service providers (public facilities) is higher in the poorest wealth group and the proportion decreases with the increase of wealth (Table F, Appendix). Mixed impacts were recorded for wealth in utilizing public facilities in baseline and endline, while wealth had a direct impact on the distribution of women receiving check-ups at private facilities (Table G, Appendix). In 2012, women in the poorest wealth group were three times less likely in the full sample and five times less likely in selected samples to seek care at private facilities compared to their richest counterparts. Again, home-based ANC was more common in the lowest wealth group of both full and selected samples, meaning vouchers could not decrease the financial barriers to ANC over time.

Comparison of the equity ratio (ER) of the lowest to highest wealth quintiles reveals slight improvement in wealth's impact on uptake of ANC check ups in all voucher areas, with a higher magnitude of improvement in high performing voucher areas (Table 10). The equity ratio for four or more ANC visits improved after initiation of the voucher program, evinced in Panel 1 (0.58 to 0.81), but surprisingly, almost similar improvement is visible in the control (0.43 to 0.72) with highest improvement in Panel 2 voucher areas (0.64 to 0.97).

TABLE 10 Equity ratio in the uptake of ANC services across sites over time

\begin{tabular}{|c|c|c|c|c|c|c|c|c|}
\hline \multirow{3}{*}{ ANC services } & \multicolumn{4}{|c|}{ Panel 1, All voucher areas } & \multicolumn{4}{|c|}{ Panel 2, High performing voucher areas } \\
\hline & \multicolumn{2}{|c|}{ Intervention } & \multicolumn{2}{|c|}{ Control } & \multicolumn{2}{|c|}{ Intervention } & \multicolumn{2}{|c|}{ Control } \\
\hline & 2010 & 2012 & 2010 & 2012 & 2010 & 2012 & 2010 & 2012 \\
\hline Received ANC & 0.62 & 0.73 & 0.66 & 0.73 & 0.78 & 0.94 & 0.66 & 0.73 \\
\hline $\mathrm{N}$ & 1,650 & 1,662 & 1,650 & 1,672 & 750 & 745 & 1,650 & 1,672 \\
\hline \multicolumn{9}{|c|}{ Number of ANC visits } \\
\hline 1 & 1.72 & 1.67 & 1.78 & 3.61 & 1.67 & 0.76 & 1.78 & 3.61 \\
\hline 2 & 1.34 & 1.22 & 1.31 & 1.08 & 1.43 & 0.76 & 1.31 & 1.08 \\
\hline 3 & 1.05 & 0.93 & 1.20 & 0.73 & 1.40 & 1.57 & 1.20 & 0.73 \\
\hline $4+$ & 0.58 & 0.81 & 0.43 & 0.72 & 0.64 & 0.97 & 0.43 & 0.72 \\
\hline $\mathrm{N}$ & 1,174 & 1,369 & 1,197 & 1,367 & 635 & 713 & 1,197 & 1,367 \\
\hline \multicolumn{9}{|l|}{ Place of ANC } \\
\hline Public & 1.54 & 1.60 & 1.21 & 1.08 & 1.13 & 0.96 & 1.21 & 1.08 \\
\hline Private & 0.34 & 0.33 & 0.44 & 0.54 & 0.14 & 0.21 & 0.44 & 0.54 \\
\hline NGO & 2.54 & 0.82 & 1.72 & 0.97 & 1.11 & 0.26 & 1.72 & 0.97 \\
\hline Home & 3.55 & 2.57 & 2.33 & 2.19 & 3.01 & 1.96 & 2.33 & 2.19 \\
\hline $\mathrm{N}$ & 1,174 & 1,369 & 1,197 & 1,367 & 635 & 713 & 1,197 & 1,367 \\
\hline ANC by MTP & 0.53 & 0.56 & 0.63 & 0.67 & 0.48 & 0.62 & 0.63 & 0.67 \\
\hline $\mathrm{N}$ & 1,174 & 1,369 & 1,197 & 1,367 & 635 & 713 & 1,197 & 1,367 \\
\hline
\end{tabular}

$\mathrm{h}$ has a noticeable impact on public facility ANC utilization, as the equity ratio stayed above one (1.0) over time, indicating a higher propensity of women in the poorest wealth groups to seek check ups from public facilities. Similarly, women in the highest wealth group were more prone to check-ups in private facilities (ER 0.33 in Panel 1 and 0.21 in Panel 2). A higher equity ratio (ER>2) is observed when ANC service is received at home, indicative of a higher number of the poorest women receiving that care.

PNC service utilization varied positively with the economic condition in full sample analysis (Table $\mathrm{H}$, Appendix; while Table I, Appendix shows PNC services for high performing analysis). According to BDHS 2011, only 10 percent of women from the lowest quintile and 61 percent from the highest had at least one PNC service following childbirth. Endline data show PNC uptake in the lowest quintile at 38 percent, and 67 percent in the highest. National data and endline data differ little for PNC utilization of the highest wealth group (61\% versus $67 \%$ ), but they differ highly for the lowest wealth group (10\% versus $38 \%$ ). As expected, vouchers have a strong bearing on seeking PNC services within a recommended stipulated time. The number 
of women receiving PNC check ups has changed surprisingly over time, as only 16 percent women received PNC within two days after birth in 2010, jumping to 89 percent in 2012.

Findings presented in Table 11 suggest that economic status has a mixed impact on seeking PNC services, receiving PNC within a recommended stipulated time, place of PNC, and PNC by medically trained providers. Equity in utilization of skilled PNC services is strongly associated with wealth, as women in the poorest wealth group are less likely to seek PNC in all voucher areas as well as high performing voucher areas (ER 0.57 in Panel 1 and 0.76 in Panel 2). Conversely, PNC within two days of delivery does not show any difference in equity ratio in Panel 1, but the ratio decreased sharply over time in Panel 2 sample analysis. The equity ratio improved over time for seeking PNC by medically trained providers, both in the intervention and control areas, meaning that more of the poorest women are receiving PNC by medically trained providers than before. On the other hand, wealth does not have any noticeable impact on utilization of public facilities for PNC as the equity ratio of over one (1.0) was sustained during the intervention period, indicating higher likelihood of women in the poorest wealth groups to seek check ups from public facilities (Panel 1). Yet the poorest women in intervention areas are more likely to receive care at home, which is indicated by the higher equity ratio (ER near 2 in both panels) observed for PNC service.

TABLE 11 Equity ratio in uptake of postnatal care services across sites over time

\begin{tabular}{|c|c|c|c|c|c|c|c|c|}
\hline \multirow{3}{*}{ Characteristics } & \multicolumn{4}{|c|}{ Panel 1, All voucher areas } & \multicolumn{4}{|c|}{ Panel 2, High performing voucher areas } \\
\hline & \multicolumn{2}{|c|}{ Intervention } & \multicolumn{2}{|c|}{ Control } & \multicolumn{2}{|c|}{ Intervention } & \multicolumn{2}{|c|}{ Control } \\
\hline & 2010 & 2012 & 2010 & 2012 & 2010 & 2012 & 2010 & 2012 \\
\hline Received care & 0.99 & 0.57 & 0.77 & 0.56 & 1.85 & 0.76 & 0.77 & 0.56 \\
\hline $\mathrm{N}$ & 1650 & 1662 & 1650 & 1672 & 750 & 745 & 1650 & 1672 \\
\hline \multicolumn{9}{|l|}{ Received PNC within } \\
\hline 48 hours & 0.92 & 0.95 & 0.92 & 0.92 & 1.64 & 0.97 & 0.92 & 0.92 \\
\hline $3-7$ days & 1.26 & 1.93 & 0.98 & 4.55 & 1.37 & 3.70 & 0.98 & 4.55 \\
\hline 8-42 days & 0.92 & 1.07 & 1.07 & 0.98 & 0.78 & 0.23 & 1.07 & 0.98 \\
\hline $\mathrm{N}$ & 321 & 892 & 309 & 933 & 156 & 534 & 309 & 933 \\
\hline \multicolumn{9}{|l|}{ Place of PNC } \\
\hline Public & 1.26 & 1.47 & 0.74 & 1.04 & 1.64 & 0.98 & 0.74 & 1.04 \\
\hline Private & 0.44 & 0.33 & 1.01 & 0.46 & 0.21 & 0.37 & 1.01 & 0.46 \\
\hline NGO & 0.00 & 0.96 & 0.00 & 0.47 & 0.00 & 0.71 & 0.00 & 0.47 \\
\hline Home & 2.40 & 1.97 & 1.16 & 2.11 & 1.85 & 1.82 & 1.16 & 2.11 \\
\hline $\mathrm{N}$ & 321 & 892 & 309 & 933 & 156 & 534 & 309 & 933 \\
\hline PNC by MTP & 0.35 & 0.67 & 0.36 & 0.57 & 0.50 & 0.73 & 0.36 & 0.57 \\
\hline $\mathrm{N}$ & 321 & 892 & 309 & 933 & 156 & 534 & 309 & 933 \\
\hline
\end{tabular}

\section{Delivery services}

Wealth has a positive impact on facility delivery rates, as reported in the 2010 survey, with a gradual rise in the proportion of women in higher wealth quintiles delivering in facilities (Table J, Appendix). A similar picture is seen in the endline survey as well as in BDHS 2011. According to BDHS 2011, 10 percent of women from the lowest quintile had facility delivery whereas 60 percent from the highest quintile had delivered in a facility. The endline survey reveals that 19 percent women from the lowest quintile and 51 percent women from the highest quintile had a facility delivery (Table J, Appendix). Facility delivery improved sharply in all wealth groups, with highest utilization by the wealthiest quintile (65\%) (Table K, Appendix). In 2012, public facility utilization increased among all wealth quintiles with greater magnitude in the full sample analysis.

In both panels the proportion of women receiving normal delivery services decreases across wealth groups in both the baseline and endline surveys; this was complemented by an upsurge in the proportion of women receiving cesarean section delivery in accordance with wealth, as wealth increases, indicating that rich women prefer cesarean deliveries, while poor women do not have any choice.

Seeking delivery care from qualified providers by the top wealth group increased in both Panel 1 and Panel 2 sample analysis. Half of women in the richest group delivered with a medically trained provider compared to one in five in the poorest group in Panel 1. The percentage is much higher in Panel 2 (richest quintile 67\% versus 39\% for lowest), suggesting that professional maternity care is highly dependent on its affordability. 
As expected, wealth has a direct impact in using doctors at childbirth, while no noticeable impact was seen in either panel on the distribution of women with deliveries assisted by other qualified providers such as nurses, paramedics, FWVs, or CSBAs. (Table J, Appendix and Table K, Appendix show a positive association between the use of medically trained providers for delivery services and the level of wealth.)

TABLE 12 Equity ratio in uptake of delivery care services across sites over time

\begin{tabular}{|c|c|c|c|c|c|c|c|c|}
\hline \multirow{3}{*}{ Characteristics } & \multicolumn{4}{|c|}{ Panel 1, All voucher areas } & \multicolumn{4}{|c|}{ Panel 2, High performing voucher areas } \\
\hline & \multicolumn{2}{|c|}{ Intervention } & \multicolumn{2}{|c|}{ Control } & \multicolumn{2}{|c|}{ Intervention } & \multicolumn{2}{|c|}{ Control } \\
\hline & 2010 & 2012 & 2010 & 2012 & 2010 & 2012 & 2010 & 2012 \\
\hline Deliveries at home & 1.51 & 1.63 & 1.47 & 1.68 & 1.86 & 1.78 & 1.47 & 1.68 \\
\hline Deliveries at facility & 0.22 & 0.38 & 0.22 & 0.34 & 0.24 & 0.57 & 0.22 & 0.34 \\
\hline $\begin{array}{l}\mathrm{N} \\
\text { Type of facility }\end{array}$ & 1650 & 1662 & 1650 & 1672 & 750 & 745 & 1650 & 1672 \\
\hline Public & 2.29 & 2.20 & 1.09 & 1.60 & 1.89 & 1.31 & 1.09 & 1.60 \\
\hline Private & 0.62 & 0.42 & 0.88 & 0.79 & 0.57 & 0.51 & 0.88 & 0.79 \\
\hline NGO & 0.00 & 1.33 & 0.00 & 0.79 & 0.00 & 0.92 & 0.00 & 0.79 \\
\hline $\begin{array}{l}\mathrm{N} \\
\text { Type of delivery }\end{array}$ & 306 & 517 & 342 & 532 & 171 & 306 & 342 & 532 \\
\hline Normal & 1.32 & 1.54 & 1.34 & 1.49 & 1.49 & 1.49 & 1.34 & 1.49 \\
\hline Cesarean & 0.17 & 0.21 & 0.23 & 0.21 & 0.16 & 0.36 & 0.23 & 0.21 \\
\hline Assisted & 0.17 & 0.48 & 0.06 & 0.44 & 0.19 & 0.86 & 0.06 & 0.44 \\
\hline $\begin{array}{l}\mathrm{N} \\
\text { Service provider }\end{array}$ & 1650 & 1662 & 1650 & 1672 & 750 & 745 & 1650 & 1672 \\
\hline Doctor & 0.17 & 0.25 & 0.22 & 0.25 & 0.18 & 0.41 & 0.22 & 0.25 \\
\hline Nurse, FWV, Midwife & 0.40 & 0.80 & 0.21 & 0.54 & 0.47 & 0.89 & 0.21 & 0.54 \\
\hline CSBA & 1.67 & 0.45 & 0.00 & 0.46 & 0.76 & 0.00 & 0.00 & 0.46 \\
\hline Unqualified & 1.56 & 1.67 & 1.63 & 1.83 & 1.95 & 1.82 & 1.63 & 1.83 \\
\hline $\mathrm{N}$ & 1650 & 1662 & 1650 & 1672 & 750 & 745 & 1650 & 1672 \\
\hline Delivery by MTP & 0.25 & 0.40 & 0.22 & 0.34 & 0.29 & 0.59 & 0.22 & 0.34 \\
\hline $\mathrm{N}$ & 1650 & 1662 & 1650 & 1672 & 750 & 745 & 1650 & 1672 \\
\hline
\end{tabular}

2 illustrates that economic status is positively associated to the utilization of professional delivery care $(E R<1)$ as the practice of facility-based delivery is more common among the rich than the poor. Irrespective of the interventions, the poorest women are more likely to receive care at home, which is seen in the higher equity ratio $(E R>1)$ of Panel 1 and Panel 2 . The equity ratio of using a public health facility and a private health facility did not show any noticeable changes after the introduction of vouchers. On the other hand, the equity ratio has improved in cases of receiving delivery care from medically trained providers and the magnitude of change is higher in Panel 2 compared to Panel 1. Equity ratio of delivery by a medically trained provider improved to 0.40 from 0.25 in Panel 1 with a similar change in control areas while the ratio rose to 0.59 from 0.29 in Panel 2.

\section{Changes in out-of-pocket expenditures}

The demand side incentive package covers essential transportation costs while other costs such as medicine, unofficial provider fees, and incidental facility costs are not covered. In Bangladesh, incurring expenses even for free health services at government facilities is common. This report considers an out-ofpocket cost as a direct cash payment by an individual or household for a health service at the time of the service, which differs from Murray (2000) and WHO (2003). Murray defines household expenditures for health as all direct and indirect financial contributions to the health system attributable to a household through taxes, social security contributions, private insurance, and out-of-pocket payments. WHO defines out-of-pocket cost as the direct outlay of a household, including gratuities and payments in kind, made to health practitioners and suppliers of pharmaceuticals, therapeutic appliances, and other goods and services.

Additionally, informal out-of-pocket payments to expedite services as well as guaranteeing prescribed services and benefits are accounted for in this evaluation. Literature reviews indicate incidental costs and hidden charges are invariably demanded at facilities (Afsana 2004, Khan 2005). Public sector providers often charge unreported fees outside official payment channels, or for purchases covered by the government health system, free of cost to patients. Informal payments cover in-patient care of a hospitalized patient, 
including bed, food, drugs, accommodation, bed sheets, etc. Incidental costs include tips for supporting and cleaning staff and personal expenses not usually incurred at home. This increases the poor people's out-ofpocket costs and creates a financial burden for poor families (Rob, Talukder, and Ghafur 2006).

To examine the expenditure pattern, expenses a woman incurred to receive care have been divided into three broad categories: medical costs at the facility, medical costs outside the facility, and transportation costs. "Medical costs at the facility" or internal medical costs includes admission fees, consultation fees (unofficial), laboratory charges, drug costs (unofficial), tips to support staff for expediting services, and attendant expenditures for staying at the facility. Expenditures to purchase drugs and get laboratory services from the private sector are considered "medical costs outside the facility" or external medical costs, and the actual costs women pay to transportation providers is calculated as "transportation cost."

To assess the impact of financial benefits on the reduction of out-of-pocket payments for receiving delivery services from facilities, a comparison was made at three levels: intervention and control, public and private, and voucher and non-voucher clients.

Table 13 focuses on out-of-pocket expenditure for receiving normal and cesarean delivery services in public facilities of all 11 voucher areas, control areas, and high-performing voucher areas. The amount of money women spent for receiving services varied considerably across types of deliveries.

TABLE 13 Changes in expenditure pattern for public facility-based delivery services by area type (percent)

\begin{tabular}{|c|c|c|c|c|c|c|c|c|}
\hline \multirow{3}{*}{ Cost Indicator } & \multicolumn{4}{|c|}{ Panel 1, All voucher areas } & \multicolumn{4}{|c|}{ Panel 2, High performing voucher areas } \\
\hline & \multicolumn{2}{|c|}{ Intervention } & \multicolumn{2}{|c|}{ Control } & \multicolumn{2}{|c|}{ Intervention } & \multicolumn{2}{|c|}{ Control } \\
\hline & 2010 & 2012 & 2010 & 2012 & 2010 & 2012 & 2010 & 2012 \\
\hline \multicolumn{9}{|l|}{ Normal delivery } \\
\hline Up to Taka 1,000 & 24.6 & 47.4 & 39.6 & 25.6 & 29.6 & 50.6 & 39.6 & 25.6 \\
\hline Taka 1,001-2,000 & 20.0 & 26.8 & 20.8 & 33.7 & 22.7 & 27.7 & 20.8 & 33.7 \\
\hline Taka 2,001-5,000 & 33.8 & 21.6 & 25.0 & 32.6 & 31.8 & 16.9 & 25.0 & 32.6 \\
\hline Taka 5,001+ & 21.6 & 4.1 & 14.6 & 8.1 & 15.9 & 4.8 & 14.6 & 8.1 \\
\hline $\begin{array}{l}\text { Average per capita } \\
\text { cost (Taka) }\end{array}$ & 2,019 & 1,398 & 1,817 & 1,852 & 1,829 & 1,537 & 1,817 & 1,852 \\
\hline $\mathrm{N}$ & 65 & 97 & 48 & 86 & 44 & 83 & 48 & 86 \\
\hline \multicolumn{9}{|l|}{ Cesarean delivery } \\
\hline Up to Taka 1000 & 3.6 & 16.1 & 0.0 & 0.0 & 4.8 & 18.1 & 0.0 & 0.0 \\
\hline Taka 1,001-2,000 & 3.6 & 12.5 & 0.0 & 2.9 & 4.7 & 15.9 & 0.0 & 2.9 \\
\hline Taka 2,001-5,000 & 7.1 & 32.1 & 10.8 & 11.8 & 4.7 & 36.4 & 10.8 & 11.8 \\
\hline Taka 5,001-10000 & 42.9 & 17.9 & 46.0 & 44.1 & 42.9 & 18.2 & 46.0 & 44.1 \\
\hline Taka >10,000 & 42.9 & 21.4 & 43.2 & 41.2 & 42.9 & 11.4 & 43.2 & 41.2 \\
\hline $\begin{array}{l}\text { Average per capita } \\
\text { cost (Taka) }\end{array}$ & 7,615 & 4,688 & 7,186 & 8,330 & 7,303 & 3,463 & 7,186 & 8,330 \\
\hline $\mathrm{N}$ & 28 & 56 & 37 & 34 & 21 & 44 & 37 & 34 \\
\hline
\end{tabular}

The 2012 expenditure pattern shows that all delivery services involved out-of-pocket payments and the average volume of expenditures is higher in control than intervention areas. On average, women in control areas spent Taka 1,852 for normal delivery services while the corresponding expenditure is Taka 1,398 for all voucher areas and Taka 1,537 for high performing voucher areas. There has been a large increase in the proportion of women spending under Taka 1,000 for normal delivery services from intervention facilities, while control facilities experienced a large decrease, indicative of a potential link between the DSF scheme and low consumer cost. The proportion of women spending more than Taka 2,000 has largely been reduced in the intervention areas regardless of the performance of the program while the proportion increased for the control areas, which may be a result of the financial benefits from the DSF scheme.

Cesarean delivery care is less favorable for poor pregnant women, as women's expenditures for cesareans were three times those reported for normal delivery. Comparison of out-of-pocket expenditures for cesarean delivery suggests a strong association between amount spent and intervention exposure. Women spent Taka 4,688 in all voucher areas, Taka 3,463 in high performing voucher areas, and Taka 8,330 in control areas. Cesarean delivery expenditures have been divided into five different tiers. No woman in control areas 
reported spending less than or equal to Taka 1,000 for cesarean delivery, while one sixth of women in intervention areas spent that amount, the minimum expenditure for cesarean delivery (both panels). Again, in control facilities, 85 percent of women spent more than Taka 5,000 for cesarean delivery compared to 39 percent of women in Panel 1 and 30 percent of women in Panel 2.

The figure below illustrates the average medical cost spent at a facility, the medical costs incurred outside the facility, and transportation costs to receive normal delivery services from a public health facility at all intervention, control, and higher performing areas. Costs incurred outside the facility for purchasing drugs and laboratory services is the largest component of out-of-pocket expenditure for normal delivery services, and the amount declined significantly over the two year period in intervention and control areas.

Expenditures incurred inside the facility were higher in the control (Taka 826) than the intervention areas (for all intervention areas Taka 503, and high performing areas Taka 620), which was the result of an increase in the control. Average transportation costs were somewhat higher in the control areas than in the intervention areas, including an increase in both the intervention and control areas.

\section{FIGURE 1 CHANGES IN EXPENDITURE PATTERN FOR NORMAL DELIVERY SERVICES ACCORDING TO SITE, BY TYPE OF EXPENSE}

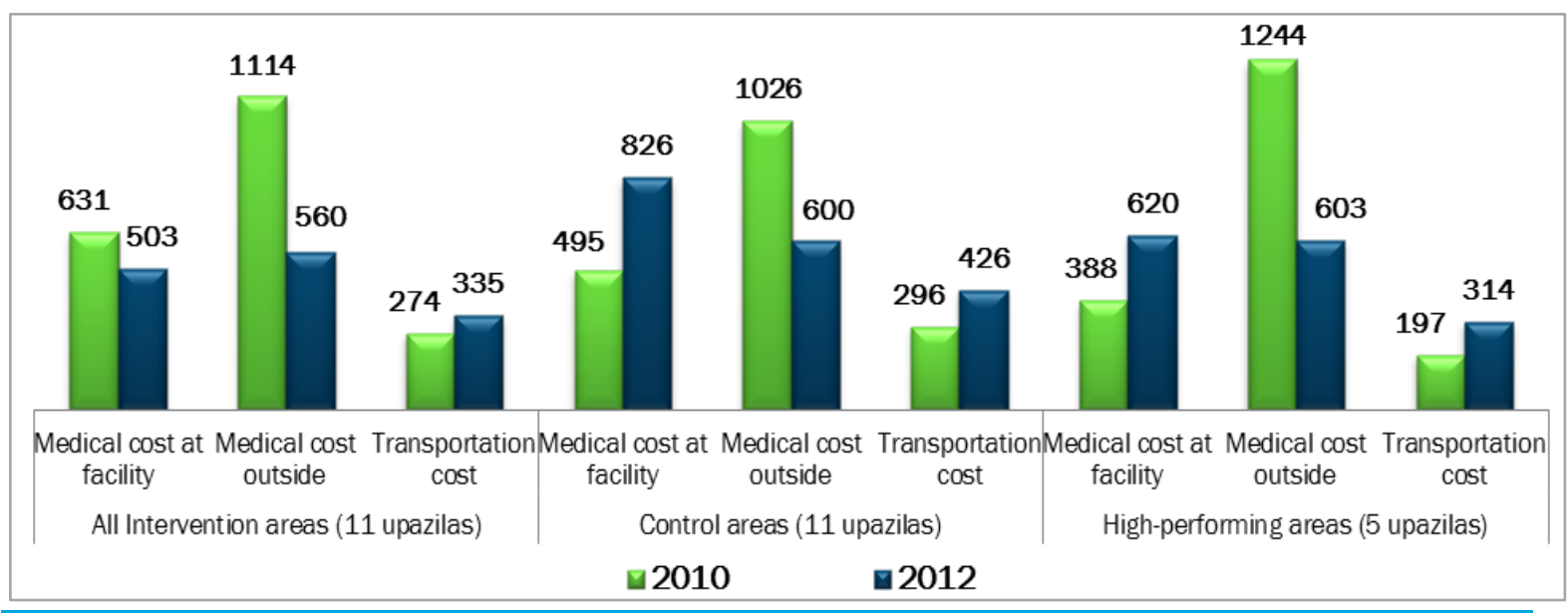

The following figure (page 24) presents medical costs inside the facility, outside the facility, and transportation expenses for cesarean delivery at a public facility. There has been a decline in the out-ofpocket cost women incurred as medical costs both inside and outside the facility in the intervention area, while the corresponding cost increased for the control areas. In high performing voucher areas medical costs at the facility increased moderately and cost outside the facility declined by one fourth within a two year intervention period. Reduction in medical costs whether inside or outside the facility implies a positive impact of DSF benefits on women receiving cesarean deliveries. The amount women pay for transportation increased at a higher rate in the intervention area than in the control area. The focus of the public maternal health programs should be on how to reduce the costs women incur when purchasing medicine and undergoing laboratory services outside the facility. The increase in transportation expenses strongly justifies the need to increase the existing amount of financial assistance the government provides to poor clients. 
FIGURE 2 CHANGES IN EXPENDITURE PATTERN FOR CESAREAN DELIVERY SERVICES ACCORDING TO SITE, BY TYPE OF EXPENSE

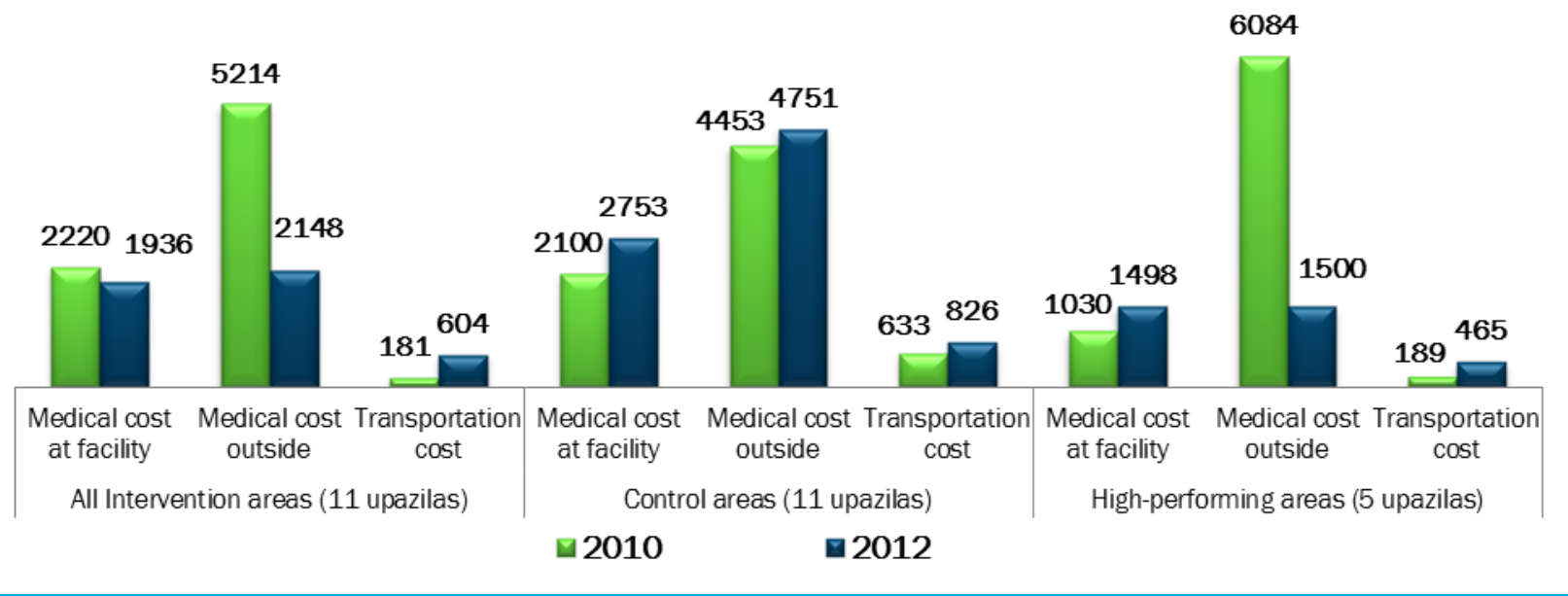

Table 14 presents the costs involved in normal and cesarean delivery in public and private hospitals of all voucher areas and high performing voucher areas. Women incurred higher expenses for normal delivery services from private facilities than from public facilities, since women spent more than two folds at private facilities than at public facilities in 2012. After initiation of the voucher program, costs for normal delivery and cesarean delivery decreased in public facilities in all intervention areas and high performing voucher areas, while it increased in the control areas. The likelihood of spending Taka 2,000 or less is more widespread among women who sought services from public facilities than private facilities in both panels. Expenditure pattern tends to be reversed for women who incurred cost more than Taka 2,000. Average cost for normal delivery services from public facilities reduced notably in intervention areas, while it increased for private facilities. Such a reduction may be due to the implementation of the DSF scheme in public facilities.

TABLE 14 Changes in expenditure pattern for facility-based delivery services by facility type in DSF upazilas (percent)

\begin{tabular}{|c|c|c|c|c|c|c|c|c|}
\hline \multirow{3}{*}{ Cost Indicator } & \multicolumn{4}{|c|}{ Panel 1, All voucher areas } & \multicolumn{4}{|c|}{ Panel 2, High performing voucher areas) } \\
\hline & \multicolumn{2}{|c|}{ Public } & \multicolumn{2}{|c|}{ Private } & \multicolumn{2}{|c|}{ Public } & \multicolumn{2}{|c|}{ Private } \\
\hline & 2010 & 2012 & 2010 & 2012 & 2010 & 2012 & 2010 & 2012 \\
\hline \multicolumn{9}{|l|}{ Normal delivery } \\
\hline Up to Taka 1,000 & 24.6 & 47.4 & 5.1 & 4.0 & 29.6 & 50.6 & 15.4 & 14.3 \\
\hline Taka 1,001-2,000 & 20.0 & 26.8 & 15.4 & 12.0 & 22.7 & 27.7 & 23.0 & 14.3 \\
\hline Taka 2,001-5,000 & 33.8 & 21.6 & 46.2 & 40.0 & 31.8 & 16.9 & 46.2 & 28.6 \\
\hline More than Taka 5,000 & 21.6 & 4.1 & 33.3 & 44.0 & 15.9 & 4.8 & 15.4 & 42.8 \\
\hline Average per capita cost (Taka) & 2019 & 1398 & 2821 & 3443 & 1829 & 1537 & 2000 & 5254 \\
\hline $\begin{array}{l}\mathrm{N} \\
\text { Cesarean delivery }\end{array}$ & 65 & 97 & 39 & 25 & 44 & 83 & 13 & 7 \\
\hline Up to Taka 1,000 & 3.6 & 16.1 & 2.0 & 0.0 & 4.8 & 18.1 & 5.2 & 0.0 \\
\hline Taka 1,001-2,000 & 3.6 & 12.5 & 0.0 & 0.0 & 4.7 & 15.9 & 0.0 & 0.0 \\
\hline Taka 2,001-5,000 & 7.1 & 32.1 & 3.0 & 1.3 & 4.7 & 36.4 & 0.0 & 2.3 \\
\hline Taka 5,001-10,000 & 42.9 & 17.9 & 22.7 & 18.7 & 42.9 & 18.2 & 23.0 & 16.7 \\
\hline More than Taka 10,000 & 42.9 & 21.4 & 72.3 & 80.0 & 42.9 & 11.4 & 71.8 & 81.0 \\
\hline Average per capita cost (Taka) & 7615 & 4688 & 14228 & 14675 & 7303 & 3463 & 10775 & 15590 \\
\hline $\mathrm{N}$ & 28 & 56 & 101 & 155 & 21 & 44 & 39 & 42 \\
\hline
\end{tabular}

Note: NGO facilities excluded from the analysis due to paucity of samples.

Expenditure for cesarean delivery suggests a strong association between the amount of money spent and facility type (Table 14). After two years of the intervention, women spent less money for delivering at public facilities, one third of that incurred at private facilities (Taka 4,688 versus Taka 14,675) in Panel 1 and less 
than one fourth (Taka 3,463 versus 15, 590) in Panel 2. There has been a drastic reduction in the per capita out-of-pocket expense for cesarean deliveries at public facilities in contrast to an increase at private facilities, apparently contributing to the reduction in out-of-pocket cost incurred at public facilities. It is common for women who received cesarean delivery services from private facilities to spend more than Taka 10,000. Taka 5,000 appears to be insufficient for a pregnant woman to receive cesarean services from a private facility, while this amount is adequate for most women who received services from a public facility. It is encouraging to note that the proportion of the women who spent more than Taka 5,000 for cesarean delivery services from public facilities sharply declined over two years (from $86 \%$ to 39\%). Yet, arranging or saving Taka 5,000 for delivery services is not easy for rural women.

The following figures focus analysis on only the DSF upazilas and high-performing DSF upazilas regarding utilization of normal delivery services from public and private health facilities, illustrating the direct effect of intervention on the reduction in out-of-pocket expenses, if any. Analysis of out-of-pocket expenditures by types of expenses for normal delivery services in Figure 3 reveals that expenditure on the medical costs inside and outside the facility decreased in public facilities but increased in private facilities. Women spent three times as much on internal medical costs at private facilities than at public facilities. External medical costs were also three times higher at private facilities than at public facilities, suggestive of free services and medicines provided at public facilities. Expenses required for traveling to the hospital were higher for private facilities, which may be partly due to the location of private facilities.

\section{FIGURE 3 CHANGES IN EXPENDITURE PATTERN FOR NORMAL DELIVERY} SERVICES, IN FACILITIES OVER TIME, IN ALL VOUCHER AREAS

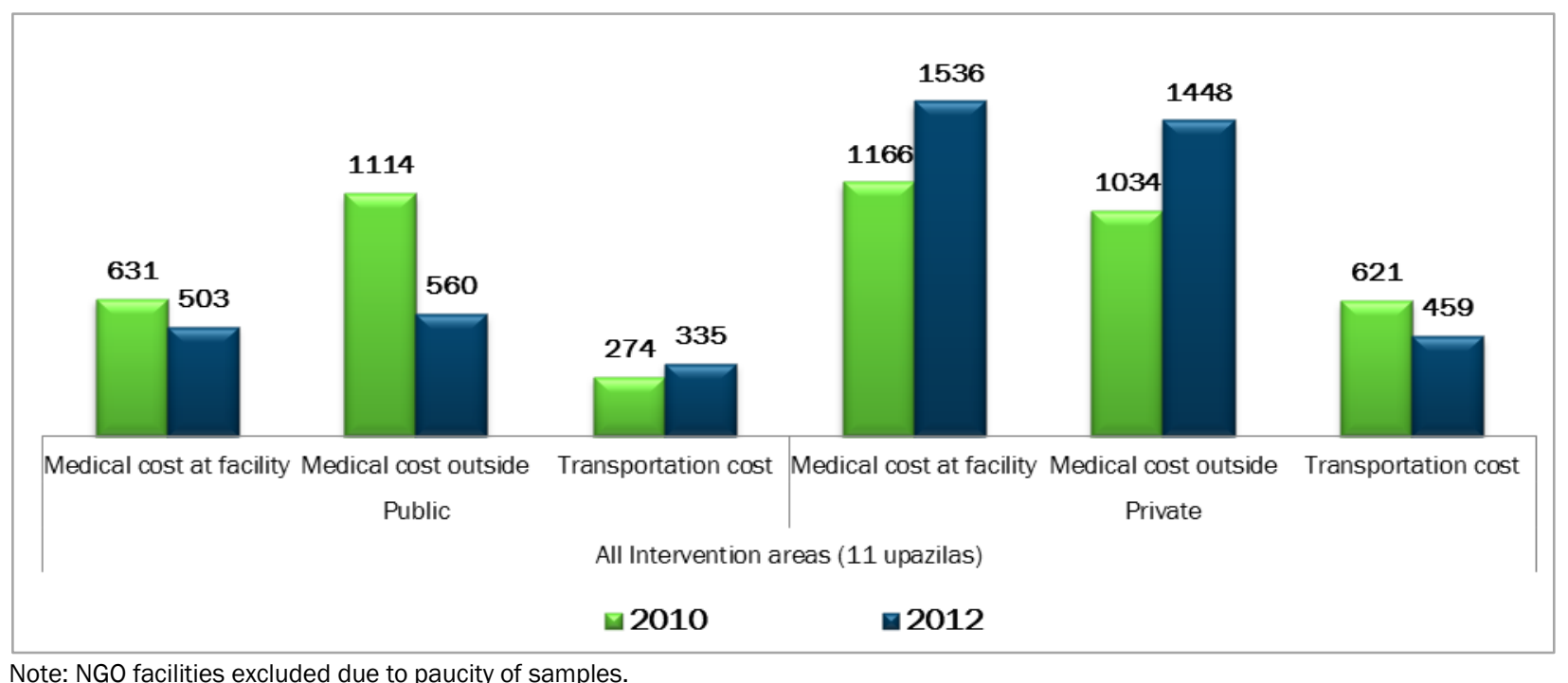

Note: NGO facilities excluded due to paucity of samples.

The next figure (page 26) shows that in high-performing areas, medical costs at private facilities were about seven times higher than that of public health facilities (Taka 4,142 versus Taka 620). Medical cost incurred outside facilities was also higher in private health facilities compared to their public counterparts. Medical costs at public health facilities increased moderately in the two year period and medical costs outside facilities decreased by half within same period. At private health facilities, medical costs at the facility increased four folds and medical costs outside the facility doubled from the time of first survey (Figure 4). 
FIGURE 4 CHANGES IN EXPENDITURE PATTERN FOR NORMAL DELIVERY SERVICES, IN FACILITIES OVER TIME, IN HIGH PERFORMING AREAS

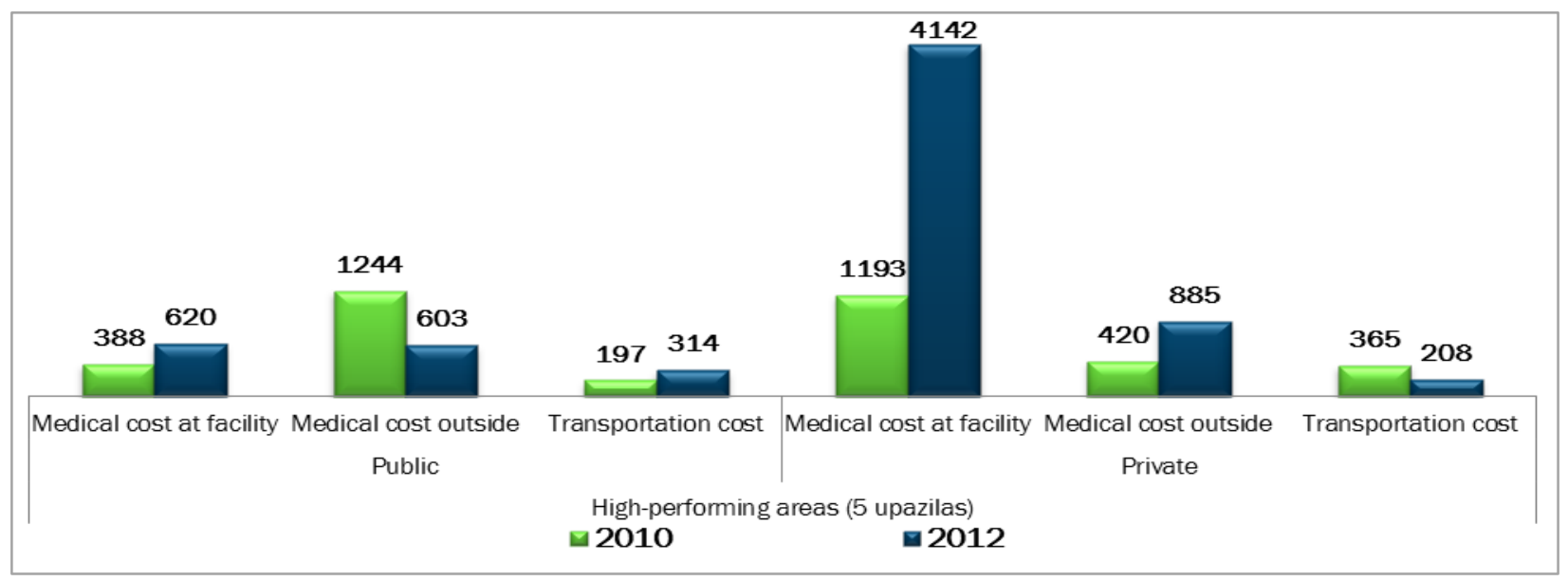

Note: NGO facilities excluded due to paucity of samples.

Without fully subsidizing normal delivery, it will be difficult to increase the rate of institutional delivery, as women still spend large shares of their family income on normal delivery services. There needs to be financial motivation for providers and support staff as well as financial assistance to clients during their hospital stay.

The following figure shows that medical costs within health facilities are the largest component of out-ofpocket expenditures for cesarean delivery in private facilities (Taka 10,592), while external medical costs (Taka 2,148 ) account for the largest share of public facility out-of-pocket expenses. Encouragingly, there has been a decrease in both internal and external medical expenses at public facilities, with a much greater reduction for external expenses. Medical expenses inside private facilities were five times higher than in public facilities and increased over time. On the other hand, medical costs outside facilities were also higher than public facilities, but they decreased slightly over time. Similar to normal delivery services, traveling to private facilities required more money than public facilities when cesarean delivery services were sought.

FIGURE 5 CHANGES IN EXPENDITURE PATTERN FOR CESAREAN SERVICES, BY EXPENSE TYPE, IN FACILITIES IN ALL INTERVENTION AREAS

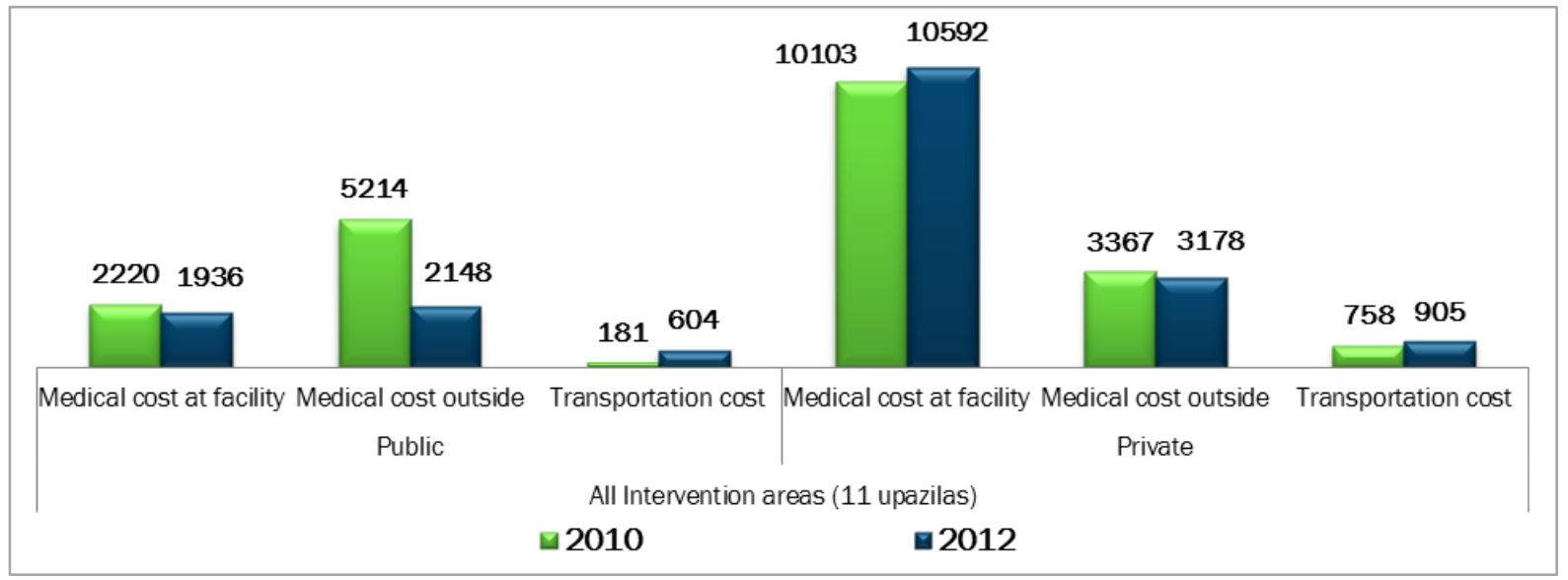

Note: NGO facilities excluded due to paucity of samples.

The following figure shows that women spent the same amount of money on internal medical costs and external costs for cesarean delivery services at public facilities in 2012. After initiation of the voucher 
program medical costs inside facilities increased slightly, while external medical costs decreased by three fourths in the two year period. Internal medical costs increased in private facilities while their external costs decreased. Transportation costs were higher for private facilities for cesarean services.

FIGURE 6 CHANGES IN EXPENDITURE PATTERN FOR CESAREAN DELIVERY, BY EXPENSE TYPE, IN FACILITIES IN HIGH PERFORMING VOUCHER INTERVENTION AREAS

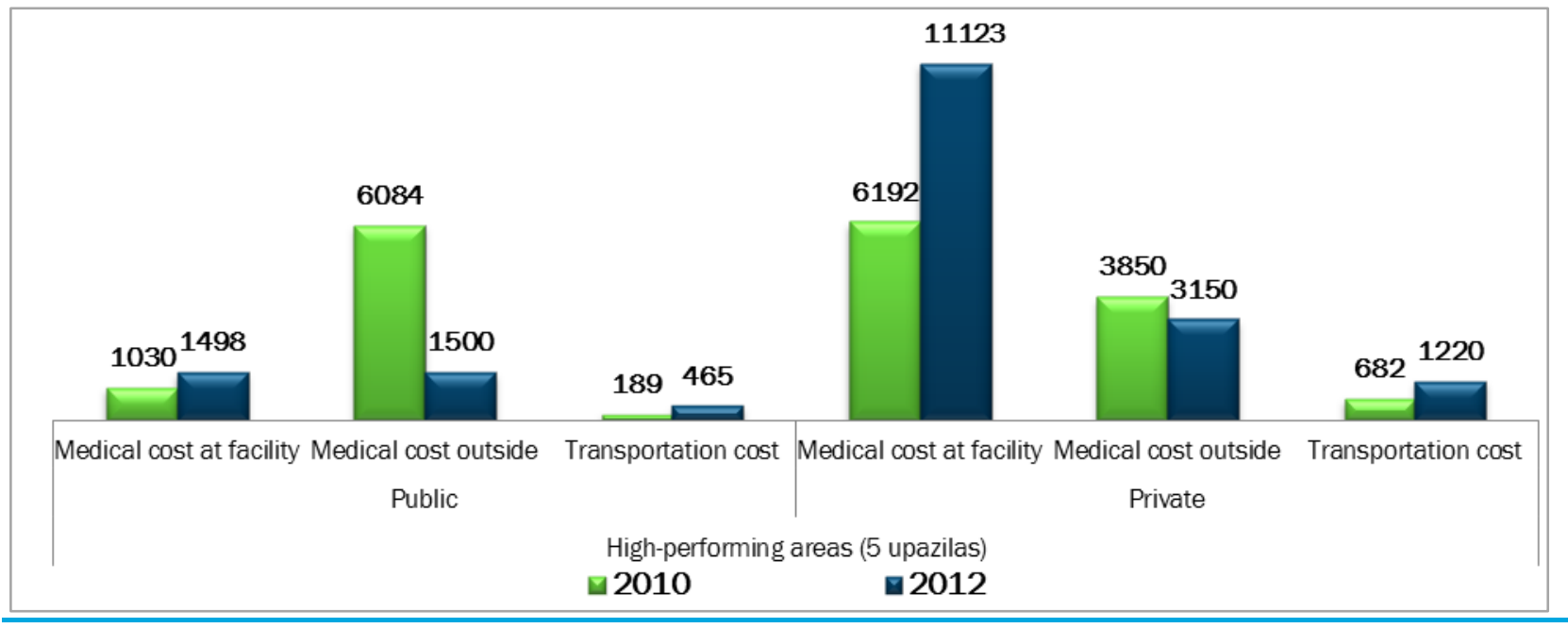

These findings demonstrate the need to allocate resources to subsidize women's costs for medicine and laboratory services not available in government facilities, and the current level of financial assistance GoB provides to poor clients should be reviewed in accordance with inflation.

In DSF upazilas no woman completely avoided delivery service costs. Voucher clients spend less for facility services than non-voucher clients, and differences in the proportion of voucher and non-voucher clients' expenditure patterns are more pronounced for cesarean delivery. For normal facility delivery, the likelihood of spending less is greater for voucher than non-voucher clients: 78 percent of voucher clients reported spending Taka 2,000 or less, compared to 67 percent for non-voucher clients. In high performing areas, 20 percent of women spent more than Taka 2,000 compared to 27 percent of non-voucher clients. About five percent of voucher clients in Panel 1 and two percent of voucher clients in Panel 2 spent Taka 5,000 or more compared to three percent and 14 percent of non-voucher clients in Panels 1 and 2, respectively.

TABLE 15 Out-of-pocket expenses by voucher and non-voucher clients for public facility delivery services (percent)

\begin{tabular}{|c|c|c|c|c|}
\hline \multirow{2}{*}{ Type of Services } & \multicolumn{2}{|c|}{ Panel 1, All voucher clients } & \multicolumn{2}{|c|}{ Panel 2, High performing voucher areas } \\
\hline & Voucher & Non-voucher & Voucher & Non-voucher \\
\hline \multicolumn{5}{|l|}{ Normal delivery } \\
\hline Up to Taka 1,000 & 50.0 & 42.4 & 52.4 & 45.4 \\
\hline Taka $1,001-2,000$ & 28.1 & 24.2 & 27.9 & 27.3 \\
\hline Taka 2,001-5,000 & 17.2 & 30.4 & 18.0 & 13.6 \\
\hline More than Taka 5,000 & 4.7 & 3.0 & 1.7 & 13.7 \\
\hline Average per capita cost (Taka) & 1167 & 1828 & 1200 & 2400 \\
\hline $\mathrm{N}$ & 64 & 33 & 61 & 22 \\
\hline \multicolumn{5}{|l|}{ Cesarean delivery } \\
\hline Up to Taka 1,000 & 22.8 & 4.8 & 25.1 & 0.0 \\
\hline Taka 1,001-2,000 & 20.0 & 0.0 & 21.9 & 0.0 \\
\hline Taka 2,001-5,000 & 40.0 & 19.0 & 40.6 & 25.0 \\
\hline Taka 5,000-10,000 & 8.6 & 33.3 & 9.3 & 41.7 \\
\hline More than Taka 10,000 & 8.6 & 42.9 & 3.1 & 33.3 \\
\hline Average per capita cost (Taka) & 2943 & 8248 & 2138 & 7735 \\
\hline $\mathrm{N}$ & 35 & 21 & 32 & 12 \\
\hline
\end{tabular}


sarean delivery make a large difference in women's expenditures. Voucher clients are much better off, with a mean out-of-pocket expenditure about one third of the payment for non-voucher clients. Seventy-six percent of non-voucher clients in Panel 1 and 75 percent in Panel 2 spent more than Taka 5,000 for cesarean delivery, while 17 percent of voucher clients in Panel 1 and 12 percent of voucher clients in Panel 2 reported the same expenses. Voucher clients spent much less money than non-voucher clients, which implies that DSF may have contributed to remarkably lower out-of-pocket payments by voucher clients (Table 15).

The following figure illustrates analysis of expenditure patterns by type of expenses, with internal medical costs accounting for the largest share of out-of-pocket expenses, which is much higher for non-voucher clients in both samples. For normal delivery services, medical costs inside a health facility incurred by voucher clients is about half (Taka 360 versus Taka 770) of that spent by non-voucher clients in all voucher areas and slightly less than one fourth in high performing voucher areas. The difference is less intense for external medical costs required for normal delivery services (Figure 7).

\section{FIGURE 7 OUT-OF-POCKET EXPENDITURES BY VOUCHER AND NON-VOUCHER CLIENTS FOR NORMAL DELIVERY SERVICES IN 2012, BY EXPENSE TYPE}

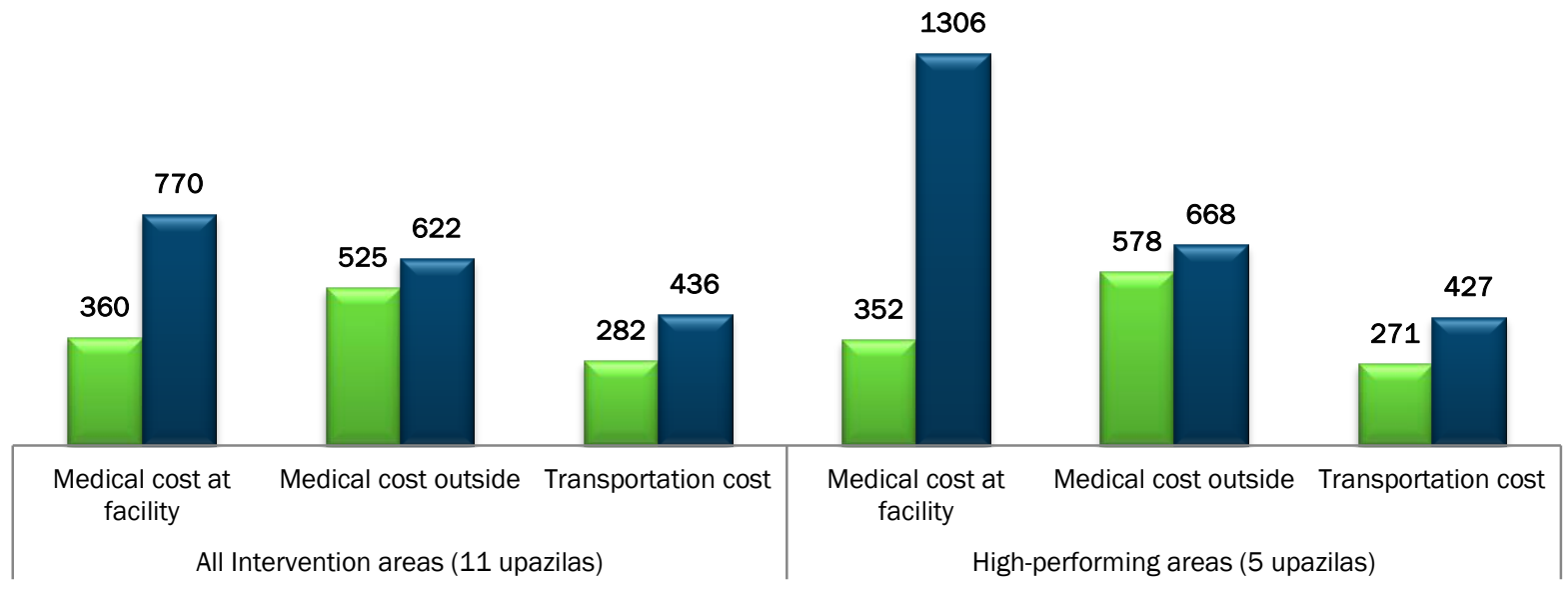

$\square$ Voucher

a Nonvoucher

The next figure reveals vast difference in expenditures for cesarean delivery between voucher and nonvoucher clients: Non-voucher clients spent more than three times (Taka 3,767 versus Taka 1,020) in Panel 1 and about six times more (Taka 4,148 versus Taka 713) in Panel 2 on internal medical costs than voucher clients. Voucher clients spent much less on drugs and laboratory services outside facilities partly because of greater availability of required medicine and laboratory services at DSF facilities, which suggests that poor women benefit more from the DSF program. Voucher clients spent less money for transportation for cesarean delivery than non-voucher clients, and costs were higher in all voucher areas than in high performing voucher areas. 
FIGURE 8 OUT-OF-POCKET EXPENDITURES BY VOUCHER AND NON-VOUCHER CLIENTS FOR NORMAL DELIVERY SERVICES IN 2012, BY EXPENSE TYPE

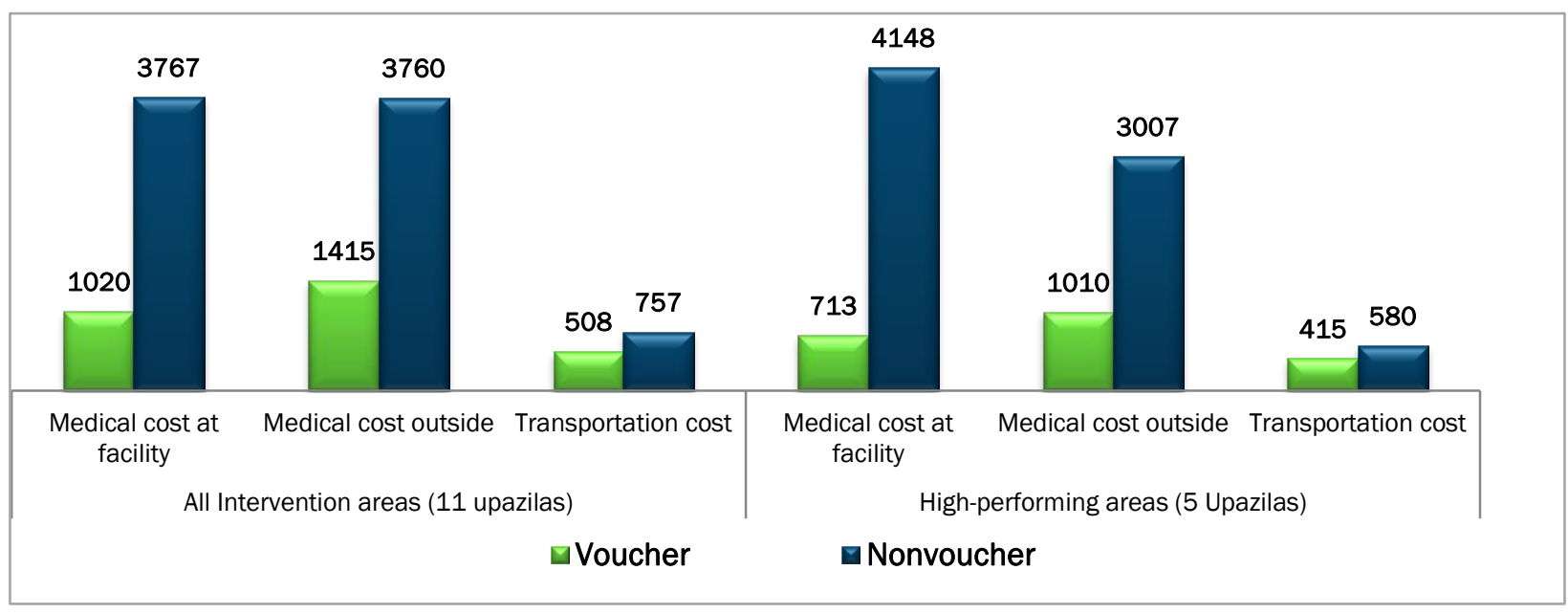

\section{Antenatal and postnatal out-of-pocket expenditures}

Table 16 (page 29) presents costs incurred for ANC and PNC services from facilities in DSF areas. Among ANC service recipients, voucher clients in Panel 1 spent less money than non-voucher clients, while Panel 2 voucher clients spent the same amount of money as non-voucher clients. Nearly 80 percent of voucher and non-voucher clients in both panels spent Taka 1,000 or less to receive ANC from public health facilities meaning that vouchers had little effect in subsidizing ANC-related expenditures. A maximum of two percent of the clients spent more than Taka 2,000, irrespective of vouchers for ANC. More than 90 percent of women incurred no costs for PNC. The main reason for widespread nonpayment for PNC is that most women (more than $80 \%$ ) received PNC check ups within two days of delivery at the facility without incurring any additional cost.

TABLE 16 Out-of-pocket expenditures by voucher and non-voucher clients for three or more ANC visits and PNC services in public facilities (percent)

\begin{tabular}{lcccc}
\hline \multirow{2}{*}{ Type of services } & \multicolumn{2}{c}{ Panel 1, All voucher areas } & Panel 2, High performing voucher areas \\
\cline { 2 - 4 } & Voucher client & $\begin{array}{c}\text { Non-voucher } \\
\text { client }\end{array}$ & $\begin{array}{c}\text { Voucher client } \\
\text { Non-voucher } \\
\text { client }\end{array}$ \\
\hline ANC cost distribution & & & & 22.8 \\
None & 8.9 & 18.5 & 7.5 & 28.1 \\
Taka Less than 500 & 47.9 & 29.6 & 48.3 & 24.6 \\
Taka 501-1,000 & 22.6 & 28.7 & 22.5 & 7.0 \\
Taka 1,001-2,000 & 6.2 & 12.0 & 4.2 & 1.8 \\
Taka More than 2,000 & 0.7 & 1.9 & 1.7 & 15.7 \\
Don't remember & 13.7 & 9.3 & 15.8 & 423 \\
Average per capita cost (Taka) & 402 & 509 & 128 & 57 \\
N & 146 & 108 & & \\
PNC cost distribution & & & 96.1 & 97.2 \\
None & 95.7 & 96.0 & 1.9 & 2.8 \\
Less than 500 Taka & 1.9 & 2.0 & 2.0 & 0.0 \\
More than 500 Taka & 2.4 & 2.0 & 150 & $\mathbf{7 2}$ \\
N & 162 & 102 & $\mathbf{4 0}$ & $\mathbf{2 8}$ \\
Average per capita cost (Taka) & $\mathbf{4 1}$ & $\mathbf{2 3}$ & & \\
\hline
\end{tabular}

Voucher clients appear to benefit from ANC as a result of the DSF scheme, as they spent less money than non-voucher clients in Panel 1. On the other hand, less expense incurred by non-voucher clients than voucher clients seeking PNC does not indicate any notable impact of DSF on postpartum clients. These comparisons demonstrate the need for policymakers to pay greater attention to reducing costs for ANC. 


\section{Supply side results}

\section{FACILITY CHANGES}

\section{Provider competence}

Provider competence is defined in this report as sufficient knowledge and skills to comply with standard practices of obstetric care. In assessing knowledge and skills, an arbitrary competency score is used.

In the 2010 baseline survey 206 service providers were available for interview from intervention and control areas. For the second survey in 2012, 209 providers were interviewed. Table 17 shows the distribution of providers from all intervention areas as Panel 1 and providers from high performing areas as Panel 2, by designation, experience, and training. The number of providers varied between survey periods but remained almost the same for intervention and control sites. Nine types of providers were interviewed and for analysis were divided into two broad categories: doctors and mid-level providers. Managers, consultants, and medical officers are categorized as "doctors" and senior staff nurses, FWVs, MAs, SACMOs, senior FWVs and assistant nurses are "mid-level providers." Both intervention and control facilities underwent staff changes in the two years characterized by increases in the proportion of doctors and decreases in mid-level providers. Although these changes were more pronounced in intervention sites, the ratio of doctors and mid-level providers (2:3) was the same in 2012 across sites. Due to the national shortage of doctors, an increase in mid-level providers, to conduct normal delivery services, is critical for increasing institutional delivery.

As shown in Table 17, approximately 44 percent of Panel 1 providers had at least 20 years' experience, compared to 46 percent in Panel 2, declining by eight and 15 percentage points, respectively, during the two year period. Thirty three percent of providers in Panel 1 and 35 percent in Panel 2 were on the job for 10 years or more, and the proportion declined over time. The two year period witnessed a rising share of young providers in overall staff. The intervention area does not differ notably from the control in either Panel for the proportion of providers employed for five years or less, for all sites (15\% to 18\%) in 2010, but in 2012 the proportion increased to 33 percent in Panel 1, 31 percent in Panel 2, and 28 percent in control sites. A remarkably small share of providers with six to 10 years' experience requires deeper investigation, focusing on factors that influence experienced provider retention at sub-district facilities.

TABLE 17 Distribution of service providers by selected characteristics (percent)

\begin{tabular}{|c|c|c|c|c|c|c|c|c|}
\hline \multirow{3}{*}{ Indicator } & \multicolumn{4}{|c|}{ Panel 1, All voucher areas } & \multicolumn{4}{|c|}{ Panel 2, High performing voucher areas } \\
\hline & \multicolumn{2}{|c|}{ Intervention } & \multicolumn{2}{|c|}{ Control } & \multicolumn{2}{|c|}{ Intervention } & \multicolumn{2}{|c|}{ Control } \\
\hline & 2010 & 2012 & 2010 & 2012 & 2010 & 2012 & 2010 & 2012 \\
\hline Type of provider & & & & & & & & \\
\hline Doctor & 28.8 & 39.2 & 34.3 & 39.3 & 25.0 & 41.2 & 34.3 & 39.3 \\
\hline Mid-level provider* & 71.2 & 60.8 & 65.7 & 60.7 & 75.0 & 58.8 & 65.7 & 60.7 \\
\hline $\begin{array}{l}\mathrm{N} \\
\text { Experience }\end{array}$ & 104 & 102 & 102 & 107 & 52 & 51 & 102 & 107 \\
\hline Less than 5 years & 18.3 & 33.3 & 16.7 & 28.0 & 15.4 & 31.4 & 16.7 & 28.0 \\
\hline 6 to 10 years & 4.8 & 6.9 & 9.8 & 8.4 & 3.8 & 11.8 & 9.8 & 8.4 \\
\hline 11 to 20 years & 32.7 & 23.5 & 36.3 & 26.2 & 34.6 & 25.4 & 36.2 & 26.2 \\
\hline More than 20 years & 44.2 & 36.3 & 37.2 & 37.4 & 46.2 & 31.4 & 37.3 & 37.4 \\
\hline $\mathbf{N}$ & 104 & 102 & 102 & 107 & 52 & 51 & 102 & 107 \\
\hline Training in last 5 years & 53.8 & 54.9 & 49.0 & 55.1 & 61.5 & 54.9 & 49.0 & 55.1 \\
\hline $\begin{array}{l}\mathrm{N} \\
\text { Training* }\end{array}$ & 104 & 102 & 102 & 107 & 52 & 51 & 102 & 107 \\
\hline EmOC & 35.7 & 10.7 & 22.0 & 20.3 & 40.6 & 10.7 & 22.0 & 20.3 \\
\hline $\mathrm{IMCl}$ & 53.6 & 44.6 & 52.0 & 50.8 & 62.5 & 50.0 & 52.0 & 50.8 \\
\hline Neonatal care & 8.9 & 25.0 & 6.0 & 18.6 & 12.5 & 28.6 & 6.0 & 18.6 \\
\hline ANC & 8.9 & 16.1 & 10.0 & 18.6 & 9.4 & 14.3 & 10.0 & 18.6 \\
\hline PNC & 8.9 & 16.1 & 8.0 & 22.0 & 12.5 & 14.3 & 8.0 & 22.0 \\
\hline FP & 7.1 & 3.6 & 0.0 & 11.9 & 3.1 & 3.6 & 0.0 & 11.9 \\
\hline $\mathbf{N}$ & 56 & 56 & 50 & 59 & 32 & 28 & 50 & 59 \\
\hline
\end{tabular}


Skills training has a strong effect on provider motivation. A comparison of the surveys does not yield an optimistic picture. Thirty-six percent of service providers in Panel 1 and 41 percent of providers in Panel 2 were trained in maternal and neonatal health within the past five years at the baseline survey, but the share declined sharply over time. Fifty four percent of providers in all voucher areas and 63 percent providers in high-performing voucher areas received training on integrated management of childhood illnesses (IMCl), which decreased a little over time in the intervention sites. The 2012 survey findings indicate that only onesixth of the providers reported receiving training on ANC, with almost the same level in the corresponding proportions across sites and panels. A relatively higher proportion of providers in the intervention area received training on neonatal care (25\% and 29\%, respectively, in Panels 1 and 2); while on PNC counseling, a maximum of 22 percent of providers in the control area received such training. Providers miss an important opportunity to provide postpartum contraception services as they hardly received any family planning training (Table 17).

Table 18 attempts to assess the basic level of knowledge by calculating percentage scores for selected maternal health service components. In particular, it describes the comparative percentage scores in maternal and neonatal knowledge of doctors (Table 18) and mid-level providers (Table L, Appendix). The proportion of providers with correct knowledge of the ANC schedule has multiplied over the time and sites. Doctors in high performing areas were more likely to mention the correct number of medical check ups a woman should complete during her pregnancy than doctors of Panel 1 (76\% versus $68 \%$ ). There has been an increase in the proportion of doctors with knowledge on "three delays," whereas mid-level providers' knowledge decreased slightly over time.

TABLE 18 Changes in doctors' knowledge of selected maternal health service components in the intervention areas (percent)

\begin{tabular}{lcccc}
\hline \multirow{2}{*}{ Knowledge indicators } & \multicolumn{2}{c}{ Panel 1, All voucher areas } & \multicolumn{2}{c}{$\begin{array}{c}\text { Panel 2, High performing } \\
\text { voucher areas }\end{array}$} \\
\cline { 2 - 5 } & $\mathbf{2 0 1 0}$ & $\mathbf{2 0 1 2}$ & $\mathbf{2 0 1 0}$ & $\mathbf{2 0 1 2}$ \\
\hline Four ANC schedule & 13.3 & 67.5 & 23.1 & 76.2 \\
Three delays & 50.0 & 67.5 & 61.5 & 85.7 \\
Five danger signs & 53.3 & 62.5 & 69.2 & 66.7 \\
Six or more conditions for high risk pregnancy & 80.0 & 90.0 & 84.6 & 90.5 \\
Correct schedule for 5 TT vaccines & 63.3 & 67.5 & 84.6 & 76.2 \\
Supplementary medicine for pregnancy & 30.0 & 25.0 & 46.2 & 19.0 \\
PNC within 48 hours & 0.0 & 5.0 & 0.0 & 0.0 \\
PNC within 42 days & 100.0 & 92.5 & 100.0 & 100.0 \\
Vitamin A capsule schedule within 6 weeks & 83.3 & 92.5 & 92.3 & 100.0 \\
Exclusive breastfeeding for 6 months & 93.3 & 95.0 & 100.0 & 95.2 \\
Knowledge of 5 or more EPI vaccines & 70.0 & 75.0 & 76.9 & 81.0 \\
Average score & 58 & 67 & 67 & $\mathbf{7 2}$ \\
$\mathrm{N}$ & $\mathbf{3 0}$ & $\mathbf{4 0}$ & $\mathbf{1 3}$ & $\mathbf{2 1}$ \\
\hline \hline
\end{tabular}

Identification of five danger signs of pregnancy and conditions for high risk pregnancy is subject to providers' correct knowledge and skills. Findings indicate a discouraging scenario of the perception of providers regarding correct knowledge of the five danger signs of pregnancy (less than $70 \%$ of providers from both Panels reported all five danger signs of pregnancy). Similarities continue for knowledge on the conditions for high risk pregnancy. In both cases, doctors had better knowledge than mid-level providers. It is critical that all providers correctly know the danger signs of pregnancy and conditions for high risk pregnancy; otherwise they risk being unable to recognize obstetric complications.

The findings presented in Table 18 indicate that in the 2012 survey 68 percent of doctors in Panel 1 and 76 percent of doctors in Panel 2 knew the correct TT schedule. A reversed scenario appears for knowledge of supplementary medicine for pregnancy (25\% in Panel 1 and 19\% in Panel 2). Mid-level providers have shallow knowledge of supplementary medicine (iron, folic acid, zinc, vitamin A) for pregnancy, despite an increase in the corresponding proportion for mid-level providers. 
Providers do not know the correct PNC schedule, with only a meager proportion mentioning PNC provision within 48 hours after birth. In both surveys, doctors and mid-level providers nearly universally recommended PNC within 42 days of childbirth.

It is encouraging that approximately 90 percent of mid-level providers knew the correct schedule for vitamin A capsules and the duration of exclusive breastfeeding, without any marked differences in the two panels over time. A greater proportion of doctors than mid-level providers knew the correct schedule for EPI vaccines, yet findings suggest about 39 percent of mid-level providers from Panel 1 and 40 percent of Panel 2 providers lack proper knowledge.

Every primary health care provider should have complete, basic maternal and neonatal health knowledge. The summary score for their basic knowledge in Table 18 shows the mean 2012 score for doctors is 67 percent in Panel 1 and 72 percent in Panel 2. Mid-level providers scored 58 and 59 percent (Table L), respectively. A maximum mean score of 72 indicate a serious deficiency in knowledge of basic maternal and neonatal care. Mid-level providers earned an optimum competency score in only one third of maternal health service components, indicating need for drastic improvement in their knowledge in other components.

Provider counseling was assessed on birth planning, discharge after delivery, postpartum care, and newborn care and feeding (Table 19, and Table M, Appendix). Overall, provider (doctors and mid-level providers) counseling skills were discouraging, never achieving a score of 70 of 100, suggesting lack of training or supportive supervision. It is disappointing that doctors' counseling scores in intervention areas decreased over time, with scores stagnant among mid-level providers; reasons may include doctors are not generally provided training on basic maternal health service counseling in their academic education nor in jobs.

TABLE 19 Doctors' counseling skills in intervention areas, by type of maternal health service (percent)

\begin{tabular}{|c|c|c|c|c|}
\hline \multirow[t]{2}{*}{ Aspect of maternal health services } & \multicolumn{2}{|c|}{ Panel 1, All voucher areas } & \multicolumn{2}{|c|}{$\begin{array}{c}\text { Panel 2, High performing } \\
\text { voucher areas }\end{array}$} \\
\hline & 2010 & 2012 & 2010 & 2012 \\
\hline \multicolumn{5}{|l|}{ Birth planning* } \\
\hline Select skilled birth attendant & 60.0 & 25.0 & 76.9 & 25.0 \\
\hline Select facility for delivery & 56.7 & 57.5 & 38.5 & 58.0 \\
\hline Arrange money in case of emergency & 80.0 & 65.0 & 84.6 & 65.0 \\
\hline Arrange transportation in case of emergency, delivery & 70.0 & 40.0 & 76.9 & 40.0 \\
\hline Collect necessary supplies in case of home delivery & 36.7 & 22.5 & 61.5 & 23.0 \\
\hline Identify blood group and manage donor & 60.0 & 55.0 & 61.5 & 55.0 \\
\hline Average score & 61 & 44 & 67 & 44 \\
\hline $\mathrm{N}$ & 30 & 40 & 13 & 21 \\
\hline \multicolumn{5}{|l|}{ Advice for discharge after delivery* } \\
\hline Monitor baby's physical growth & 46.7 & 27.5 & 53.8 & 28.0 \\
\hline Immunization of baby & 80.0 & 65.0 & 76.9 & 65.0 \\
\hline Family planning & 50.0 & 30.0 & 46.2 & 30.0 \\
\hline Breastfeeding method & 86.7 & 57.5 & 76.9 & 58.0 \\
\hline Vitamin A capsule uptake & 16.7 & 35.0 & 23.1 & 35.0 \\
\hline Maternal nutrition & 86.7 & 85.0 & 100.0 & 85.0 \\
\hline Average score & 61 & 50 & 63 & 52 \\
\hline $\mathrm{N}$ & 30 & 40 & 13 & 21 \\
\hline \multicolumn{5}{|l|}{ Advice for postpartum mothers* } \\
\hline Vitamin A for mother after delivery & 36.7 & 25.0 & 46.2 & 33.3 \\
\hline Counseling on nutrition for mother \& baby & 76.7 & 75.0 & 84.6 & 66.7 \\
\hline Family planning & 73.3 & 37.5 & 76.9 & 42.9 \\
\hline Care of perineum/cesarean stitches & 36.7 & 32.5 & 38.5 & 28.6 \\
\hline Average score & 59 & 43 & 58 & 43 \\
\hline $\mathrm{N}$ & 30 & 40 & 13 & 21 \\
\hline \multicolumn{5}{|l|}{ Advice for newborn care and feeding* } \\
\hline Breastfeeding method & 70.0 & 67.5 & 69.2 & 61.9 \\
\hline Food with breastfeeding at 6 months & 46.7 & 50.0 & 46.2 & 47.6 \\
\hline Cord care & 50.0 & 47.5 & 69.2 & 57.1 \\
\hline Infant immunization & 70.0 & 57.5 & 69.2 & 71.4 \\
\hline Average score & 59 & 56 & 52 & 49 \\
\hline $\mathrm{N}$ & 30 & 40 & 13 & 21 \\
\hline
\end{tabular}


Provider performance in counseling skills was best on "newborn care and feeding," which is partly due to better counseling on breastfeeding and infant immunization. Among other aspects of counseling, "discharge after delivery" earned higher scores, with little variation between doctors and mid-level providers. At discharge, however, less than 40 percent of doctors and mid-level providers counseled women on how to monitor their baby's physical growth, uptake of Vitamin A capsules, and family planning.

On birth planning counseling, providers could not obtain optimum scores and the scores did not improve over time. During birth planning counseling, most midlevel providers missed opportunities to give advice on arranging necessary supplies in case of a home delivery and a blood donor for facility delivery, and selecting a skilled birth attendant. Closing the gaps in these counseling skills could be critical for the survival of a newborn

Postpartum care, along with advice on newborn care and feeding, constitute PNC. Providers demonstrated better competency in PNC's neonatal component than its maternal component. The low score for the maternal component could be accounted for by the inclusion of care for perineum or cesarean stitches, care for which is not required for all postpartum women. No major change in neonatal counseling skills was observed for all providers, while doctors' postnatal maternal birth planning competence declined somewhat.

Assessment of the basic level of counseling skills shows that service providers could not manage to score a high competency level in any panel. The disappointing performance of service providers in essential counseling skills reflects their inadequate knowledge on basic maternal and newborn health care. Providers in the intervention areas were not offered any skills training as part of the voucher program and there was no professional monitoring.

A minimum competency level was fixed at an arbitrary 50 percent cutoff in the management of obstetric complications. Findings presented in Table 20 (page 34; and Table N, Appendix) on skills assessment of obstetric complications management indicates poor performance among doctors and disappointing performance by mid-level providers. Mid-level providers could not achieve a minimum score in any of five components. Doctors managed to score a minimum in one out of five components each in all voucher areas and high performing voucher areas. Doctors and mid-level providers both demonstrated poor competency for managing eclampsia and obstructed labor: Less than 40 percent from both Panels could outline the steps of clinical care.

High rates of referral by both doctors and mid-level providers indicate UHCs' lack in infrastructural capacity to provide comprehensive EmOC services (Table 20; and Table N, Appendix). In most cases, there has been an increase in making referrals by both cadres. Referral for obstetric complications is more common among mid-level providers of both panels than among doctors. Except for "removal of retained placenta," almost all mid-level providers refer clients either to a doctor or to a higher facility for other obstetric complications, as they are not trained to provide services for those complications. Referral of a majority of the obstetric complications made by doctors reveals the critical condition of the complicated cases they receive or their inadequate technical capacity.

Summary results as shown in the skill scores expose the disappointing performance of both doctors and mid-level providers in essential obstetric complications management skills. Extensive academic training of the doctors is found to be inadequate to raise their competency score. The country's health system has yet to provide a systematic opportunity for doctors in the public health sector to receive training after they join the service. The situation is dismal even in higher performing areas, which indicates the need for medical training of service providers tailored to the needs and resources at upazila and to enhance the capacity of upazila hospitals to address complicated obstetric cases. 
TABLE 20 Doctors' clinical skills in intervention areas, by type of obstetric complication (percent)

\begin{tabular}{|c|c|c|c|c|}
\hline \multirow[t]{2}{*}{ Obstetric complications } & \multicolumn{2}{|c|}{ All voucher areas } & \multicolumn{2}{|c|}{$\begin{array}{l}\text { High performing } \\
\text { voucher areas }\end{array}$} \\
\hline & 2010 & 2012 & 2010 & 2012 \\
\hline \multicolumn{5}{|l|}{ Antepartum hemorrhage (APH)* } \\
\hline Check vital signs & 46.7 & 60.0 & 53.8 & 47.6 \\
\hline Set up intravenous fluid & 53.3 & 60.0 & 69.2 & 61.9 \\
\hline Take blood for Hb, grouping, cross-matching & 46.7 & 35.0 & 69.2 & 28.6 \\
\hline Refer to higher level hospital & 46.7 & 62.5 & 38.5 & 57.1 \\
\hline Average skill score & 48 & 54 & 58 & 49 \\
\hline $\mathrm{N}$ & 30 & 40 & 13 & 21 \\
\hline \multicolumn{5}{|l|}{ Postpartum hemorrhage (PPH)* } \\
\hline Give Ergometrin if no product in uterus & 43.3 & 47.5 & 53.8 & 47.6 \\
\hline Take blood for Hb, grouping, cross-matching & 60.0 & 42.5 & 69.2 & 42.9 \\
\hline Give intravenous fluid & 66.7 & 55.0 & 69.2 & 66.7 \\
\hline Repair the tear & 50.0 & 15.0 & 46.2 & 9.5 \\
\hline Refer to a doctor or hospital & 60.0 & 80.0 & 15.4 & 71.4 \\
\hline Average skill score & 57 & 48 & 55 & 48 \\
\hline $\mathrm{N}$ & 30 & 40 & 13 & 21 \\
\hline \multicolumn{5}{|l|}{ Removal of retained placenta* } \\
\hline Give Oxytocin & 50.0 & 63.0 & 69.2 & 57.1 \\
\hline Apply manual removal of placenta & 43.3 & 55.0 & 46.2 & 61.9 \\
\hline Ensure all parts of placenta come out & 53.3 & 45.0 & 69.2 & 42.9 \\
\hline Give intravenous fluids & 30.0 & 73.0 & 46.2 & 76.2 \\
\hline Refer to a doctor or hospital & 36.7 & 10.0 & 15.4 & 9.5 \\
\hline Average skill score & 36 & 40 & 49 & 50 \\
\hline $\mathrm{N}$ & 30 & 40 & 13 & 21 \\
\hline \multicolumn{5}{|l|}{ Obstructed labor* } \\
\hline Rule out cephalo-pelvic disproportion & 33.3 & 25.0 & 38.5 & 19.0 \\
\hline Start on $10 \%$ dextrose & 20.0 & 17.5 & 38.5 & 0.0 \\
\hline Take blood for grouping and cross matching & 43.3 & 37.5 & 69.2 & 47.6 \\
\hline Prepare for cesarean section & 43.3 & 55.0 & 76.9 & 66.7 \\
\hline Consult the doctor or refer to hospital & 70.0 & 57.5 & 46.2 & 33.3 \\
\hline Average skill score & 42 & 39 & 53 & 28 \\
\hline $\mathrm{N}$ & 30 & 40 & 13 & 21 \\
\hline \multicolumn{5}{|l|}{ Eclampsia management* } \\
\hline Start vital signs chart & 33.3 & 40.0 & 53.8 & 42.9 \\
\hline Monitor fetal heart rate & 30.0 & 32.5 & 46.2 & 33.3 \\
\hline Quantitative monitoring of proteinuria & 46.7 & 7.5 & 61.5 & 0.0 \\
\hline Administer antihypertensive & 33.3 & 37.5 & 53.8 & 33.3 \\
\hline Administer anticonvulsant & 70.0 & 47.5 & 76.9 & 38.1 \\
\hline Refer to doctor or hospital & 36.7 & 65.0 & 7.7 & 71.4 \\
\hline Average skill score & 42 & 38 & 50 & 37 \\
\hline $\mathrm{N}$ & 30 & 40 & 13 & 21 \\
\hline
\end{tabular}

Note: *Multiple responses

\section{Service quality}

\section{Client perspectives on maternal health check-up quality}

Client perspectives on maternal health check ups were analyzed to measure the quality of those services, which implies the level of client satisfaction. A weighted composite quality score was constructed based on a maximum of six processes or aspects: medical history and background check, client and provider rapport, physical examination, medical screening, birth planning counseling, FP counseling, and prevention and case management. The composite quality score was constructed using the data collected through the observation of client and provider interactions. A total of 76 indicators were used to calculate the quality score for ANC services (Appendix 1) and 59 indicators for PNC service (Appendix 2). A weighted score on a 0 to 100 scale 
is used to measure the performance on quality of care. The findings are presented in Table 21 (page 35). Comparison of composite scores across the sites reveals a slightly better quality of ANC services provided at the control facilities reported by clients compared to intervention facilities. Conversely, the quality score obtained for PNC services is higher for the intervention areas than the control areas.

TABLE 21 Clients' opinion of quality of care for maternal health check ups

\begin{tabular}{|c|c|c|c|c|c|c|c|c|}
\hline \multirow{3}{*}{ Quality indicator } & \multicolumn{4}{|c|}{ Panel 1, All voucher areas } & \multicolumn{4}{|c|}{$\begin{array}{l}\text { Panel } 2, \text { High performing } \\
\text { voucher areas }\end{array}$} \\
\hline & \multicolumn{2}{|c|}{ Intervention } & \multicolumn{2}{|c|}{ Control } & \multicolumn{2}{|c|}{ Intervention } & \multicolumn{2}{|c|}{ Control } \\
\hline & 2010 & 2012 & 2010 & 2012 & 2010 & 2012 & 2010 & 2012 \\
\hline \multicolumn{9}{|l|}{ ANC services } \\
\hline Medical history and background check & 48 & 54 & 54 & 59 & 49 & 60 & 54 & 59 \\
\hline Client and provider rapport & 74 & 70 & 74 & 79 & 79 & 74 & 74 & 79 \\
\hline Physical examination & 39 & 43 & 44 & 51 & 41 & 45 & 44 & 51 \\
\hline Medical screening & 21 & 22 & 12 & 27 & 27 & 27 & 12 & 27 \\
\hline Birth preparedness counseling & 19 & 25 & 19 & 26 & 17 & 29 & 19 & 26 \\
\hline Prevention and case management & 30 & 32 & 31 & 34 & 29 & 39 & 31 & 34 \\
\hline Composite score (weighted) & 40 & 44 & 43 & 48 & 41 & 49 & 43 & 48 \\
\hline $\mathrm{N}$ & 507 & 406 & 521 & 431 & 236 & 198 & 521 & 431 \\
\hline \multicolumn{9}{|l|}{ PNC services } \\
\hline Medical history and background check & 37 & 43 & 46 & 50 & 44 & 50 & 46 & 50 \\
\hline Client and provider rapport & 65 & 68 & 69 & 69 & 69 & 70 & 69 & 69 \\
\hline Physical examination & 17 & 68 & 30 & 59 & 20 & 58 & 30 & 59 \\
\hline Medical screening & 00 & 63 & 00 & 40 & 00 & 48 & 00 & 40 \\
\hline Family planning & 03 & 50 & 05 & 31 & 03 & 35 & 05 & 31 \\
\hline Prevention and case management & 24 & 43 & 26 & 34 & 23 & 26 & 26 & 34 \\
\hline Composite score (weighted) & 27 & 57 & 35 & 51 & 29 & 51 & 35 & 51 \\
\hline $\mathrm{N}$ & 44 & 124 & 33 & 115 & 14 & 56 & 33 & 115 \\
\hline
\end{tabular}

For ANC services, 25 indicators were used for medical history and background checks, seven service indicators for client and provider rapport, 14 indicators for physical examination, four indicators for medical screening, eight indicators for birth planning counseling, and 18 service indicators for prevention and case management.

Indicators covered under medical history and background check can be broadly described as ensuring duration of gestation or conception and expected date of delivery; history of hypertension, diabetes and asthma; checking any current medication; history of previous pregnancy, miscarriage or abortion, stillbirth, neonatal deaths and cesarean delivery; menstruation-related problems, urination related problems; contraceptive history; and demography of clients.

Client and provider rapport was measured by whether the provider greeted the client in a friendly manner, maintained client privacy, listened attentively, explained the problem, ensured client comfort by asking questions, and took verbal consent from the client for the physical examination.

The physical examination included measuring client height, weight, blood pressure, pulse, and body temperature; checking breasts for pain or lump and abdomen for any mark of operation; palpating abdomen for fetal presentation, movement and heart rate; internal examination for vaginal discharge; and checking for anemia, dehydration, and edema.

Medical screening covered performing or referring for urine test, blood test, ultra-sonogram, and syphilis test.

Prevention and case management included advice on nutrition, personal hygiene, rest, and exercise during pregnancy; tetanus vaccination; vitamin A and iron or folic acid supplementation; advice on postpartum complications for emergency care; importance of early postpartum visit for mother and newborn; breast care and feeding; FP counseling; need for other services; and counseling for follow up visit and referral. 
Aspects or processes considered for the composite quality score are not constant across services. Besides, the number of indicators for each of the processes varies according to the types of services. For ANC services, it is more important to explore the quality of birth planning counseling than round-the-clock provider availability as ANC services are provided six days a week from 8:00 am to 2:00 pm. Similarly, for PNC services, FP counseling is critical, while birth preparedness counseling is irrelevant.

Composite scores for ANC services marginally improved (4\% in Panel 1 and $8 \%$ in Panel 2) at intervention facilities compared to control facilities (weighted composite score for control facilities was 48), with small differences for the aspects of care. In both panels, two aspects of care were rated more than 50 (out of 100). The quality score was highest for client and provider rapport, reaching 79 , differing by sites. Medical history and background check for necessary diagnosis also scored more than 50 , with control facilities performing better than intervention facilities. Birth planning counseling, the backbone of ANC services, is the area where both intervention and control facilities struggled, reflected in its maximum score of 29 in Panel 2. A nearly similar situation is true for preventive care. Advice or preventive care including follow up services is scarcely practiced irrespective of the presence of the intervention, obtaining a highest score of 39 out of 100 in Panel 2 intervention areas.

The composite quality score for PNC services suggests a remarkable increase in the quality score for both sites and the facilities in intervention areas outperformed the facilities in control areas in most of the aspects of services. Variability is observed over time for each of the processes. As with ANC, the quality score was highest for client and provider rapport reaching 70 in Panel 2, which remains almost the same across sites and over time, followed by physical examination. The quality score for physical examination increased by four times in Panel 1, three times in Panel 2 in intervention facilities, while there was a twofold increase reported for control facilities. A maximum score of 50 on diagnosis (medical history and background check) across facilities indicates that providers do not generally undertake a comprehensive client history. An overwhelming increase was observed for medical screening in both intervention and control areas. On FP counseling, the facilities in the intervention area, obtaining a score of 50 in 2012, outperformed the control facilities score of 31. Among the six service processes or aspects, the lowest score on preventive counseling and follow up suggests a great deal of opportunity for improvement. Preventive counseling and follow up is a comprehensive process which includes advice for both mother and child, covering one-third of PNC indicators. Unlike ANC services, the client satisfaction level was relatively higher at the intervention sites as the weighted composite quality score for intervention was estimated at 57 in Panel 1, and 51 in Panel 2 compared to 51 in the control.

Client perspectives on ANC and PNC services discussed above covers only two out of 11 service units in operation at the facility; therefore these findings represent a segment of the aggregate quality of services provided at the facility.

\section{Client perspectives on delivery services quality}

Client perspectives on delivery services were analyzed to measure the quality of services including client satisfaction. Using data from client exit interviews, a weighted composite quality score was constructed based on a maximum of four processes or aspects: physical check ups, medical screening, prevention and case management, and client satisfaction (Appendix 3). The quality score obtained is higher for intervention than for control facilities.

Physical check ups included checking vital signs including pulse and blood pressure, palpitating abdomen and listening to fetal heartbeat, checking for edema, and examining eyes. Medical screening included blood and urine tests and ultra-sonogram. Prevention and case management was measured by whether the provider asked clients' problem and gave advices on delivery-related problems or complications, where to go in case of complications, breast care and feeding, diet and nutrition, uptake of vitamin A capsules after delivery, PNC check up or follow up visit, child immunization, and child spacing and FP.

Service and client satisfaction was measured through several clusters of indicators including waiting time, provider availability, provider behavior, and no payment for care. Waiting time is considered to improve the quality of services of the facility if a pregnant woman spent less than 30 minutes to be admitted, transferred 
from outdoor/emergency to a ward, and be visited by a doctor after reaching the ward. Provider availability was measured for whether hospital staff was present during patient admission, delivery service is provided by a doctor or nurse, doctors visited the admitted patient at least once daily, and nurses routinely visited the admitted client. How the client was treated during the services was considered as part of provider behavior. The remaining cluster included whether the client received any financial benefits and paid no money for purchasing medicine outside.

The composite quality score on delivery services presented in Table 22 reveals that facilities achieved a composite score of a maximum of 60 out of 100 in Panel 2, without any significant variation across sites. Even for each of the processes or aspects of care, no notable variation is observed across intervention and control sites. Among the four aspects, level of service or client satisfaction earned the highest score (Panel 2) while medical screening (Panels 1 and 2) scored the lowest. Indicators used to measure the level of service are not related to the physical infrastructure of a facility. Hence, a high score on level of service suggests good management practices in the facilities. Most of the delivery clients do not require blood tests, urine tests, and ultra-sonograms at time of labor; therefore, the score achieved for medical screening is the lowest.

TABLE 22 Clients' opinions of delivery service quality of care in all sites

\begin{tabular}{lcccccccc}
\hline \hline & \multicolumn{3}{c}{ Panel 1, All voucher areas } & \multicolumn{3}{c}{ Panel 2, High performing voucher areas } \\
\cline { 2 - 8 } Quality indicator & \multicolumn{2}{c}{ Intervention } & \multicolumn{2}{c}{ Comparison } & \multicolumn{2}{c}{ Intervention } & Comparison \\
\cline { 2 - 8 } & $\mathbf{2 0 1 0}$ & $\mathbf{2 0 1 2}$ & $\mathbf{2 0 1 0}$ & $\mathbf{2 0 1 2}$ & $\mathbf{2 0 1 0}$ & $\mathbf{2 0 1 2}$ & $\mathbf{2 0 1 0}$ & $\mathbf{2 0 1 2}$ \\
\hline Physical check ups & 66 & 64 & 55 & 58 & 66 & 73 & 55 & 58 \\
Medical screening & 11 & 08 & 22 & 07 & 11 & 11 & 22 & 07 \\
Prevention and case & 47 & 63 & 44 & 56 & 47 & 62 & 44 & 56 \\
management & 69 & 67 & 67 & 60 & 65 & 73 & 67 & 60 \\
Level of service & $\mathbf{5 1}$ & $\mathbf{5 7}$ & $\mathbf{4 9}$ & $\mathbf{5 1}$ & $\mathbf{5 0}$ & $\mathbf{6 0}$ & $\mathbf{4 9}$ & $\mathbf{5 1}$ \\
Composite score (weighted) & $\mathbf{4 0}$ & $\mathbf{6 2}$ & $\mathbf{2 9}$ & $\mathbf{4 9}$ & $\mathbf{2 7}$ & $\mathbf{4 0}$ & $\mathbf{2 9}$ & $\mathbf{4 9}$ \\
N & & & & & & &
\end{tabular}

A maximum score of 73 for physical check ups in high performing areas indicates it is not yet common practice for providers to take a comprehensive medical history and conduct a thorough physical examination, with a higher quality score reported for intervention facilities. The quality score on prevention and case management was higher for the facilities in intervention areas compared with those in the control area. Yet, the quality score on prevention and case management was below 70 in Panel 1 and 2, which indicates lapses in provision of advice and preventive services.

Comparison of quality scores across antenatal, delivery, and postnatal services reveals the lowest quality score for ANC services and greatest improvement in the quality score for PNC services. Nevertheless, the composite score achieved by these services is far below the optimum level. A score of 80 out of 100 is arbitrarily set as an "optimum score" after assessing the need for individual indicators in offering the specified service.

Out of all aspects of care, level of service and physical check ups for delivery care in high performing intervention areas earned 73 , close to an optimum score. Client and provider rapport is the only aspect of care where ANC and PNC services fared well. Both level of service and client and provider rapport are related to facility management. Other aspects of care are struggling to earn high scores, which depend on physical infrastructure and provider technical skills. Overall, low scores demonstrate the program's weaknesses in improving overall maternal health service quality. Although service utilization increased due to the DSF program, the quality of services did not improve, as benefits are attached to quantitative performance alone. 


\section{Program effectiveness}

\section{SERVICE TRENDS}

The evaluation of program performance indicates a greater level of service volume at intervention facilities (UHCs) as a result of the DSF project. Two years of interventions brought noticeable changes in the utilization of maternal health services.

The following figure compares institutional deliveries for 11 intervention and 11 control facilities. Overall, the intervention facilities increased their performance more than twofold while the comparison facilities did not make any noticeable improvement in their performance. On average, an intervention facility performs 750 deliveries annually, while a control facility conducts half that number. The performance of the intervention facilities in conducting deliveries could be higher, as one third of such facilities either do not offer cesarean deliveries or lack required human resources to provide adequate delivery and complication management care as identified through the facility assessment.

\section{FIGURE 9 CHANGES IN SERVICE VOLUME IN INSTITUTIONAL DELIVERIES FOR ALL SITES, 2010-2012}

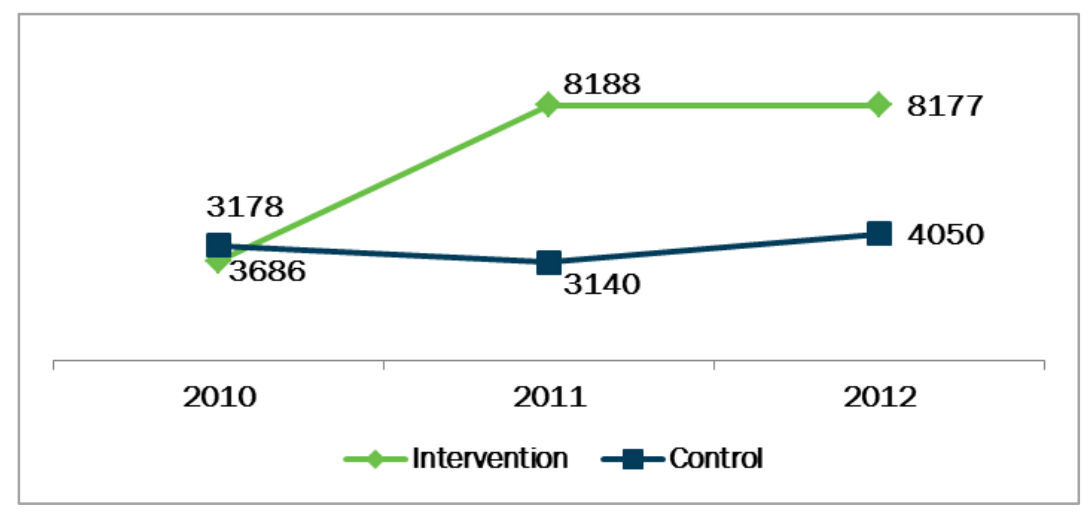

The next figure illustrates that both intervention and control facilities increased their performance in ANC services. Increase in the service volume is greater for intervention facilities. Specifically, the number of services provided at the intervention facilities is twice the volume of control facilities. On average, each intervention facility serves 10 ANC clients a day, compared with only four per day for a control facility, leaving a limited scope for the intervention facilities to further increase service volume for ANC services.

\section{FIGURE 10 CHANGES IN ANTENATAL CARE SERVICE VOLUMES FOR ALL SITES, 2010-2012}

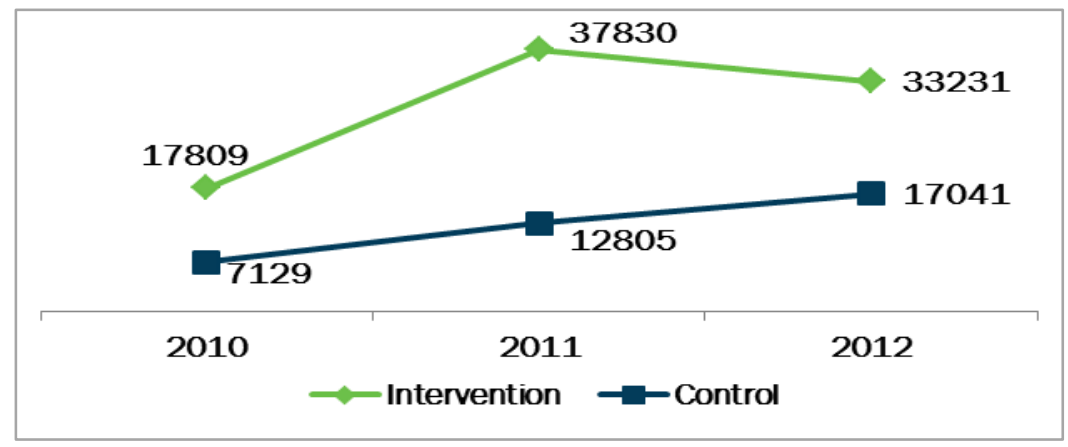


PNC service volume increased by a large margin in the intervention's first year in DSF facilities, then it decreased. There is no improvement in the performance of postnatal services at control facilities. The intervention facilities serve a greater number of postnatal clients: three times that of the comparison facilities (Figure 11). Nevertheless, opportunities exist for the intervention facilities to motivate clients to receive skilled PNC from nearby facilities as the daily performance of serving only three PNC clients is not encouraging from the program perspective.

\section{FIGURE 11 CHANGES IN POSTNATAL CARE SERVICE VOLUME FOR ALL SITES, 2010 TO 2012}

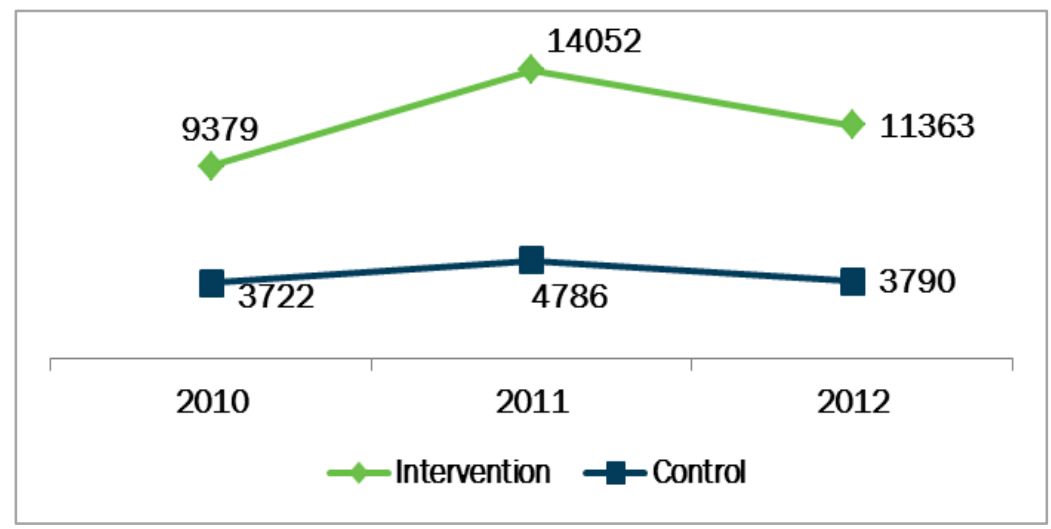

\section{CLIENT EXPERIENCES}

Recipients in all voucher areas were compared with recipients in high performing voucher areas on voucher services, financial benefits, voucher book utilization, and reimbursement timing. Women in high performing voucher areas had better knowledge of voucher service and benefits, utilized more voucher services, and waited less. About 56 percent of eligible women received vouchers from UHCs, with the remainder from government outreach workers. On average, women received vouchers during their sixth month of pregnancy. In 11 percent of cases, some monetary transaction occurred (not shown in the table). Table 23 (page 40) describes women's awareness of the services covered by vouchers as well as the financial benefits attached to those services.

In Panel 1, 72 percent of women had heard about maternal health voucher program, compared to 92 percent in Panel 2. The main sources of information for the voucher program are relatives, neighbors or community members, followed by government outreach workers. It is evident that only half of all women from Panel 1 and 60 percent of women from Panel 2 received voucher information from outreach workers. Only in four percent of cases from all voucher areas and five percent cases from high performing voucher areas did women receive information from doctors and mid-level providers. When information is garnered mostly from non-program individuals, there is a great risk of not receiving comprehensive information (Pandey et al. 2007).

Maternal health voucher program covers seven medical services in a facility. A large variation exists over the awareness of those services. None of the service benefits is universally known in any panel's respondents. Delivery services (both normal and cesarean) and antenatal services are mostly known to the voucher clients (about $80 \%$ to $90 \%$ ). The level of knowledge on four other services-blood tests, urine tests, complications care, and PNC-is moderate in Panel 1 and the percentage is slightly higher in Panel 2. Low awareness or large variation in awareness may prove to be counterproductive to the effectiveness of the program in two ways: low utilization of targeted services and a limited role of community members in enhancing accountability of service providers. 
TABLE 23 Distribution of voucher clients' knowledge of DSF program, services, and benefits (percent)

\begin{tabular}{|c|c|c|}
\hline Knowledge indicators & $\begin{array}{c}\text { Panel } 1 \\
\text { All voucher areas }\end{array}$ & $\begin{array}{c}\text { Panel } 2 \\
\text { High performing voucher areas }\end{array}$ \\
\hline Heard of DSF program & 72.3 & 92.1 \\
\hline $\mathrm{N}$ & 1662 & 745 \\
\hline \multicolumn{3}{|l|}{ Sources of information * } \\
\hline Doctor & 1.2 & 1.3 \\
\hline Nurse, FWV, SACMO, MA & 3.0 & 4.1 \\
\hline CSBA, FWA, HA & 51.4 & 59.5 \\
\hline Relatives and neighbors & 66.3 & 63.5 \\
\hline $\mathrm{N}$ & 1662 & 686 \\
\hline 3 ANC visits & 78.8 & 89.1 \\
\hline 2 Blood tests & 53.4 & 61.6 \\
\hline 2 Urine tests & 53.9 & 62.0 \\
\hline Normal delivery & 81.7 & 89.8 \\
\hline Cesarean delivery & 77.0 & 82.0 \\
\hline Complications care & 52.9 & 54.9 \\
\hline One PNC & 43.7 & 48.9 \\
\hline $\mathrm{N}$ & 382 & 284 \\
\hline \multicolumn{3}{|l|}{ Knows financial benefits covered by voucher } \\
\hline Transportation cost for ANC & 67.8 & 80.6 \\
\hline Transportation cost for delivery & 55.0 & 63.7 \\
\hline Transportation cost for PNC & 34.8 & 40.5 \\
\hline Transportation for referrals & 31.7 & 35.2 \\
\hline Gift box for safe delivery & 73.0 & 78.2 \\
\hline Money for nutritious food & 77.5 & 79.2 \\
\hline $\mathrm{N}$ & 382 & 284 \\
\hline \multicolumn{3}{|l|}{$\begin{array}{l}\text { Knows the selection criteria for receiving } \\
\text { vouchers * }\end{array}$} \\
\hline Monthly family income less than Taka 2500 & 77.0 & 78.2 \\
\hline Less than 0.15 acre & 4.5 & 4.2 \\
\hline First pregnancy & 25.4 & 27.5 \\
\hline Using FP methods before second pregnancy & 16.5 & 27.5 \\
\hline $\mathrm{N}$ & 382 & 284 \\
\hline
\end{tabular}

Vouchers allow pregnant women to receive conditional cash incentives, transportation subsidies and a gift box. From the UHC, a voucher beneficiary receives a gift box worth Taka 500 (typically contains a Sari, baby dress, towel and soap) and Taka 2,000 (US\$29) to purchase nutritious food. Transportation costs includes Taka 100 (\$1.4) for each ANC, delivery, and PNC service from home to the UHC, and an additional Taka 500 (\$7) for outgoing referral to the designated health facility or hospital for delivery. Knowledge about the financial benefits covered by the voucher program is noticeably discouraging in Panel 1 . Women are more likely to know about large cash benefits than about small ones. Awareness of the transportation and transportation cost for referral for PNC is alarmingly low.

Four criteria are mainly used to select the pregnant women eligible for vouchers: monthly family income of less than 2,500 Taka, land ownership of less than 0.15 acre, first pregnancy, and using FP methods in case of a second pregnancy. Awareness of the economic criteria is much higher than that of the demographic criteria. A majority of women in Panel 1 and Panel 2 (respectively $77 \%$ and $78 \%$ ) knew of the monthly family income as a voucher selection criterion. On the other hand, a maximum of 28 percent of voucher clients from high performing areas knew whether or not a woman should be first time pregnant or have used FP if pregnant the second time to become eligible for vouchers (Table 23).

Low awareness on subsidized services and financial benefits opens up an avenue for a new intervention in the DSF program, including strong community awareness raising activities and involving non-government outreach workers to educate pregnant women about the government voucher program. Lessons from the government's child vaccination campaign can be utilized in designing communication activities. 
The extent of the utilization of vouchers for services and experiences of women receiving the payment against vouchers are shown in Table 24. Women who availed themselves of vouchers (86\% from Panel 1 and $90 \%$ from Panel 2) used vouchers to receive any of the maternal health services. In conformity with service utilization patterns, women in high performing voucher areas had better uptake of voucher services compared to women in all voucher areas. Vouchers are used most frequently for maternal health checkups while their use is lowest for complications care. Among women who utilized laboratory care, the majority used vouchers for two tests, both blood and urine tests.

TABLE 24 Voucher utilization and reimbursement (percent)

\begin{tabular}{|c|c|c|}
\hline Category & $\begin{array}{c}\text { Panel } 1 \\
\text { All voucher areas } \\
\end{array}$ & $\begin{array}{c}\text { Panel } 2 \\
\text { High performing voucher areas }\end{array}$ \\
\hline Services through voucher & 86.1 & 90.1 \\
\hline $\mathrm{N}$ & 382 & 284 \\
\hline \multicolumn{3}{|l|}{ Type of service provided by vouchers } \\
\hline ANC 1 & 86.0 & 93.8 \\
\hline ANC 2 & 69.0 & 80.1 \\
\hline ANC 3 & 52.0 & 60.5 \\
\hline Delivery & 50.5 & 59.8 \\
\hline Complications care & 18.2 & 21.5 \\
\hline PNC & 45.6 & 53.9 \\
\hline $\mathrm{N}$ & 329 & 256 \\
\hline Laboratory services through voucher & 68.4 & 82.0 \\
\hline $\mathrm{N}$ & 329 & 256 \\
\hline \multicolumn{3}{|l|}{ Type of laboratory service } \\
\hline Both blood and urine tests & 92.9 & 95.2 \\
\hline Only blood test & 1.8 & 1.9 \\
\hline Only urine test & 5.3 & 2.9 \\
\hline $\mathrm{N}$ & 225 & 210 \\
\hline \multicolumn{3}{|l|}{ Payment for safe delivery and transport } \\
\hline Reimbursed & 52.0 & 55.9 \\
\hline Did not get reimbursed & 48.0 & 44.1 \\
\hline $\mathrm{N}$ & 329 & 256 \\
\hline \multicolumn{3}{|l|}{ Reimbursement type* } \\
\hline Total payment at one time & 76.6 & 72.0 \\
\hline Partial payment & 10.5 & 4.1 \\
\hline In installments & 12.9 & 23.9 \\
\hline $\mathrm{N}$ & 171 & 143 \\
\hline \multicolumn{3}{|l|}{ Reasons for not receiving payment* } \\
\hline Hospital yet to receive DSF funds & 76.0 & 73.5 \\
\hline $\begin{array}{l}\text { Not aware of receiving money } \\
\text { for voucher use }\end{array}$ & 4.0 & 3.0 \\
\hline Other & 24.6 & 25.0 \\
\hline $\mathrm{N}$ & 158 & 113 \\
\hline $\begin{array}{l}\text { Average wait for payment } \\
\text { after delivery (in months) }\end{array}$ & 4 & 4 \\
\hline $\mathrm{N}$ & 171 & 143 \\
\hline
\end{tabular}

Note: *Multiple responses

Women are reimbursed for voucher-covered services by UHCs. Like the previous evaluation studies on the DSF program, this report also identified problems in the reimbursement mechanism, particularly delays in reimbursement. Only 52 percent and 56 percent of voucher recipients from Panel 1 and Panel 2 , respectively, had been reimbursed at the time of interview. Among them, about three fourths received total payment at a time, 11 percent received partial payment, and 13 percent received their payment in installments (all voucher areas). On average, it took four months for the UHC to clear payments to the voucher users. Three fourths of UHCs ascribed the delay in receiving DSF funds from the central level as the reason for making delayed payment to clients. A small proportion of women are not aware of receiving money for using vouchers (both areas). Delayed payment to beneficiaries has a negative impression about the program, causing the trust of community members on the program to diminish over time. 


\section{PROVIDER PERCEPTIONS}

Service providers were asked about their experience with the voucher program as well as their perception of the program's impact on service delivery. Information about whether the program needs any further improvement was also gathered from the provider survey. Results will be helpful to improve the management of program implementation and also to improve the quality of services.

Table 25 illustrates that implementation of DSF program in 11 new upazilas is not effectively managed, according to most providers, who identified several major areas where the program is fraught with difficulties, mostly financial in nature. According to more than half of providers, selection of eligible women and timely payment of the nutrition incentive are not effective. Provider experiences with the reimbursement mechanism are even more discouraging. The reimbursement mechanism appears to be effective only with one third of providers, with less than half of providers and program managers reporting program funds received at regular intervals. Many UHCs wait for more than 180 days to receive funds from the central level, only after which can UHCs distribute voucher beneficiaries' incentive payments.

TABLE 25 Provider experiences (percent)

\begin{tabular}{lc}
\hline Indicator & Percent \\
\hline Program implementation mechanism is effective & 46.0 \\
N & 102 \\
Areas of non-effectiveness* & \\
Selection of eligible women & 50.9 \\
Timely payment of nutrition incentive & 52.7 \\
Timely payment of gift box & 29.1 \\
Timely payment of provider incentive & 25.5 \\
N & 55 \\
Reimbursement mechanism effective & 32.0 \\
N & 102 \\
Received voucher funds at a regular interval (every six months) & 48.0 \\
N & 102 \\
Problems encountered in payment* & \\
Delay in receiving funds from central level & 97.1 \\
Frequent unavailability of adequate money & 35.7 \\
Absence of money-disbursing personnel & 4.3 \\
(on leave, out station office work) & 70 \\
Problems in providing quality services * & \\
Lack of support staff & 56.8 \\
Shortage of doctors & 58.1 \\
Shortfalls in medicine & 44.6 \\
Lack of training & 21.6 \\
No blood transfusion & 18.9 \\
Shortage of delivery kits and equipment & 24.3 \\
No proper implementation guidance & 12.2 \\
N & 74 \\
\hline Note: Multiple responses & \\
\hline
\end{tabular}


Delay in receiving funds from the central level has become a perpetual obstacle to the program's effective management; 97 percent of providers replied negatively about funds disbursement. Beneficiary payments are often hindered by lack of funds at facilities or absent disbursement personnel due to vacations or outstation office work. The DSF program has no provisions for its administration at upazila hospitals.

Service providers face a number of different challenges. They mainly mentioned a shortage of staff and medicine, a lack of blood transfusion provision and delivery instrument, and a lack of training. A small proportion of providers felt the absence of proper implementation guidelines or supervision. Less than optimal working conditions, including inadequate staff, lack of training, and lack of basic services and functional equipment, contribute to providers' poor performance. Most of these problems can be resolved, however, easily and at minimal cost.

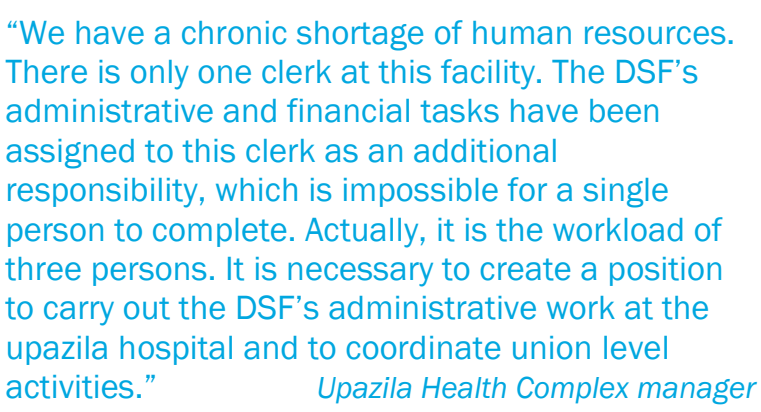

"We have a chronic shortage of human resources. There is only one clerk at this facility. The DSF's administrative and financial tasks have been assigned to this clerk as an additional responsibility, which is impossible for a single person to complete. Actually, it is the workload of three persons. It is necessary to create a position upazila hospital and to coordinate union level activities."

Upazila Health Complex manager

Table 26 describes provider DSF satisfaction and opinions. Any new program requires additional responsibilities from personnel and should compensate additional work with professional and monetary benefits. One third of providers consider additional work as reason for discontentment; and on average they work an additional 28 hours each month. Only one third of providers expressed contentment with DSF. Reasons for provider resentment include inadequate financial incentives and excessive workloads. Almost all providers perceived their financial incentives as insufficient.

TABLE 26 Providers' opinions of the voucher program(percent)

\begin{tabular}{lc}
\hline Indicator & Measure \\
\hline Additional work for DSF program (hours per month) & 28.0 \\
$\mathrm{~N}$ & 102 \\
Provider motivated by voucher benefits (\%) & 36.3 \\
$\mathrm{~N}$ & 102 \\
Reasons for dissatisfaction* & 93.8 \\
Existing financial incentive inadequate (\%) & 31.3 \\
Excessive work load (\%) & 48 \\
$\mathrm{~N}$ & 70.0 \\
Incentive encourages provider to improve quality of services (\%) & 102 \\
$\mathrm{~N}$ & 97.8 \\
Impact on utilization of services* & 73.0 \\
Service volume increased (\%) & 89 \\
Pregnant women more aware than before (\%) & \\
$\mathrm{N}$ & 68.0 \\
Advice to improve program* & 25.0 \\
Regular payment of DSF money (\%) & 21.0 \\
Regular monitoring (\%) & 15.0 \\
Ensure provider availability (\%) & 19.0 \\
Increase incentive for providers (\%) & 57 \\
Increase incentive for pregnant mothers (\%) & \\
$\mathrm{N}$ &
\end{tabular}

Most providers acknowledge the impact of the financial incentive in encouraging providers to improve service quality. The impact on users is even more intense. Three-fourths of providers report increased awareness among women about maternal health services.

Providers were asked for recommendations to improve the program. A large majority emphasized improvements in regular DSF payments (68\%). The need for regular monitoring was emphasized by one fourth of providers, and one fifth suggested ensuring provider availability, particularly the obstetrician and anesthesiologist pair, as well as increasing incentives for both providers and clients (Table 26). 


\section{STAKEHOLDERS' VIEWS}

In 11 DSF intervention upazilas, 11 managers (UHFPOs/UFPOs/RMOs), 13 direct providers (doctors, nurses, paramedics), 10 outreach providers, seven community leaders, and six administrative staff were interviewed about their DSF implementation experiences and suggestions for further improvement, with more than half of respondents engaged in DSF-related activities for 18 months or more at the time of their interview. Findings from the 47 interviews are summarized in five sections: program awareness, community participation, implementation challenges, monitoring, and impact.

\section{Program awareness}

Outreach workers play a key role in informing local populations and beneficiaries about the voucher program. A large majority of the 47 respondents-37, in all groups-mentioned field workers' routine visits as the primary source of information for beneficiaries. The second most cited DSF information source, emphasized by most managers, providers, and administrative staff in particular, was information circulated by upazila and union DSF committee members and local representatives. One third of respondents, comprising primarily managers and direct providers, mentioned beneficiary registration and voucher distribution as contributing to program awareness. Service provision to pregnant women, during which providers inform clients about the voucher package, was also mentioned by 13 respondents.

Four fifths of respondents reported that most people in their communities know of the program, but the same proportion strongly stated that targeted women's awareness of subsidized services and the program's financial benefits should be improved, through expanded demand creation mechanisms at the community level, involving community clinics, NGOs, educational institutions, and local program committees. They also emphasized the need for recruitment of a dedicated staff member to coordinate field campaigns.

\section{Community involvement and beneficiary selection}

Almost all respondents stated that there was active involvement of local government members with the DSF program. Community members' role in reviewing the list of voucher-eligible women was highlighted as their key contribution to the program. Local government members also contributed by taking the initiative to enlist eligible pregnant women who might be otherwise excluded, and the members also participated in meetings.

Nearly half of the respondents considered the eligibility criteria for selecting beneficiaries as inappropriate. A greater proportion advocated for changing the eligibility criteria in selecting voucher beneficiaries. Some questioned keeping "land ownership" as an eligibility criteria, instead there was a suggestion to set the minimum monthly

"Some eligibility criteria for selecting voucher recipients are not logical. Income threshold such as Taka 2,500 per month should not be a proper criterion, because, nowadays, even a day laborer's monthly income is around Taka 6,000. Similarly, there are some people who possess less than 15 decimals of land but have other income-generating activities or businesses, and there are some people who have one acre of land but it is not arable. Under these circumstances, the amount of land should not be a criterion for selecting a voucher recipient."

Upazila Health Complex manager income at a higher level.

\section{Implementation challenges}

Although a majority of respondents (33, in all groups) found the implementation structure and process effective, many emphasized need for improved financial management, incentives, and service provision.

Almost half of the respondents did not receive funds at regular intervals. Alternative measures to ensure timely disbursement of funds include disbursement at the beginning of the fiscal year; monthly or quarterly disbursement; and disbursement directly to a seed fund. A similar proportion of respondents reported problems with incentive payment systems, and they cautioned that uncertain payment time periods create a lack of credibility among the people. Respondents sketched out solutions such as immediate incentive payment after service delivery, or monthly payments to clients. 
Almost every respondent reiterated the need to increase the monetary benefits in incentive packages for both clients and providers. Many explained that the incentive amount was insufficient according to present market value and the specific incentives to providers and fieldworkers were inadequate with respect to their additional workload. On the incentives to clients, about one third of respondents proposed increasing the transportation package and increasing the incentive amount of the gift package. Additionally, they recommended providing incentives to the whole team of maternal health service providers as service providers who do not receive incentives are losing interest in service delivery, as reported in the interviews.

Respondents found a seed fund to be a useful and effective mechanism for purchasing medicines and equipment in case of emergency, to defray the expenses for transportation, and to make emergency reimbursement during the delay in receiving voucher funds.

New maternal health care service provision was another improvement recommended by more than half of respondents. While many ideas were raised, common suggestions include post-abortion care, free ultrasonography, safe blood transmission, eclampsia treatment, and FP counseling.

Currently, upazila hospitals are covered by the voucher program. Below upazila hospitals, HFWCs provide (outdoor) services within unions for populations of 30,000. Introducing normal delivery services at union HFWCs under the voucher scheme is another recommendation.

Despite the intentions of the government and the tireless contributions of providers, complaints included eligible women missing from beneficiary lists and voucher distribution to ineligible women. Encouragingly, remedial actions have been taken when irregularities are detected, such as the restrictions levied on home deliveries by CSBAs.

Not all eligible women use vouchers for facility services. Most voucher clients avail services from CSBAs at home or from local community or satellite clinics--the primary reason why many women do not receive services from health facilities. Lack of program awareness and problems in accessing facilities, which include travel distances and delays in receiving transportation benefits, also lead to low voucher client facility use.

\section{Monitoring}

Monitoring occurs at different levels, from facilities to the field. Responses for current performance monitoring efforts were mixed. Twelve respondents-managers, providers, facility administration-mentioned that higher authorities and managers (UHFPO/RMO) monitor DSF activities as part of their routine duties, and monitoring is through a monthly staff meeting of a UHC. A respondent group of outreach providers emphasized the active participation of the local government representative and supervisors of outreach

\begin{abstract}
"The system of financial incentive under DSF program has created a scope for unauthorized monetary deal between providers and clients. Under such arrangements, financial benefits are received even if deliveries are not performed by designated, skilled provider. Often, supervision fails to detect these fraudulent activities because of mutual understanding of the two parties. Therefore, institutional delivery should be encouraged and their incentive to be increased. CSBAs, along with their assigned responsibilities, can perform normal deliveries but their incentive level to be revised and decreased."
\end{abstract}

Upazila Health Complex manager 
workers in monitoring the voucher activities at the field level. Yet 12 respondents, in all respondent groups, claimed an absence of monitoring, while another six felt the monitoring system was not structured.

Among the respondents who found a monitoring system to be in place, only half considered the current system to be effective. At the facility level, regular monitoring visits from higher authorities and employing a separate, dedicated staff for monitoring the program or providing an honorarium to the monitoring person were recommended to improve the current monitoring system. As part of monitoring the reimbursement mechanism, registration and fund disbursement can be done by the same person. At the field level, union DSF committee members should monitor the status of respective unions, and share their experiences at the upazila DSF committee meeting for effective and timely coordination in program implementation.

The respondents' lack of awareness on the reporting on program implementation is apparent as half of the respondents confirmed that monthly performance reports and service statistics were submitted to higher authorities by the UHC. A small proportion of respondents mentioned report submission on the financial operation and registration and distribution of vouchers. As expected, no community members were aware of any of the facility reports.

\section{Impact}

In-depth interviews provided valuable insights into the program's demonstrated impact and the potential improvements that could be made to enhance its impact further. Most respondents (38 out of 47) appreciate the DSF program and its contribution to improved maternal and newborn health, poverty reduction, and improved service delivery. Increases in the number of facility deliveries, poor women receiving skilled delivery care, and financial incentives to purchase nutritional food for the mother is the most visible impact of the program directed toward maternal health.

Half of the respondents acknowledged the contribution of the DSF program to reducing poverty through reduction of out-of-pocket costs. Voucher clients do not have to resort to catastrophic expenditure as these poor women benefit through financial incentives, enabling them to save money for the future or invest in productive activities. Voucher clients can return to their economic activities soon after delivery because of quality services during pregnancy and delivery, reducing the risk of morbidity.

There has been a qualitative change in maternal health service provision. Changes were especially noticeable for safe and skilled delivery (every delivery performed by trained personnel), antenatal, postnatal and FP counseling, and laboratory services. Improving facility cleanliness and waste management is another significant change reported by respondents.

Improving the program management, timely payments of reimbursements and incentives, better incentive packages, strengthened human resources (recruitment of a staff to perform the administrative work of DSF), and improving program monitoring efforts for ensuring accountability of the providers appear to be among the top priorities. If incentive amounts for all benefits are increased and all pregnant women are subsidized irrespective of economic or demographic status, it is likely to enhance program performance. 


\section{Discussion and Recommendations}

The DSF program grants vouchers to pregnant women for free antenatal, delivery, and postpartum care in addition to medicine. Financial assistance is also provided for transportation, along with financial incentives for delivering with a designated service provider. The DSF program's interventions are designed to reduce pregnant women's financial barriers to facility-based services.

The program contributes to reducing consumer cost, as voucher clients do not have to resort to catastrophic expenditures for maternal health care. An increase in institutional deliveries and poor women receiving skilled delivery care are the most visible impacts of the program. Implementation of such a single intervention is not adequate for achieving optimum changes in both provider and client behaviors. Unless other barriers to care are addressed, the DSF financing scheme is not expected to generate desired population outcomes.

\section{BENEFICIARY AWARENESS}

Utilization of skilled obstetric care relies on quality antenatal check-ups that contribute to improved knowledge of danger signs of pregnancy and birth preparedness practices. Awareness of pregnancy complications and birth preparedness among women is grossly inadequate, and utilization of facility-based obstetric care varies. Women are ignorant of necessary preparations for a cesarean section delivery, such as arranging blood donors and the necessity of blood transfusion. Lack of awareness exists for institutional delivery as well, reflected by the preference for home births. Improved provider counseling at both facility and community levels is necessary for women's awareness of the necessity of seeking care when experiencing obstetric complications.

The maternal voucher program covers selected medical services and provides financial benefits, which are not universally known to all voucher clients. Increasing awareness of program benefits among target populations is necessary; otherwise the interventions will be counterproductive, with low utilization of targeted services.

\section{UTILIZATION OF SKILLED CARE}

A maximum 82 percent of pregnant women sought ANC services, with small changes over time and no notable difference between voucher and non-voucher areas. Most women did receive ANC check-ups from medically trained providers (doctor, FWV/nurse, MA/SACMO, CSBA). Women received, on average, three check-ups regardless of intervention exposure, but one-third of pregnant women receive ANC at home, primarily from unqualified and NGO providers. As ANC service utilization approaches maturity, the quality of ANC services should be scrutinized where use of skilled providers is critical for identifying pregnancy risks and improving both mother and newborn health outcomes.

In 2012, facility deliveries stood at 31 percent, regardless of intervention exposure. Upazila Health Cpmplexes are the public facilities primarily used for deliveries. Because they are covered by the DSF scheme, UHC use for delivery services increased over time, and decreased for other facilities. Facility delivery is more prevalent among voucher than non-voucher clients. Voucher clients were more than twice as likely as non-voucher clients to deliver their babies at a facility. Maternal and Child Welfare Centers (MCWCs), which are meant to provide comprehensive EmOC services, are significantly underutilized (by less than $1 \%$ of clients). MCWCs are covered by the DSF scheme. Pregnant women without vouchers scarcely utilized delivery services from community-based health centers, such as HFWCs. In addition to strengthening focus on UHCs for optimum utilization, program managers need to ensure MCWCs are fully functional, with adequate staff, to provide comprehensive EmOC services in rural areas, and strengthen HFWCs for community delivery services. 
Voucher and non-voucher clients' modes of delivery do not differ much, but do vary in use of medically trained providers. More than half of voucher client deliveries were by medically trained providers, compared to one fourth of non-voucher clients. Mid-level providers were mostly used for delivery services by voucher clients, followed by doctors. Due to the shortage doctors in the public sector, increasing mid-level providers at different service levels for normal delivery services is critical for increasing rates of institutional delivery.

Utilization of PNC increased dramatically, from 20 percent to 54 percent, in two years, characterized by similar increases across sites. Most women sought PNC from medically trained providers, and within 48 hours after childbirth. Intervention areas evince better public facility utilization for PNC services than control areas, which can be attributed to program effect. Meanwhile, the proportion of women seeking care from public facilities is lower than those seeking care at home. This situation provides an important opportunity for public sector community providers to offer a large proportion of women PNC check ups during their doorstep services.

\section{INEQUITY IN SERVICE UTILIZATION}

Economic status affects women's ability to seek ANC check ups from medically trained providers. Encouragingly, subsidies for government facilities are appropriately used by the poor, as the proportion of women seeking ANC from public providers is higher among poor women, and decreases as wealth increases.

Unlike ANC, seeking skilled PNC services by medically trained providers varies positively with economic status. Home PNC provision is much more common among poor than rich women, which indicates that poor women, in the most need, cannot afford to consult qualified providers for PNC at facilities.

Economic status has a large impact on where delivery occurs, as well as delivery type and skilled provider use. Money makes a difference in whether doctors are utilized at childbirth. Wealth does not have a noticeable impact, however, on the distribution of women with deliveries assisted by mid-level, qualified providers.

\section{CONSUMER COST SUBSIDIZATION}

Almost all delivery services involved out-of-pocket payments, with average volume of expenditure higher in non-voucher areas than voucher areas, which indicates a potential link between the DSF scheme and consumer cost. Cesarean delivery care was three times more expensive than normal delivery, while comparison of out-of-pocket expenditures for cesarean delivery suggests a strong association between expenditures and intervention exposure. Average per capita out-of-pocket expense for cesarean delivery in voucher areas dropped sharply in only two years, while it increased in non-voucher areas.

Facility type has a telling effect on cesarean delivery expenditures. Two years after the program's introduction, women spend less on cesarean delivery at public facilities, nearly one third of what is spent at private facilities in all voucher areas, while it is more than one third in high performing voucher areas. The cost for cesarean delivery services from public facilities sharply declined (from Taka 7,615 to Taka 4,688) over two years in Panel 1 and Panel 2 (from Taka 7,303 to Taka 3,463), contributing to out-of-pocket cost reductions. Arranging this money for cesarean delivery services is not easy for rural women.

Vouchers for cesarean delivery services make a large difference in expenditures, with voucher clients much better off, with a mean out-of-pocket expenditure in all voucher areas of one third of the payment incurred by non-voucher clients, and about one fourth in high performing areas. External costs, for purchasing drugs and laboratory services, are large components of out-of-pocket delivery service expenditures. Reducing women's costs for medicines and laboratory tests not available in government facilities is a key challenge for public maternal health programs.

Regardless of where the voucher program operates, the amounts women pay for transportation increased over time, which justifies increasing financial assistance provided to poor clients. 


\section{PROVIDER COMPETENCE AND MOTIVATION}

Health providers' (doctors and mid-level providers) knowledge of basic maternal health service components was not found competitive. A maximum mean percentage score of 67 for doctors indicates a deficiency in knowledge about basic maternal and neonatal care. In one-third of the maternal health service components, providers earned an optimum score of competency (scored more than $90 \%$ ), leaving other components of knowledge in need of drastic improvement.

Summary scores on the basic level of knowledge about maternal health components shows a higher competency score among doctors than mid-level providers. Yet, the overall score is particularly low for doctors, in the context of their extensive academic training, thus indicating a deficiency in the country's health system capacity to provide training at the upazila level. The disappointing performance of service providers in essential counseling skills reflects their inadequate knowledge of basic maternal and newborn health care, which furthermore suggests absence of supportive supervision.

Skills assessment of obstetric complications management exposes the disappointing performance of both doctors and mid-level providers. Mid-level providers could not achieve a minimum competency score (50 percent) on any of the five obstetric complications. It is necessary to provide continuing medical education training tailored to the needs of and to enhance the capacity of the upazila hospital to address complicated obstetric cases.

The provider survey does not yield an optimistic picture on training either. Slightly more than half of the service providers were trained on any maternal and neonatal health topics within the past five years and among them only 11 percent received training on EmOC. Until now, a maximum of 25 percent in panel 1 and 29 percent in panel 2 of the providers in the intervention sites received training on neonatal care and PNC counseling. Providers need skills training as part of the program; professional monitoring from a higher level should also be in place.

\section{QUALITY OF SERVICES}

The composite score achieved by antenatal, delivery, and postnatal services is far below optimum. A comparison of the composite quality index for antenatal, delivery, and postnatal services reveals the lowest quality score, of 44 out of 100 , for ANC services and the highest of 57 for delivery and PNC services. There are small differences in the quality score for maternal health service between voucher and non-voucher areas of both Panel 1 and Panel 2. Out of all aspects of care, "client and provider rapport" for ANC and PNC services achieved the highest score (70 or more) while "level of service," or client satisfaction, for delivery care earned the second highest score (67 or more); the latter element is related to facility management. Other aspects of care are struggling to earn high quality scores, which depend on physical infrastructure and provider technical skills. In particular, quality scores on "preventive care and follow up" were low for both ANC and PNC services, which indicates lapses in providing advice and preventive care and justifies the need for skills improvement. Birth planning counseling, the backbone of ANC counseling, is the area where both intervention and control facilities are struggling, requiring them to undertake comprehensive training and monitoring.

Overall, quality scores demonstrate the gaps in the DSF program in improving the quality of maternal health services. Although service utilization increased after the initiation of DSF program, there is scope of work to improve quality of ANC, delivery, and PNC service through the DSF program.

\section{PROGRAM IMPROVEMENT}

\section{User experience}

Few cases of irregularities in the distribution of vouchers and unofficial monetary transactions to obtain vouchers were reported by beneficiaries. Most beneficiaries miss out benefits for antenatal check-ups within 
the first two trimesters as, on average, women received vouchers at the sixth month of pregnancy. In one in nine cases, there was some monetary transaction to receive the voucher book.

Clients are at risk of not receiving comprehensive information on voucher programs and benefits as they garner such information from non-program individuals such as relatives and community members. Not all of the medical services and financial benefits covered by the voucher program are known to voucher clients. Low awareness about subsidized services and financial benefits opens up an avenue for a new intervention in the DSF program, including strong community awareness activities and involving nongovernment outreach workers to educate pregnant women about the government voucher program.

The program has yet to ensure optimum utilization of vouchers for services and timely payments against vouchers. A total of 86 percent of women used vouchers for any of the maternal health services. Half of the women used vouchers for delivery services. Delayed payment is widely complained of by beneficiaries. On average, it took four months for a UHC to clear payments to the voucher user. The main reason for delayed payment is the delay in receiving DSF funds from the central level by the UHC. Delayed payment creates a negative impression about the program among the beneficiaries, causing the trust of community members on the program to diminish over time. At the facility level, delayed release of funds restricts the UHCs from making voucher payments and closing accounts within a short period of time. This requires additional efforts of the management staff (as no staff is recruited for the DSF program at upazila level) beyond office hours.

\section{Provider perception}

Implementation of the DSF program in 11 new upazilas is not effectively managed as providers identified several areas where they encountered difficulties, primarily financial in nature: selection of eligible women for vouchers, delays and irregularities in receiving program funds from the central level, unavailability of adequate money at the facility, and no program staff recruited for carrying out administrative work.

Service providers considered suboptimal working conditions as reasons for the poor performance of the facility, such as, inadequate staff, training, and basic services (blood transfusion provision), shortfall in necessary supplies (medicines), and nonfunctional equipment (delivery instruments).

Generally, any new program requires additional responsibilities from the personnel and compensates the additional work through professional and monetary benefits. Until now, no effective measures have been introduced for provider motivation by the DSF program. Inadequate performance incentives and excessive workload are the reasons providers are not satisfied with the program.

\section{Stakeholder views}

Providers highlighted the need for improvements in financial management and incentive. To earn credibility among the people, it is important to ensure immediate incentive payments after service delivery. An increase in financial assistance for clients in the context of present market value was underscored. With regard to provider incentive, one recommendation is to increase incentive amounts for providers commensurate with the additional workload, as well as to provide incentives to the whole team of maternal health service providers as service providers who do not receive incentives may lose their interest in service delivery.

The current system of monitoring is not structured. At the facility level, regular monitoring visits from higher authorities and employing a separate, dedicated staff for monitoring the program or providing an honorarium to the monitoring person were recommended to improve the current monitoring system.

Effectiveness of the existing eligibility criteria for selecting beneficiaries was questioned and it was suggested to exclude "land ownership" as an eligibility criterion, and instead to set the minimum monthly income at a higher level.

Only sub-district hospitals are covered by the voucher program. Union HFWCs that provide outdoor services can be strengthened to introduce normal delivery services under the voucher scheme. Inclusion of new service provisions related to maternal health care into the DSF program was a frequently recommended 
measure for improving UHC maternal health services, which include post-abortion care, free ultrasonography, safe blood transmission, treatment for eclampsia, and FP counseling.

Not all eligible women use vouchers for health facility services: Most voucher clients avail services from CSBAs at home or from community or satellite clinics in the proximity of their home. Long distances and delays for transportation benefits are two reasons for low use of facilities by voucher clients.

Respondents acknowledged outreach workers' important role in informing local people and beneficiaries about the voucher program. Additionally, they strongly recommend expanding demand creation channels by arranging awareness meetings through fieldworkers, HFWCs, community clinics, NGOs, educational institutions, and courtyard meetings with targeted women.

\section{KEY PROGRAM RECOMMENDATIONS}

\section{Client level}

Consumer-cost subsidization. Economic status has a large impact on where delivery takes place, type of delivery, and use of skilled providers. Demand-side financial benefits have contributed to remarkably lowering the out-of-pocket payments made by voucher users for cesarean deliveries. The necessity of continuing the DSF program as source of wealth for enabling poor clients to receive services from facilities has been well demonstrated through the evaluation.

Demand creation. Awareness among women on subsidized services and financial benefits covered by voucher requires expanding demand creation channels at the community level by involving community clinics, NGOs, educational institutions, and the local program committees. At the facility level, improvement in provider counseling can raise awareness among pregnant women on the obstetric complications and birth preparedness practices.

\section{Facility level}

Quality of care. The level of utilization of ANC services is reaching saturation; therefore, the focus should be more on quality rather than quantity to ensure use of skilled providers for every ANC service. A majority of women still receive delivery care at home, attended by unqualified providers. Both an increase in institutional delivery and improvement in the quality of services are required for delivery services. For PNC check-ups, an important opportunity lies for the government to ensure optimum utilization of its skilled community providers through home services.

In the context of the growing importance of improving the quality of healthcare services, the DSF program can incorporate the quality of care framework tested in other maternal health programs, such as DGHS's Pay for Performance (P4P) project with technical assistance from Population Council and UNICEF. The quality of care approach also successfully contributed to the improvement of the monitoring of health service delivery at the district level and below.

Facility readiness. The DSF mechanism is not designed to strengthen maternal health service delivery. Supply side investment is needed to ensure provider availability and provision of support services like ultrasonography and safe blood transmission. Due to the doctor shortage in rural areas, and as most deliveries do not require surgical intervention, increasing mid-level providers at different service delivery levels for normal delivery services is critical for increasing institutional delivery rates.

Provider capacity. Service providers (doctors and mid-level providers) show gap in possessing adequate knowledge and skills on basic maternal and newborn health care and management of obstetric complications. Providers need skills training as part of the program and professional monitoring from a higher level should be in place. 


\section{Policy level}

Policy changes are needed to improve financial management, increase incentive amount, and expand service delivery.

- For clients, in addition to ensuring immediate incentive payments after service delivery, it is necessary to increase financial assistance in the context of present market value. Additionally, new resources should be allocated to subsidize the cost women incur to purchase medicine and undergo laboratory services that are not available in government facilities.

- On provider incentive, increasing the incentive amounts for providers commensurate with the additional workload is recommended. A carefully designed incentive for providers can be considered as an alternative. For instance, the DSF program could replace the case-based incentives for providers with the target-based incentive approach tested in the P4P project which rewarded incentives to the maternal health team of a facility for achieving specified performance targets.

- Improving the DSF program focusing on the UHCs alone cannot raise the rate of delivery in rural areas. Additionally, for optimum utilization of the existing health structure in rural areas, program managers need to pay attention to ensure that MCWCs are fully functional with adequate staff to provide comprehensive EmOC services in rural areas and strengthen HFWCs for offering community delivery services.

- DSF is the only safety net project that government implements to ensure safe delivery of poor pregnant mothers in rural areas. The program should be scaled up gradually in other sub-districts too to bring equity in accessibility to safe delivery service between rich and poor.

\section{STUDY LIMITATIONS}

The key limitation of the evaluation study is not carrying out a cost effectiveness analysis. A cost analysis enables policymakers to understand the economic viability of the program inputs and the expected resources to expand the program to the national level. Scaling up requires a comparison of relative costs and benefits of program interventions.

The impact on the outcomes of pregnancies was not assessed, which is another flaw of the evaluation. Women who were referred to higher facilities, and their referral indications, transportation details, and pregnancy or health outcomes were not studied.

The significant limitation of the analysis is arbitrarily using an arithmetic method for estimating the quality and competency score in assessing provider performance and skills. Quality or competency scores estimated for each aspect of care are not scientifically driven; however, they are useful in providing a summary performance of service providers. 


\section{References}

Afsana, K. 2004. The tremendous cost of seeking hospital obstetric care in Bangladesh. Reproductive Health Matters 12(24): 171-180.

Bellows, N.M., B.W. Bellows, C.E. Warren. 2011. Systematic Review: The use of vouchers for reproductive health services in developing countries: systematic review. Tropical Medicine and International Health 16: 84-96. DOI: 10.1111/j.1365-3156.2010.02667.

Bellows, B.W. et al. 2013. A Taxonomy and Results from a Comprehensive Review of 28 Maternal Health Voucher Programmes. Journal of Health, Population and Nutrition 31(4 supp. 2): 106-128.

Borghi, J. et al. 2006. Mobilizing financial resources for maternal health. The Lancet 368(9545): $1457-$ 1465.

Glassman, A., J. Todd, M. Gaarder. 2007. Performance-based incentives for health: Conditional cash transfer programs in Latin America and the Caribbean. CGD Working Paper 120. Washington, DC: Center for Global Development.

Gwatkin, D.R., S. Rutstein, R.P. Pande, A. Wagstaff. 2000. Socio-economic Differences in Health, Nutrition and Poverty. HNP/Poverty Thematic Group of the World Bank. Washington, DC: World Bank.

Hatt, L. et al. 2010. Economic Evaluation of Demand-Side Financing (DSF) for Maternal Health in Bangladesh. Bethesda, MD: Review, Analysis and Assessment of Issues Related to Health Care Financing and Health Economics in Bangladesh, Abt Associates Inc.

Khan, S.H. 2005. Free does not mean affordable: Maternity patient expenditures in a public hospital in Bangladesh. www.resource- allocation.com/content/3/1/1.

Koehlmoos, T.L.P. et al. 2008. Rapid Assessment of Demand-side Financing Experiences in Bangladesh. ICDDR,B Working Paper 170. Dhaka: ICDDR,B.

Koenig, M.A. et al. 2007. Maternal health and care-seeking behavior in Bangladesh: Findings from a National Survey. International Family Planning Perspectives 33(2): 75-82.

Murray, C.J. et al. 2000. Defining and Measuring Fairness in Financial Contribution to the Health System. GPE Discussion Paper Series: No. 24. Geneva: World Health Organization. http://ssrn.com/ abstract $=2053994$

National Institute of Population Research and Training (NIPORT), Mitra and Associates, ICF International. 2013. Bangladesh Demographic and Health Survey 2011. Dhaka, Bangladesh and Calverton, MD: NIPORT, Mitra and Associates, and ICF International.

Nguyen, H.T.H. et al. 2012. Encouraging maternal health service utilization: An evaluation of the Bangladesh voucher program. Social Science and Medicine 74(7): 989-996.

Pandey, P., A.R. Sehgal, M. Riboud, D. Levine, M. Goyal. 2007. Informing resource-poor populations and the delivery of entitled health and social services in rural India: A cluster randomized controlled trial. Journal of the American Medical Association 298(16): 1867-1875.

Pitchforth, E., E. Teijlingen, W. Graham, M. Dixon-Woods, M. Chowdhury. 2006. Getting women to hospital is not enough: A qualitative study of access to emergency obstetric care in Bangladesh. Quality and Safety in Health Care 15: 214-219.

Rob, U., M.N. Talukder, T. Ghafur. 2006. Health policies: Pledges and implementation. The State of Health in Bangladesh 2006: Challenges of Achieving Equity in Health. Dhaka: BRAC University, James P. Grant School of Public Health. 
Rob, U., M. Rahman, B. Bellows. 2011. Evaluation of the impact of the voucher and accreditation approach on improving reproductive behaviors and RH status: Bangladesh. BMC Public Health 11: 257. DOI: 10.1186/1471-2458-11-257.

Rutstein, S. 1999. Wealth versus expenditure: Comparison between DHS wealth index and household expenditures in four departments of Guatemala. Calverton, MD: ORC Macro.

Rutstein, S., K. Johnson. 2004. The DHS Wealth Index. DHS Comparative Report 6. Calverton, MD: ORC Macro.

Standing, H., D. Peters, B. Varghese. 2003. Demand-side financing in Bangladesh: Support to pilot design. London: DfID Health System Resource Center.

WHO. 2003. Guide to Producing National Health Accounts with Special Applications for Low-Income and Middle-Income Countries. Geneva: WHO. 


\section{Appendixes}

\section{APPENDIX 1: QUALITY SCORE INDICATORS FOR ANTENATAL CARE}

\section{Medical history/background check (25)}

Did the provider ask about LMP?

Did the provider ask about EDD?

Did the provider ask about menstruation related problems?

Asked if have a burning sensation during urination?

Asked if have an increased frequency of micturition?

Asked about duration of gestation/conception?

Asked about any current medication?

Asked about history of hypertension/high blood pressure?

Asked about history of diabetes?

Asked about general health problems?

Asked about history of asthma?

Asked about type of last delivery?

Asked about date of last delivery?

Asked about place of last delivery?

Asked about duration of last labor?

Asked about any previous miscarriage/abortion?

Asked about any previous stillbirth(s)?

Asked about previous early neonatal deaths?

Asked about any previous history of cesarean?

Asked about previous symptoms/signs/treatment suggestive of maternal health?

Asked client's age?

Asked total number of pregnancies?

Asked number of living children?

Asked age of youngest child (years)?

Asked contraceptive history?

\section{Client and provider rapport (7)}

Did the provider greet the client in a friendly manner?

Did the provider maintain audio privacy for the client?

Did the provider maintain visual privacy for the client?

Listened attentively to client?

Explained client enquiry/problem?

Ensured client's comfort in asking questions?

Did the provider take verbal consent from the client for physical examination?

\section{Physical examination (14)}

Took client's weight

Checked breasts for pain or lump

Palpated abdomen for fetal presentation

Checked fetal movement

Listened to fetal heart rate 
Performed internal examination for vaginal discharge

Took client's height

Took client's blood pressure

Checked client's pulse

Checked woman's conjunctiva (eyelids, tongue, finger, and palms) for anemia

Checked for dehydration (eye, tongue, skin)

Measured body temperature

Checked for edema

Checked abdomen for any mark of operation

\section{Medical screening (4)}

Performed/referred for urine test

Performed/referred for blood test

Performed/referred for ultra-sonogram

Referred client for a syphilis test (VDRL)

\section{Birth planning (8)}

Informed the client about the progress of the pregnancy?

Asked client where she plans to deliver?

Advised the client to use a health facility or skilled birth attendants during delivery?

Asked the client about who else will provide support during delivery?

Discussed birth partners accompanying client to visit facility (husband, sister, mother-in-law, mother, aunt)?

Advised client about supplies/items on hand at home in preparation for delivery?

Advised/asked client about which healthcare facility to go to in case of complication?

Advised/asked client about her financial arrangements?

\section{Prevention and case management (18)}

Emphasized the danger signs of pregnancy*

Did the provider discuss the usefulness of breastfeeding or taking care of breasts?

Did the provider counsel about referral?

Advised on quantity and quality of food to eat during pregnancy

Advised on personal hygiene

Advised on rest during pregnancy

Advised on exercise during pregnancy

Advised to avoid heavy work

Advised about TT injection

Did the service provider ask client to come if she experiences any problem/complications?

Did the provider discuss the importance of the early postpartum visit (within first week) for mother?

Did the provider discuss the importance of the early postnatal visit for baby (within first week)?

Did the provider offer advice regarding child vaccination immediately after childbirth?

Did the provider discuss the importance of the postpartum family planning?

Asked whether the client needs other services

Was the client told when to come for re-visit or follow up?

Was the client told where to go for re-visit or follow up?

Did the provider provide or advise taking iron syrup/tablet or folic acid to the client?

*Danger signs of pregnancy include high fever, severe headache, or blurred vision or tiredness; vaginal bleeding; baby's cord, hand, or leg out first; labor pains more than 12 hours; foul smelling vaginal discharge; sudden flow of water from vagina; leakage from vagina; baby moving less or not moving at all; convulsions or fits during labor (eclampsia), premature labor pains (severe backache, lower abdominal pains), ruptured membranes without labor for more than 12 hours; labored (difficult) breathing. 


\section{APPENDIX 2: QUALITY SCORE INDICATORS FOR POSTNATAL CARE}

\section{Medical history/background check (13)}

Asked about delivery date

Asked about place of delivery

Asked about type of delivery

Asked about restart of period

Asked about total number of pregnancies

Asked about whether breastfeeding is continuing

Asked about chest pain

Asked about decreasing weights

Asked about fever over last two weeks

Asked client's age

Asked number of living children

Asked age of youngest child (years)

Asked contraceptive history

\section{Client and provider rapport (7)}

Greeted in a friendly manner

Ensured privacy (aural)

Ensured privacy (visual)

Listened attentively to client

Explained client's enquiry/problem

Ensured client's comfort in asking questions

Took verbal consent for physical examination

\section{Physical examination (23)}

Checked the woman's conjunctiva (eyelids, tongue, finger, and palms) for anemia

Measured body temperature

Checked if bleeding since birth

Checked color/smell of vaginal discharge

Checked condition of perineum/cesarean scar

Headache or blurred vision

Swelling in feet/edema

Tiredness or breathlessness

Convulsions or fits

Client's weight

Client's pulse

Client's blood pressure

Client's respiratory rate

Examine breasts and nipples

Lower abdominal examination for uterine involution

Checked/asked about extent of vaginal bleeding

Examine the baby (undressed)

Check baby's temperature

Checked baby's respirations

Baby weighing 
Checked the reflection of baby

Checked eye

Checked on the cord

\section{Medical screening (2)}

Performed/referred for urine test

Performed/referred for blood test

\section{Family planning (5)}

Healthy timing and birth spacing or use family planning after delivery

Health benefits for mother and baby when birth spacing

Various family planning methods

Client's desired number of children

Did the provider emphasize a particular method?

\section{Prevention and case management (9)}

Discussed immunizations for the baby

Re-emphasized exclusive feeding for six months (either breast or replacement)

Emphasized cracked nipples

Emphasized mastitis

Emphasized breast abscess

Emphasized danger signs for newborn*

Emphasized follow up visit**

Did the provider provide or advise taking iron syrup/tablet or folic acid to the client?

Inquired about the need for any other service

*Danger signs for newborns include difficulty breathing, poor feeding (poor sucking or refusal to suck); jaundice; bleeding from cord; redness, swelling, and/or pus around cord: baby feels too hot or too cold, abnormal crying, abdominal distension/vomiting; septic spots/boils on body, lethargy, convulsions.

** Follow up visit includes whether or not client was told when to come for re-visit or follow up; client was told where to go for re-visit or follow up. 


\section{APPENDIX 3: QUALITY SCORE INDICATORS FOR DELIVERY CARE}

\section{Physical check-ups (5)}

What types of physical examination did they perform? (pulse rate)

What types of physical examination did they perform? (edema)

What types of physical examination did they perform? (BP)

What types of physical examination did they perform? (lower abdomen examined)

What types of physical examination did they perform? (eyes examined)

\section{Medical screening (3)}

Laboratory test during ANC (blood test-hemoglobin)

Laboratory test during ANC (urine test-protein)

Laboratory test during ANC (ultra-sonogram)

\section{Prevention and case management (10)}

Did the service provider asked about your problem?

Did the service provider inform you about PNC-related problems/complications?

Did the service provider inform you where to go if you experience an increase of complications?

Did the service provider discuss with you about breast care and breastfeeding?

Did the service provider give information or advice on diet and nutrition?

Did the service provider inform you to take vitamin A capsule after delivery?

Did the service provider advise you on breastfeeding your baby?

Did the doctor/nurse suggest a postnatal checkup or follow up visit?

Did the doctor/nurse suggest child immunization?

Did the service provider inform or advise on child spacing and family planning?

\section{Level of services (5)}

Service provider's assistance during client's admission to hospital*

Service during and after childbirth**

During this service delivery, did the service provider behave well with you?

Have you paid money for any other reason except receiving services?

Did you buy any medicine outside?

*Service provider's assistance during client's admission to hospital includes waiting time for admission, the time that hospital staff takes to transfer a patient from outdoors to indoors after admission, and after reaching the ward, how long until the doctor visited.

**Service during and after childbirth includes which hospital staff was present during client's admission to hospital, who assisted the delivery of child, whether doctors visited clients regularly when they were admitted into the facility, whether nurses visit regularly when they were admitted into the facility. 
TABLE A Selected sites

\begin{tabular}{lll|lll}
\hline & Intervention & & & Control & \\
\hline District & Upazila & UHC & District & Upazila & UHC \\
\hline Sirajgonj & Chowhali & BEmOC & Sirajgonj & Belkuchi & BEmOC \\
Rangpur & Gangachhara & BEmOC & Rangpur & Pirgonj & BEmOC \\
Mymensingh & Haluaghat & CEmOC & Mymensingh & Gafargaon & CEmOC \\
Tangail & Mirzapur & BEmOC & Tangail & Delduar & BEmOC \\
Sunamgonj & Jagannathpur & CEmOC & Sunamgonj & Doyarabazar & CEmOC \\
Brahmanbaria & Banchharampur & CEmOC & Brahmanbaria & Sarail & CEmOC \\
Gopalgonj & Tungipara & CEmOC & Gopalgonj & Kotalipara & CEmOC \\
Bagerhaat & Fakirhaat & CEmOC & Khulna & Dacop & CEmOC \\
Shatkhira & Shyamnagar & CEmOC & Shatkhira & Kolaroya & CEmOC \\
Shatkhira & Ashashuni & BEmOC & Shatkhira & Kaligonj & BEmOC \\
Bhola & Charfashion & CEmOC & Lakshmipur & Ramganj & CEmOC \\
\hline
\end{tabular}

TABLE B Data collection summary

\begin{tabular}{|c|c|c|c|}
\hline \multirow[t]{2}{*}{ Data collection method } & \multirow[t]{2}{*}{ Target respondents } & \multicolumn{2}{|c|}{ Target numbers } \\
\hline & & $\begin{array}{c}\text { Baseline } \\
\text { (May-August 2010) }\end{array}$ & $\begin{array}{c}\text { Endline } \\
\text { (December 2012- } \\
\text { March 2013) }\end{array}$ \\
\hline \multicolumn{4}{|l|}{ Program data* } \\
\hline Secondary data & Upazila level MIS & 11 DSF upazilas & 11 DSF upazilas \\
\hline on service utilization & Central level MIS & 11 control upazilas & 11 control upazilas \\
\hline Secondary data & Central level MIS & 11 DSF upazilas & 11 DSF upazilas \\
\hline $\begin{array}{c}\text { on voucher distribution and } \\
\text { use }\end{array}$ & & 11 control upazilas & 11 control upazilas \\
\hline Household survey & $\begin{array}{l}\text { Women who delivered } \\
\text { within last year }\end{array}$ & 3,300 interviews & 3,334 interviews \\
\hline \multicolumn{4}{|l|}{ Facility surveys } \\
\hline Facility assessment & $\mathrm{UHC}$ & $\begin{array}{l}11 \text { DSF Upazilas } \\
11 \text { control Upazilas }\end{array}$ & $\begin{array}{l}11 \text { DSF Upazilas } \\
11 \text { control Upazilas }\end{array}$ \\
\hline $\begin{array}{l}\text { Observation of client and } \\
\text { provider interaction }\end{array}$ & $\mathrm{UHC}$ & 1,105 observations & 1,076 observations \\
\hline Exit client interview & $\mathrm{UHC}$ & 1,105 exit interviews & 1,123 exit interviews \\
\hline Provider survey & $\mathrm{UHC}$ & 295 interviews & 209 interviews \\
\hline Key informant interviews & $\begin{array}{c}\text { DSF committees } \\
\text { at national, district, } \\
\text { upazila, and union levels }\end{array}$ & \multicolumn{2}{|c|}{53 in-depth interviews } \\
\hline
\end{tabular}

Note: *Data collected from May 2010 through April 2013 
TABLE C DSF upazilas, by voucher utilization performance

\begin{tabular}{lccccc|ccc}
\hline \multirow{2}{*}{ DSF upazila } & \multicolumn{4}{c}{ Data from DSF cell 2012 } & \multicolumn{4}{c}{ Follow up survey 2012 } \\
\cline { 2 - 9 } & $\begin{array}{c}\text { Voucher } \\
\text { Target }\end{array}$ & Actual & $\begin{array}{c}\% \\
\text { Distribution }\end{array}$ & $\begin{array}{c}\text { Facility } \\
\text { delivery } \\
\mathbf{2 0 1 2}\end{array}$ & $\begin{array}{c}\text { \% } \\
\text { Institutional } \\
\text { delivery }\end{array}$ & $\begin{array}{c}\text { Women } \\
\text { interviewed }\end{array}$ & $\begin{array}{c}\text { Voucher } \\
\text { clients }\end{array}$ & $\begin{array}{c}\text { Delivery } \\
\text { by } \\
\text { voucher }\end{array}$ \\
\hline Tungipara & 1392 & 1853 & $133 \%$ & 505 & $27 \%$ & 154 & 73 & $47 \%$ \\
Gangachara & 3252 & 3099 & $95 \%$ & 814 & $26 \%$ & 139 & 19 & $14 \%$ \\
Fakirhat & 1776 & 639 & $36 \%$ & 144 & $23 \%$ & 151 & 58 & $38 \%$ \\
Haluafghat & 4560 & 3432 & $75 \%$ & 404 & $12 \%$ & 154 & 32 & $21 \%$ \\
Shyamnagar & 4668 & 3398 & $73 \%$ & 323 & $10 \%$ & 147 & 75 & $51 \%$ \\
Bancharampur & 4548 & 2004 & $44 \%$ & 423 & $21 \%$ & 157 & 0 & $0 \%$ \\
Jagannathpur & 3252 & 134 & $4 \%$ & 18 & $13 \%$ & 152 & 5 & $3 \%$ \\
Asasuni & 3816 & 955 & $25 \%$ & 93 & $10 \%$ & 156 & 14 & $9 \%$ \\
Charfession & 4698 & 715 & $15 \%$ & 66 & $9 \%$ & 153 & 0 & $0 \%$ \\
Chouhali & 1896 & 237 & $13 \%$ & 21 & $9 \%$ & 147 & 2 & $1 \%$ \\
Mirzapur & 5400 & 2764 & $51 \%$ & 32 & $1 \%$ & 152 & 52 & $34 \%$ \\
Total & 39258 & 19230 & $49 \%$ & $\mathbf{2 8 4 3}$ & $15 \%$ & 1662 & $\mathbf{3 3 0}$ & $\mathbf{2 0 \%}$ \\
\hline
\end{tabular}

TABLE D Changes in delivery complications in high performing voucher areas (percent)

\begin{tabular}{|c|c|c|c|c|c|}
\hline \multirow{2}{*}{ Characteristics } & \multicolumn{2}{|c|}{ Intervention } & \multicolumn{2}{|c|}{ Control } & \multirow[t]{2}{*}{ DID } \\
\hline & 2010 & 2012 & 2010 & 2012 & \\
\hline Had complication & 26.3 & 48.5 & 23.6 & 57.2 & $-11.4 * * *$ \\
\hline $\mathrm{N}$ & 750 & 745 & 1650 & 1672 & \\
\hline \multicolumn{6}{|l|}{ Place of delivery } \\
\hline Home & 70.1 & 41.8 & 62.7 & 53.8 & $-19.3 * * *$ \\
\hline Facility & 29.9 & 58.2 & 37.3 & 46.2 & $19.3 * * *$ \\
\hline $\mathrm{N}$ & 197 & 361 & 389 & 956 & \\
\hline \multicolumn{6}{|l|}{ Type of delivery } \\
\hline Normal & 82.2 & 62.0 & 72.0 & 65.8 & $-14.0 * *$ \\
\hline Cesarean & 15.2 & 32.7 & 23.1 & 29.9 & $10.7 *$ \\
\hline Assisted & 2.6 & 5.3 & 4.9 & 4.3 & 3.3 \\
\hline $\mathrm{N}$ & 197 & 361 & 389 & 956 & \\
\hline \multicolumn{6}{|l|}{ Complication type* } \\
\hline Absence of labor pain & 0.0 & 29.9 & 0.0 & 36.0 & -6.1 \\
\hline Prolonged labor & 59.4 & 29.4 & 56.0 & 22.9 & 3.1 \\
\hline Excessive bleeding & 28.9 & 5.5 & 24.4 & 4.8 & -3.8 \\
\hline Eclampsia & 6.6 & 2.5 & 4.9 & 2.0 & -1.2 \\
\hline Obstructed labor & 2.5 & 3.0 & 6.9 & 1.8 & 5.6 \\
\hline Retained placenta & 10.2 & 6.6 & 11.6 & 5.9 & 2.1 \\
\hline Less fetal movement & 15.7 & 6.1 & 15.7 & 3.3 & 2.8 \\
\hline $\mathrm{N}$ & 197 & 361 & 389 & 956 & \\
\hline
\end{tabular}

Note: Multiple responses. Inference: $* * * p<0.001 ; * * p<0.01 ; * p<0.05$ 
TABLE E Changes in delivery complication service uptake in high performing voucher areas (percent)

\begin{tabular}{|c|c|c|c|c|c|}
\hline \multirow{2}{*}{ Characteristics } & \multicolumn{2}{|c|}{ Intervention } & \multicolumn{2}{|c|}{ Control } & \multirow[t]{2}{*}{ DID } \\
\hline & 2010 & 2012 & 2010 & 2012 & \\
\hline Received services & 83.2 & 91.7 & 86.1 & 95.0 & -0.4 \\
\hline $\begin{array}{l}\mathrm{N} \\
\text { Place of services* }\end{array}$ & 197 & 361 & 389 & 956 & \\
\hline Home & 66.5 & 35.3 & 60.6 & 52.0 & $-22.6 * * *$ \\
\hline Public & 18.3 & 45.3 & 17.9 & 15.4 & $29.5 * * *$ \\
\hline Private & 17.1 & 16.6 & 31.6 & 31.9 & -0.8 \\
\hline NGO & 0.6 & 2.7 & 0.6 & 0.7 & 2.0 \\
\hline $\begin{array}{l}\mathrm{N} \\
\text { Service provider* }\end{array}$ & 164 & 331 & 335 & 909 & \\
\hline Doctor & 29.9 & 44.7 & 37.0 & 35.3 & $16.5 * *$ \\
\hline Nurse/FWV/midwife & 14.0 & 22.4 & 20.6 & 17.5 & $11.5 *$ \\
\hline CSBA & 0.0 & 1.8 & 0.6 & 0.8 & 1.6 \\
\hline Unqualified providers & 59.8 & 31.1 & 50.7 & 46.4 & $-24.4 * * *$ \\
\hline $\mathrm{N}$ & 164 & 331 & 335 & 909 & \\
\hline $\begin{array}{l}\text { Services by MTP } \\
\mathrm{N} \\
\text { Facility referred }\end{array}$ & $\begin{array}{r}40.2 \\
164\end{array}$ & $\begin{array}{l}68.9 \\
331\end{array}$ & $\begin{array}{c}49.3 \\
335\end{array}$ & $\begin{array}{c}53.6 \\
909\end{array}$ & $24.4 * * *$ \\
\hline $\mathrm{DH} / \mathrm{MC}$ & 25.0 & 28.6 & 12.1 & 17.0 & -1.3 \\
\hline $\mathrm{UHC}$ & 50.0 & 19.0 & 15.2 & 25.5 & -41.3 \\
\hline MCWC & 0.0 & 0.0 & 6.0 & 0.0 & 6.0 \\
\hline NGO clinic & 0.0 & 19.1 & 0.0 & 0.0 & 19.0 \\
\hline Private clinic & 25.0 & 33.3 & 66.7 & 57.5 & 17.5 \\
\hline $\mathrm{N}$ & 4 & 21 & 33 & 47 & \\
\hline
\end{tabular}

Note: Multiple responses. Inference: $* * * p<0.001 ; * * p<0.01 ; * p<0.05$.

TABLE F Changes in ANC service uptake for all wealth quintiles in all DSF upazilas (percent)

\begin{tabular}{|c|c|c|c|c|c|c|c|c|c|c|}
\hline \multirow{2}{*}{ ANC services } & \multicolumn{5}{|c|}{ Intervention 2010} & \multicolumn{5}{|c|}{ Intervention 2012} \\
\hline & Q1 & Q2 & Q3 & Q4 & Q5 & Q1 & Q2 & Q3 & $\overline{Q 4}$ & Q5 \\
\hline Received care & 56.3 & 66.5 & 69.1 & 76.5 & 90.4 & 68.5 & 81.8 & 83.7 & 86.2 & 93.4 \\
\hline $\begin{array}{l}\mathrm{N} \\
\text { Reasons for antenatal care }\end{array}$ & 398 & 313 & 301 & 306 & 332 & 362 & 335 & 337 & 297 & 331 \\
\hline Checkup only & 70.5 & 74.5 & 75.0 & 68.4 & 74.7 & 73.8 & 75.9 & 73.4 & 76.2 & 63.8 \\
\hline Specific problem & 21.9 & 15.4 & 15.9 & 16.7 & 15.0 & 17.3 & 13.9 & 11.7 & 12.1 & 19.4 \\
\hline Both & 7.6 & 10.1 & 9.1 & 15.0 & 10.3 & 8.9 & 10.2 & 14.9 & 11.7 & 16.8 \\
\hline $\begin{array}{l}\mathrm{N} \\
\text { Number of visits }\end{array}$ & 224 & 208 & 208 & 234 & 300 & 248 & 274 & 282 & 256 & 309 \\
\hline 1 & 30.4 & 24.0 & 24.5 & 28.2 & 17.7 & 20.6 & 17.9 & 17.0 & 12.5 & 12.3 \\
\hline 2 & 22.3 & 18.3 & 16.8 & 16.7 & 16.7 & 18.5 & 15.7 & 12.4 & 10.9 & 15.2 \\
\hline 3 & 21.4 & 28.4 & 23.6 & 16.7 & 20.3 & 18.1 & 21.1 & 18.1 & 16.4 & 19.4 \\
\hline $4+$ & 25.9 & 27.9 & 35.1 & 38.5 & 44.7 & 42.8 & 45.3 & 52.5 & 60.2 & 53.1 \\
\hline $\mathrm{N}$ & 224 & 208 & 208 & 234 & 300 & 248 & 274 & 282 & 256 & 309 \\
\hline ANC by MTP & 46.0 & 45.2 & 55.3 & 70.1 & 86.0 & 44.8 & 52.6 & 57.8 & 63.3 & 79.9 \\
\hline $\begin{array}{l}\mathrm{N} \\
\text { Place of ANC }\end{array}$ & 224 & 208 & 208 & 234 & 300 & 248 & 274 & 282 & 256 & 309 \\
\hline Public & 27.7 & 27.9 & 25.0 & 24.8 & 18.0 & 29.4 & 36.1 & 25.2 & 27.0 & 18.4 \\
\hline Private & 22.8 & 21.2 & 32.7 & 47.9 & 67.0 & 19.4 & 15.3 & 28.0 & 29.7 & 58.3 \\
\hline NGO & 9.4 & 9.6 & 6.3 & 7.3 & 3.7 & 4.0 & 5.5 & 4.6 & 5.5 & 4.9 \\
\hline Home & 40.1 & 41.3 & 36.0 & 20.0 & 11.3 & 47.2 & 43.1 & 42.2 & 37.8 & 18.4 \\
\hline $\mathrm{N}$ & 224 & 208 & 208 & 234 & 300 & 248 & 274 & 282 & 256 & 309 \\
\hline
\end{tabular}


TABLE G Changes in ANC service uptake for all wealth quintiles in high performing DSF upazilas (percent)

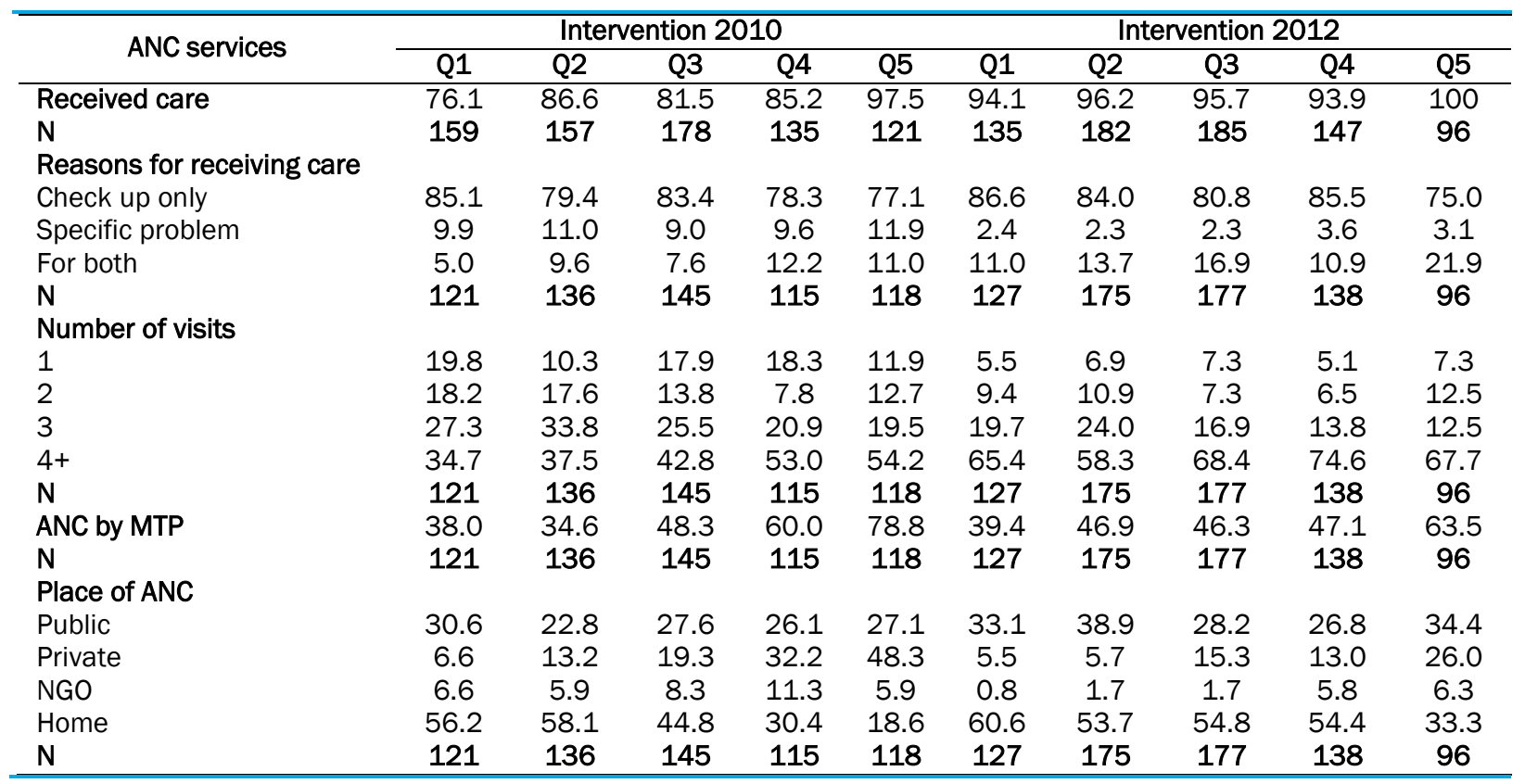

TABLE H Changes in PNC service uptake for all wealth quintiles in DSF upazilas (percent)

\begin{tabular}{|c|c|c|c|c|c|c|c|c|c|c|}
\hline \multirow{2}{*}{ Characteristics } & \multicolumn{5}{|c|}{ Intervention 2010} & \multicolumn{5}{|c|}{ Intervention 2012} \\
\hline & Q1 & Q2 & Q3 & Q4 & Q5 & Q1 & Q2 & Q3 & Q4 & Q5 \\
\hline Received care & 17.3 & 19.2 & 21.3 & 22.9 & 17.5 & 38.4 & 51.0 & 53.1 & 60.6 & 67.4 \\
\hline $\begin{array}{l}\mathrm{N} \\
\text { Received PNC within }\end{array}$ & 398 & 313 & 301 & 306 & 332 & 362 & 336 & 337 & 297 & 331 \\
\hline 48 hours & 15.9 & 35.0 & 23.4 & 27.2 & 17.2 & 88.5 & 83.6 & 87.7 & 89.4 & 92.8 \\
\hline 3-7 days & 30.4 & 36.7 & 23.4 & 31.4 & 24.2 & 8.6 & 12.3 & 8.4 & 6.7 & 4.5 \\
\hline 8-42 days & 53.7 & 28.3 & 53.2 & 41.4 & 58.6 & 2.9 & 4.1 & 3.9 & 3.9 & 2.7 \\
\hline $\begin{array}{l}\mathrm{N} \\
\text { Place of PNC }\end{array}$ & 69 & 60 & 64 & 70 & 58 & 139 & 171 & 179 & 180 & 223 \\
\hline Public & 13.0 & 10.0 & 12.5 & 17.1 & 10.3 & 32.4 & 31.6 & 33.0 & 31.7 & 22.0 \\
\hline Private & 29.0 & 18.3 & 25.0 & 31.4 & 65.5 & 16.5 & 14.0 & 20.1 & 24.4 & 49.7 \\
\hline NGO & 0.0 & 5.0 & 1.6 & 0.0 & 0.0 & 4.3 & 2.3 & 1.1 & 6.7 & 4.5 \\
\hline Home & 58.0 & 66.7 & 60.9 & 51.5 & 24.2 & 46.8 & 52.1 & 45.8 & 37.2 & 23.8 \\
\hline $\mathrm{N}$ & 69 & 60 & 64 & 70 & 58 & 139 & 171 & 179 & 180 & 223 \\
\hline PNC by MTP & 26.1 & 25.0 & 31.3 & 47.1 & 74.1 & 54.7 & 52.1 & 59.2 & 66.1 & 81.2 \\
\hline $\mathrm{N}$ & 69 & 60 & 64 & 70 & 58 & 139 & 171 & 179 & 180 & 223 \\
\hline
\end{tabular}


TABLE I Changes in PNC service uptake for all wealth quintiles in high performing DSF upazilas (percent)

\begin{tabular}{|c|c|c|c|c|c|c|c|c|c|c|}
\hline \multirow{2}{*}{ Characteristics } & \multicolumn{5}{|c|}{ Intervention 2010} & \multicolumn{5}{|c|}{ Intervention 2012} \\
\hline & Q1 & Q2 & Q3 & Q4 & Q5 & Q1 & Q2 & Q3 & Q4 & Q5 \\
\hline Received care & 24.5 & 25.5 & 19.7 & 19.3 & 13.2 & 66.7 & 68.1 & 69.2 & 73.5 & 87.5 \\
\hline $\begin{array}{l}\text { N } \\
\text { PNC within }\end{array}$ & 159 & 157 & 178 & 135 & 121 & 135 & 182 & 185 & 147 & 96 \\
\hline 48 hours & 20.5 & 35.0 & 20.0 & 34.6 & 12.5 & 90.0 & 87.1 & 90.6 & 91.6 & 92.8 \\
\hline $3-7$ days & 25.6 & 42.5 & 20.0 & 34.6 & 18.7 & 8.9 & 12.1 & 6.3 & 6.5 & 2.4 \\
\hline 8-42 days & 53.9 & 22.5 & 60.0 & 30.8 & 68.8 & 1.1 & 0.8 & 3.1 & 1.9 & 4.8 \\
\hline $\begin{array}{l}\mathrm{N} \\
\text { Place of PNC }\end{array}$ & 39 & 40 & 35 & 26 & 16 & 90 & 124 & 128 & 108 & 84 \\
\hline Public & 20.5 & 10.0 & 14.3 & 19.2 & 12.5 & 43.3 & 39.5 & 39.0 & 43.5 & 44.0 \\
\hline Private & 10.3 & 10.0 & 14.3 & 15.4 & 50.0 & 10.1 & 6.5 & 14.1 & 9.3 & 27.4 \\
\hline NGO & 0.0 & 5.0 & 2.9 & 0.0 & 0.0 & 3.3 & 2.4 & 1.6 & 7.4 & 4.8 \\
\hline Home & 69.2 & 75.0 & 68.5 & 65.4 & 37.5 & 43.3 & 51.6 & 45.3 & 39.8 & 23.8 \\
\hline $\mathrm{N}$ & 39 & 40 & 35 & 26 & 16 & 90 & 124 & 128 & 108 & 84 \\
\hline PNC by MTP & 28.2 & 27.5 & 22.9 & 38.5 & 56.3 & 58.9 & 52.4 & 57.8 & 62.0 & 81.0 \\
\hline $\mathrm{N}$ & 39 & 40 & 35 & 26 & 16 & 90 & 124 & 128 & 108 & 84 \\
\hline
\end{tabular}

TABLE J Changes in service delivery uptake for all wealth quintiles in all DSF upazilas (percent)

\begin{tabular}{|c|c|c|c|c|c|c|c|c|c|c|}
\hline \multirow[t]{2}{*}{ Characteristics } & \multicolumn{5}{|c|}{ Intervention 2010} & \multicolumn{5}{|c|}{ Intervention 2012} \\
\hline & Q1 & Q2 & Q3 & Q4 & Q5 & Q1 & Q2 & Q3 & Q4 & Q5 \\
\hline Deliveries at home & 91.2 & 92.7 & 85.7 & 75.8 & 60.5 & 80.7 & 77.6 & 71.8 & 63.0 & 49.5 \\
\hline Deliveries at facility & 8.8 & 7.3 & 14.3 & 24.2 & 39.5 & 19.3 & 22.4 & 28.2 & 37.0 & 50.5 \\
\hline $\begin{array}{l}\mathrm{N} \\
\text { Type of facility }\end{array}$ & 398 & 313 & 301 & 306 & 332 & 362 & 335 & 337 & 297 & 331 \\
\hline Public & 54.3 & 65.2 & 55.8 & 50.0 & 23.7 & 65.7 & 69.3 & 61.0 & 51.8 & 29.9 \\
\hline Private & 45.7 & 34.8 & 41.9 & 48.6 & 74.0 & 27.1 & 26.7 & 35.8 & 39.1 & 64.7 \\
\hline NGO & 0.0 & 0.0 & 2.3 & 1.4 & 2.3 & 7.2 & 4.0 & 3.2 & 9.1 & 5.4 \\
\hline $\begin{array}{l}\mathrm{N} \\
\text { Type of delivery }\end{array}$ & 35 & 23 & 43 & 74 & 131 & 70 & 75 & 95 & 110 & 167 \\
\hline Normal & 95.2 & 97.4 & 93.4 & 87.6 & 72.3 & 89.5 & 88.4 & 83.1 & 79.8 & 58.0 \\
\hline Cesarean & 4.0 & 1.9 & 6.3 & 11.1 & 23.2 & 7.7 & 10.5 & 14.8 & 17.2 & 36.3 \\
\hline Assisted & 0.8 & 0.6 & 0.3 & 1.3 & 4.5 & 2.8 & 1.2 & 2.1 & 3.0 & 5.7 \\
\hline $\begin{array}{l}\text { N } \\
\text { Service providers }\end{array}$ & 398 & 313 & 301 & 306 & 332 & 362 & 335 & 337 & 297 & 331 \\
\hline Doctor & 5.0 & 4.2 & 7.0 & 15.7 & 28.6 & 9.7 & 11.0 & 15.7 & 20.5 & 38.4 \\
\hline $\begin{array}{l}\text { Nurse/FWV/ } \\
\text { midwife }\end{array}$ & 5.0 & 3.8 & 8.3 & 10.1 & 13.6 & 10.8 & 11.9 & 12.5 & 17.5 & 12.7 \\
\hline CSBA & 0.5 & 1.6 & 0.0 & 1.0 & 0.3 & 0.8 & 2.7 & 1.5 & 2.7 & 1.8 \\
\hline Unqualified provider & 89.5 & 90.4 & 84.7 & 73.2 & 57.5 & 78.7 & 74.3 & 70.3 & 59.3 & 47.1 \\
\hline $\begin{array}{l}\mathrm{N} \\
\text { Delivery by MTP }\end{array}$ & $\begin{array}{l}398 \\
10.6\end{array}$ & $\begin{array}{c}313 \\
9.6\end{array}$ & $\begin{array}{l}301 \\
15.3\end{array}$ & $\begin{array}{l}306 \\
26.8\end{array}$ & $\begin{array}{l}332 \\
42.5\end{array}$ & $\begin{array}{l}362 \\
21.3\end{array}$ & $\begin{array}{l}335 \\
25.7\end{array}$ & $\begin{array}{l}337 \\
29.7\end{array}$ & $\begin{array}{l}297 \\
40.7\end{array}$ & $\begin{array}{l}331 \\
52.9\end{array}$ \\
\hline $\mathbf{N}$ & 398 & 313 & 301 & 306 & 332 & 362 & 335 & 337 & 297 & 331 \\
\hline
\end{tabular}


TABLE K Changes in service delivery uptake for all wealth quintiles in high performing DSF upazilas (percent)

\begin{tabular}{|c|c|c|c|c|c|c|c|c|c|c|}
\hline \multirow[t]{2}{*}{ Characteristics } & \multicolumn{5}{|c|}{2010} & \multicolumn{5}{|c|}{2012} \\
\hline & Q1 & Q2 & Q3 & Q4 & Q5 & Q1 & Q2 & Q3 & Q4 & Q5 \\
\hline Deliveries at home & 87.4 & 91.1 & 79.8 & 72.6 & 47.1 & 63.0 & 68.1 & 61.6 & 55.8 & 35.4 \\
\hline Deliveries at facility & 12.6 & 8.9 & 20.2 & 27.4 & 52.9 & 37.0 & 31.9 & 38.4 & 44.2 & 64.6 \\
\hline $\mathrm{N}$ & 159 & 157 & 178 & 135 & 121 & 135 & 182 & 185 & 147 & 96 \\
\hline Public & 65.0 & 71.4 & 63.9 & 67.6 & 34.4 & 76.0 & 81.0 & 70.4 & 72.3 & 58.0 \\
\hline Private & 35.0 & 28.6 & 33.3 & 29.7 & 60.9 & 18.0 & 13.8 & 25.4 & 15.4 & 35.5 \\
\hline NGO & 0.0 & 0.0 & 2.8 & 2.7 & 4.7 & 6.0 & 5.2 & 4.2 & 12.3 & 6.5 \\
\hline $\mathrm{N}$ & 20 & 14 & 36 & 37 & 64 & 50 & 58 & 71 & 65 & 62 \\
\hline \multicolumn{11}{|l|}{ Type of delivery } \\
\hline Normal & 93.7 & 97.5 & 91.0 & 84.4 & 62.8 & 82.2 & 86.3 & 79.5 & 80.3 & 55.2 \\
\hline Cesarean & 5.0 & 1.3 & 8.4 & 13.3 & 30.6 & 14.1 & 12.1 & 18.4 & 17.0 & 39.6 \\
\hline Assisted & 1.3 & 1.2 & 0.6 & 2.3 & 6.6 & 3.7 & 1.6 & 2.1 & 2.7 & 5.2 \\
\hline $\mathrm{N}$ & 159 & 157 & 178 & 135 & 121 & 135 & 182 & 185 & 147 & 96 \\
\hline Doctor & 6.3 & 5.1 & 9.0 & 17.8 & 35.5 & 17.0 & 12.6 & 20.0 & 19.1 & 41.7 \\
\hline $\begin{array}{l}\text { Nurse/FWV/ } \\
\text { midwife }\end{array}$ & 9.5 & 5.1 & 12.9 & 13.3 & 20.7 & 22.2 & 19.8 & 18.4 & 25.9 & 22.9 \\
\hline CSBA & 0.6 & 2.5 & 0.0 & 0.8 & 0.8 & 0.0 & 3.3 & 0.5 & 2.7 & 2.1 \\
\hline Unqualified & 83.6 & 87.3 & 78.1 & 68.1 & 43.0 & 60.8 & 64.3 & 61.1 & 52.3 & 33.3 \\
\hline $\mathrm{N}$ & 159 & 157 & 178 & 135 & 121 & 135 & 182 & 185 & 147 & 96 \\
\hline Delivery by MTP & 16.4 & 12.7 & 21.9 & 31.9 & 57.0 & 39.3 & 35.7 & 38.9 & 47.6 & 66.7 \\
\hline $\mathrm{N}$ & 159 & 157 & 178 & 135 & 121 & 135 & 182 & 185 & 147 & 96 \\
\hline
\end{tabular}

TABLE L Changes in mid-level providers' knowledge of selected maternal health service components in the intervention areas (percent)

\begin{tabular}{lcccc}
\hline & \multicolumn{2}{c}{ Panel 1, All voucher areas } & \multicolumn{2}{c}{$\begin{array}{c}\text { Panel 2, High performing } \\
\text { voucher areas }\end{array}$} \\
\hline Knowledge indicators & \multicolumn{2}{c}{ Mid-level providers } & \multicolumn{2}{c}{ Mid-level providers } \\
\cline { 2 - 5 } & $\mathbf{2 0 1 0}$ & $\mathbf{2 0 1 2}$ & $\mathbf{2 0 1 0}$ & $\mathbf{2 0 1 2}$ \\
\hline Four ANC schedule & 8.1 & 56.5 & 10.3 & 50.0 \\
Three delays & 44.6 & 37.1 & 43.6 & 40.0 \\
Five danger signs & 43.2 & 51.6 & 35.9 & 50.0 \\
Six or more conditions for high-risk pregnancy & 51.4 & 88.7 & 56.4 & 86.7 \\
Correct schedule for 5 TT vaccines & 32.4 & 43.6 & 23.1 & 50.0 \\
Supplementary medicine for pregnancy & 5.4 & 17.7 & 5.1 & 23.3 \\
PNC within 48 hours & 0.0 & 1.6 & 0.0 & 0.0 \\
PNC within 42 days & 84.0 & 92.0 & 87.2 & 96.7 \\
Vitamin A capsule schedule within 6 weeks & 83.8 & 88.7 & 92.3 & 90.0 \\
Exclusive breastfeeding for 6 months & 90.5 & 100.0 & 97.4 & 100.0 \\
Knowledge on 5 or more EPI vaccines & 58.1 & 61.3 & 48.7 & 60.0 \\
Average score & $\mathbf{4 6}$ & $\mathbf{5 8}$ & $\mathbf{4 5}$ & 59 \\
$\mathrm{~N}$ & $\mathbf{7 4}$ & 62 & $\mathbf{3 9}$ & $\mathbf{3 0}$ \\
\hline
\end{tabular}


TABLE M Mid-level providers' counseling skills in the intervention areas, by type of maternal health service (percent)

\begin{tabular}{|c|c|c|c|c|}
\hline \multirow{2}{*}{ Maternal health services } & \multicolumn{2}{|c|}{ Panel 1, All voucher areas } & \multicolumn{2}{|c|}{$\begin{array}{c}\text { Panel } 2 \text {, High performing } \\
\text { voucher areas }\end{array}$} \\
\hline & 2010 & 2012 & 2010 & 2012 \\
\hline \multicolumn{5}{|l|}{ Birth planning* } \\
\hline Select skilled birth attendant & 56.5 & 35.6 & 46.2 & 36.0 \\
\hline Select facility for delivery & 37.7 & 75.8 & 23.1 & 76.0 \\
\hline Arrange money in case of emergency & 79.7 & 80.6 & 82.1 & 81.0 \\
\hline Arrange transportation in case of emergency/delivery & 60.9 & 54.8 & 61.5 & 55.0 \\
\hline Collect necessary supplies in case of home delivery & 39.1 & 29.0 & 41.0 & 29.0 \\
\hline Identify blood group and manage donor & 26.1 & 37.1 & 28.2 & 37.0 \\
\hline Average score & 50 & 52 & 47 & 48 \\
\hline $\mathrm{N}$ & 74 & 62 & 39 & 30 \\
\hline \multicolumn{5}{|l|}{ Advice for discharge after delivery* } \\
\hline Monitor baby's physical growth & 23.2 & 19.4 & 25.6 & 19.0 \\
\hline Immunization of baby & 50.7 & 77.4 & 51.3 & 77.0 \\
\hline Family planning & 46.4 & 35.5 & 43.6 & 36.0 \\
\hline Breastfeeding method & 88.4 & 71.0 & 82.1 & 71.0 \\
\hline Vitamin A capsule uptake & 15.9 & 32.3 & 12.8 & 32.0 \\
\hline Maternal nutrition & 79.7 & 88.7 & 79.5 & 89.0 \\
\hline Average score & 51 & 54 & 49 & 58 \\
\hline $\mathrm{N}$ & 74 & 62 & 39 & 30 \\
\hline \multicolumn{5}{|l|}{ Advice for postpartum mothers* } \\
\hline Vitamin A for mother after delivery & 15.9 & 25.8 & 17.9 & 26.7 \\
\hline Counseling on nutrition for mother \& baby & 79.7 & 80.6 & 79.5 & 76.7 \\
\hline Family planning & 55.1 & 56.5 & 51.3 & 63.3 \\
\hline Care of perineum/cesarean stitches & 10.1 & 25.8 & 7.7 & 23.3 \\
\hline Average score & 42 & 46 & 39 & 48 \\
\hline $\mathrm{N}$ & 74 & 62 & 39 & 30 \\
\hline \multicolumn{5}{|l|}{ Advice for newborn care and feeding* } \\
\hline Breastfeeding method & 65.2 & 71.0 & 43.6 & 73.3 \\
\hline Food with breastfeeding at 6 months & 50.7 & 45.2 & 46.2 & 53.3 \\
\hline Care of cord & 23.2 & 38.7 & 23.1 & 33.3 \\
\hline Immunization of baby & 58.0 & 62.9 & 56.4 & 73.3 \\
\hline Average score & 49 & 54 & 42 & 58 \\
\hline $\mathrm{N}$ & 74 & 62 & 39 & 30 \\
\hline
\end{tabular}

Note: *Multiple responses 
TABLE N Mid-level providers' clinical skills in intervention areas, by type of obstetric complications (percent)

\begin{tabular}{|c|c|c|c|c|}
\hline \multirow{2}{*}{ Obstetric complications } & \multicolumn{2}{|c|}{ All voucher areas } & \multicolumn{2}{|c|}{ High performing voucher areas } \\
\hline & 2010 & 2012 & 2010 & 2012 \\
\hline \multicolumn{5}{|l|}{ Antepartum hemorrhage (APH)* } \\
\hline Check vital signs & 33.3 & 30.6 & 35.9 & 26.7 \\
\hline Set up intravenous fluid & 30.4 & 32.6 & 25.6 & 36.7 \\
\hline Take blood for $\mathrm{Hb}$, grouping, \& cross-matching & 21.7 & 17.7 & 28.2 & 13.3 \\
\hline Refer to higher level facility & 92.8 & 95.2 & 94.9 & 93.3 \\
\hline Average skill score & 46 & 43 & 45 & 44 \\
\hline $\mathrm{N}$ & 74 & 62 & 39 & 30 \\
\hline \multicolumn{5}{|l|}{ Postpartum hemorrhage (PPH)* } \\
\hline Give Ergometrin if no product in uterus & 18.8 & 8.1 & 20.5 & 10.0 \\
\hline Take blood for $\mathrm{Hb}$, grouping, \& cross-matching & 14.5 & 11.3 & 20.5 & 6.7 \\
\hline Give intravenous fluid & 37.7 & 43.5 & 35.9 & 40.0 \\
\hline Repair the tear & 29.0 & 9.7 & 25.6 & 6.7 \\
\hline Refer to a doctor or hospital & 87.0 & 96.8 & 74.4 & 96.7 \\
\hline Average skill score & 38 & 32 & 37 & 34 \\
\hline $\mathrm{N}$ & 74 & 62 & 39 & 30 \\
\hline \multicolumn{5}{|l|}{ Removal of retained placenta* } \\
\hline Give Oxytocin & 26.1 & 41.9 & 30.8 & 36.7 \\
\hline Apply manual removal of placenta & 40.6 & 51.6 & 48.7 & 46.7 \\
\hline Ensure all parts of placenta come out & 17.4 & 17.7 & 17.9 & 16.7 \\
\hline Give intravenous fluids & 27.5 & 62.9 & 30.8 & 66.7 \\
\hline Refer to a doctor or hospital & 68.1 & 25.8 & 64.1 & 33.3 \\
\hline Average skill score & 38 & 40 & 43 & 49 \\
\hline $\mathrm{N}$ & 74 & 62 & 39 & 30 \\
\hline \multicolumn{5}{|l|}{ Obstructed labor* } \\
\hline Rule out cephalo-pelvic disproportion & 15.9 & 11.3 & 15.4 & 6.7 \\
\hline Start on $10 \%$ dextrose & 11.6 & 8.1 & 12.8 & 0.0 \\
\hline Take blood for grouping \& cross matching & 10.1 & 11.3 & 15.4 & 3.3 \\
\hline Prepare for cesarean section & 30.4 & 11.3 & 41.0 & 16.7 \\
\hline Call the doctor or refer to hospital & 97.1 & 98.4 & 94.9 & 100.0 \\
\hline Average skill score & 32 & 21 & 33 & 28 \\
\hline $\mathrm{N}$ & 74 & 62 & 39 & 30 \\
\hline \multicolumn{5}{|l|}{ Eclampsia management* } \\
\hline Start vital signs chart & 26.1 & 11.3 & 28.2 & 13.3 \\
\hline Monitor fetal heart rate & 2.9 & 9.7 & 2.6 & 10.0 \\
\hline Quantitative monitoring of proteinuria & 21.7 & 6.5 & 23.1 & 6.7 \\
\hline Administer antihypertensive & 17.4 & 6.5 & 23.1 & 0.0 \\
\hline Administer anticonvulsant & 21.7 & 14.5 & 17.9 & 10.0 \\
\hline Refer to doctor or hospital & 95.7 & 100.0 & 92.3 & 100.0 \\
\hline Average skill score & 31 & 23 & 31 & 25 \\
\hline $\mathrm{N}$ & 74 & 62 & 39 & 30 \\
\hline
\end{tabular}

Note: *Multiple responses 


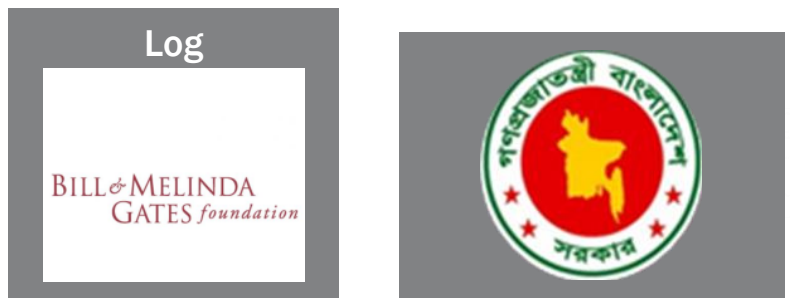

Population Council Bangladesh Office House 15B, Road 13 Gulshan, Dhaka 1212 